\title{
Validating Bachelorhood
}

Audience, Patriarchy, and Charles

Brockden Brown's Editorship of the

Monthly Magazine and American Review

Scott Slawinski 


\title{
STUDIES IN AMERICAN POPULAR HisTORY AND CULTURE
}

\author{
Edited by \\ Jerome Nadelhaft \\ University of Maine
}

A Routledge Series 


\title{
STUDIES IN AMERICAN POPULAR HisTORY AND CULTURE
}

\author{
Jerome NADELHAFT, General Editor
}

FIRST DO No HARM

Empathy and the Writing of Medical

Journal Articles

Mary E. Knatterud

PIETY AND POWER

Gender and Religious Culture in the

American Colonies, 1630-1700

Leslie Lindenauer

RACE-ING MASCULINITY

Identity in Contemporary U.S. Men's

Writing

John Christopher Cunningham

CRIME AND THE NATION

Prison Reform and Popular Fiction in

Philadelphia, 1786-1800

Peter Okun

FoOD IN FILM

A Culinary Performance of

Communication

Jane Ferry

Deconstructing Post-WWII New

YORK CITY

The Literature, Art, Jazz, and

Architecture of an, Emerging Global

Capital

Robert Bennett

RETHINKING THE RED SCARE

The Lusk Committee and New York's

Crusade against Radicalism,

1919-1923

Todd J. Pfannestiel

Hollywood AND THE Rise OF PHysical

Culture

Heather Addison

HOMELESSNESS IN AMERICAN LITERATURE

Romanticism, Realism, and Testimony

John Allen
NO WAY OF KNOWING

Crime, Urban Legends, and the Internet Pamela Donovan

The Making of The Primitive Baptists A Cultural and Intellectual History of the Antimission Movement, 1800-1840 James R. Mathis

WOMEN AND COMEDY IN SOLO

PERFORMANCE

Phyllis Diller, Lily Tomlin, and Roseanne Suzanne Lavin

THE LITERATURE OF IMMIGRATION AND RACIAL FORMATION

Becoming White, Becoming Other,

Becoming American in the Late

Progressive Era

Linda Joyce Brown

POPUlar Culture AND THE ENDURING

MYTH OF CHICAGO, 1871-1968

Lisa Krissoff Boehm

AMERICA's Fight OVER WATER

The Environmental and Political Effects

of Large-Scale Water Systems

Kevin Wehr

DAughters of Eve

Pregnant Brides and Unwed Mothers in Seventeenth-Century Massachusetts

Else L. Hambleton

Narrative, Political. Unconscious, AND RaCial. Violence in Wilmington, NORTH CAROLINA

Leslie Hossfeld

VALIDATING BACHELORHOOD

Audience, Patriarchy, and Charles

Brockden Brown's Editorship of the

Monthly Magazine and American

Review

Scott Slawinski 


\title{
VALIDATING BACHELORHOOD
}

\author{
Audience, Patriarchy, and Charles
}

BROCKDEN BROWN's EDITORSHIP OF THE

Monthly Magazine AND AMERICAN REVIEW

Scott Slawinski

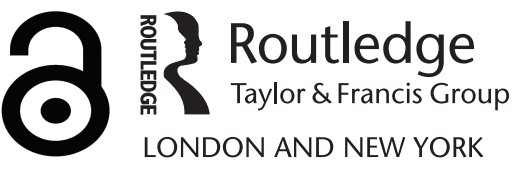


First published 2005 by Routledge

Published 2017 by Routledge

2 Park Square, Milton Park, Abingdon, Oxon OX14 4RN

711 Third Avenue, New York, NY 10017, USA

Routledge is an imprint of the Taylor \& Francis Group, an informa business

First issued in paperback 2013

Copyright (C) 2005 Taylor \& Francis.

The Open Access version of this book, available at www.tandfebooks.com, has been made available under a Creative Commons Attribution-Non Commercial-No Derivatives 4.0 license.

Library of Congress Cataloging-in-Publication Data

Slawinski, Scott.

Validating bachelorhood : audience, patriarchy, and Charles Brockden Brown's editorship of the Monthly Magazine and American Review / by Scott Slawinski.

p. $\mathrm{cm}$.

Includes bibliographical references and index.

ISBN 0-415-97178-0 (alk. paper)

ISBN 978-0-415-65474-6 (Paperback)

1. Brown, Charles Brockden, 1771-1810--Political and social views. 2. Periodicals--Publishing--United States--History--19th century. 3.

Men--Books and reading--United States--History--18th century. 4. Masculinity in literature. 5. Patriarchy in literature. 6. Bachelors in literature. 7. Men in literature. I. Title.

PS1138.M36S58 2005 
For my family

and

For my darling wife, Sally 
This page intentionally left blank 


\section{Contents}

$\begin{array}{ll}\text { Acknowledgments } & \text { ix }\end{array}$

Chapter One

Introduction 1

Chapter Two

Women Need Not Read On: Magazines in the Early Republic

and the Gendered Audience of the Montbly Magazine

Chapter Three

Constructions of Masculinity and Brown's Male Reader

Chapter Four

Marriage and Bachelorhood: Fiction in the Monthly Magazine

Chapter Five

Prospects

Notes

Bibliography

Index 
This page intentionally left blank 


\section{Acknowledgments}

Having begun its life as a dissertation, this study has benefited from discussions with my director, Ezra Greenspan, and the other committee members-Joel Myerson, Judith James, Leon Jackson, and Constance Schulz. I am also indebted to all my literature instructors, but I especially wish to acknowledge Robert Daly and Phil Beidler for their enthusiasm and passion for early American literature.

I am also appreciative of my friends in and out of graduate school who have taken an interest in my work even when they could not always share my enthusiasm for early America.

I thank the people at Routledge, for seeing value in my work.

My deepest gratitude goes to my family and my in-laws. Their support over the years has been invaluable. I also express my appreciation to our cat, Emmy, for reminding me to play. Finally, and most importantly, I thank my wife, Sally, for her love and support. 
This page intentionally left blank 


\section{Chapter One \\ Introduction}

In his study of anxiety and masculinity in early modern England, Mark Breitenberg begins with the premise that "the phrase 'anxious masculinity' is redundant."1 He believes that "masculine subjectivity constructed and sustained by a patriarchal culture-infused with patriarchal assumptions about power, privilege, sexual desire, the body-inevitably engenders varying degrees of anxiety in its male members." 2 Thus, despite the prevalence of a patriarchal order in early modern England and the very real power men wielded, they nevertheless worried about sustaining their dominant position and maintaining social order. For Breitenberg, however, this anxiety is more than just an effect of patriarchy, of being the empowered gender, and it does more than simply lead to "patriarchy's own internal discord." 3 It is also "an instrument (once properly contained, appropriated or returned) of [patriarchy's] perpetuation." "The task Breitenberg sets for himself is to investigate the cultural work anxiety accomplishes-he wants to expose not just how patriarchy breeds anxiety, but how the empowered use anxiety for the retention of power.

Breitenberg is quick to point out that his analysis, while containing implications for the late twentieth century, is very much "rooted in the cultural moment" of early modern England. ${ }^{5}$ He points in particular to the years between 1559 and 1640, bookended by Elizabeth I's ascension to the throne and the beginnings of the Puritan revolution, as a time when England "confronted and negotiated profound changes in virtually all aspects of its economic, political, and social fabric." 6 He believes these societal changes "were registered to a large extent in competing, often contradictory, conceptions of the family and, consequently, in the roles of men and women." 7 Alterations in gender dynamics were a characteristic of Elizabethan and Jacobean England and an important factor in the anxiety under discussion.

Two hundred years later, Charles Brockden Brown (1771-1810) had much to be anxious about as well, as evidenced in his personal life and in his 
career as a professional author and editor. Something of a neurotic, Brown regularly registered complaints in one form or another about the course of his life. He also felt constant pressure, much of it emanating from his family and concerning their disappointment with the way Brown was conducting his life. Brown's career choice was a particular point of contention. Upon the urging of his father, Brown began his short-lived career as a law student, perhaps entering this profession to complement his businessmen brothers in their mercantile pursuits. ${ }^{8}$ The law bored Brown, however, and made him miserable. In a letter from January 1793, Brown lamented his vocational situation, "I utterly despise myself . . . Nothing but a wide vacuity presents itself." Despite his misery, he stuck with his studies for several years until he could stand them no longer. The prospect of telling his family that he was quitting the law, though, brought on a grave crisis and only heightened his anxieties. If he were not to take the course many young men of his generation were following to prosperity, ${ }^{10}$ what was he to do? Vocational choice, for Brown, had always been "ominous," 11 and quitting the law ultimately "plunged Brown into an extended period of despair so deep as to preclude sustained creative effort for years"; 12 his friends feared Brown was suicidal. ${ }^{13}$ His family was also unsupportive of his choice to become an author, and the pressure they exerted to change his career did not cease until he joined his brothers' mercantile firm in 1801.

Brown's troubles did not begin and end with the law, for his love affairs also brought him anxiety. Steven Watts states that he "fell in and out of love with great rapidity" and "began to display intense emotional and libidinous energy." 14 But courtships of Dolly Payne, Debby Ferris, and other young women failed to mature, probably because "Brown's mother and father disapproved of their children's marriage to non-Quakers-none of these young women belonged to the Society of Friends-and evidence suggests that they moved to squelch these attachments." 15 Brown, in fact, turned thirty before he began his courtship of Elizabeth Linn, the daughter of an important Presbyterian minister in New York City, and his marriage to her in 1804 resulted in his excommunication from the Society of Friends. His parents did not even attend the ceremony. Though in his last six years he achieved a degree of happiness which he characterized as "the highest bliss," 16 courtship and his bachelor status troubled him throughout his authorial career.

The anxieties in his personal life carried over into his career as author and editor. Brown worked at a frantic pace, completing six novels in three years while editing his Monthly Magazine and American Review (1799-1800), for which he also wrote a sizable number of articles and reviews. Despite this outpouring of material, Brown was overall an undisciplined writer. Many times 
he was finishing manuscripts as they were going to the printer. His ambition soared with visions of fantastic literary feats, but he often abandoned projects as quickly as he conceived new ones or let his attention wander to fresh ideas. In his late teens, he imagined writing an epic poem like Timothy Dwight's The Conquest of Canaan (1785) or Joel Barlow's The Vision of Columbus (1787), but he never composed a line. In 1792-1793, Brown composed the "Henrietta Letters," which for a long time were thought to be actual love letters. Recent scholarship has shown, however, that they are an abandoned epistolary novel modeled on Rousseau's Heloise (1761). Perhaps the most prominent example is the Monthly Magazine serial publication Memoirs of Stephen Calvert (1799-1800), whose postscript claims that "Calvert's story is a five-act drama" but that "it is thought best to stop the piece-meal publication of it here," at the end of part one. ${ }^{17}$ Brown never returned to it, leaving critics to argue about whether the text is truly complete as it stands. Authorship itself seemed a strain to Brown as he jumped from one idea to the next.

Moreover, neither his published novels nor the Monthly Magazine brought him the financial reward he anticipated. When he first assumed his editorial duties, Brown dreamed of pecuniary success: "Four hundred subscribers will repay the annual expense of sixteen hundred dollars $[\ldots \mid$ All above four hundred will be clear profit to me; one thousand subscribers will produce four thousand five hundred dollars, and deducting the annual expense will leave two thousand seven hundred." 18 Unfortunately for Brown, the Monthly Magazine never realized his fantastic expectations ${ }^{19}$ and ended after only a year and a half in print. Money troubles constantly dogged Brown, forcing him to share quarters with friends and sacrifice luxuries. He dressed shabbily, wearing "worn-down shoes," according to Norman Grabo, as he worked furiously at his writing. ${ }^{20}$ Throughout his authorial career, Brown's family pressured him to join his brothers in business, a position he finally assumed as his novels failed to sell well enough to sustain him, as his dreams of financial reward from the Monthly Magazine evaporated, and as his courtship of Elizabeth Linn led him to the altar, requiring a steady income to support her and any children. Though Brown never abandoned his identity as writer and editor altogether (he went on to edit the Literary Magazine and American Register [1803-1807], to author many pieces for this new periodical, and to pen several political pamphlets), he also never again took up his quill full time. By 1803, he could declare in the first issue of the Literary Magazine that he "should enjoy a larger share of my own respect at the present moment if nothing had ever flowed from my pen, the production of which could be traced to me." ${ }^{21}$ Neurotic to the end, after 
vigorously embracing the identity of professional author in the 1790 s, he could as energetically cast it aside a decade later.

Beyond their relevance to Brown's personal and professional life, the issues concerning masculinity that Breitenberg identifies may also be seen at work in the early American republic. Like the masculine anxieties of early modern England, Brown's anxieties are rooted in the historical moment, in the immense changes in the political, economic, and social fabric wrought by the American Revolution and the turbulence of the 1790s. Born just five years before the signing of the Declaration of Independence, Brown was raised in Philadelphia during the American Revolution and came of age just as the nation was debating the newly drafted Constitution. He entered his twenties just as the French Revolution was reaching its bloodiest phase and the raucous decade-long battle between the Federalists and Jeffersonians was heating up. The year he turned thirty, the bitter presidential election of 1800 was over and Jefferson was president. Political controversy and upheaval on a national scale were thus factors in Brown's life for at least thirty of his thirty-nine years.

While these turbulent events may have accustomed Brown to expect political upheaval, economic and social changes were also afoot. As Joyce Appleby and others have shown, the 1790 s mark a point where the United States was beginning to move from a society largely consisting of farmers to one dominated by tradesmen and manufacturers. As wealth spread, marketplace values gained currency, and the industrial revolution began to take hold in America, the debate surrounding the significance of these changes became philosophical. Definitions of republican citizenship and civic virtue shifted from classical disinterest to individual self-interest. ${ }^{22}$ In line with Appleby's analysis, Michael Kimmel identifies the post-Revolutionary era as the beginning of the self-made man, a category of manhood "measured by accumulated wealth and status, by geographic and social mobility." 23 Accordingly, the "old standard rooted in the life of the community and the qualities of a man's character gave way to a new standard based on individual achievement." ${ }^{24}$ Using Royall Tyler's The Contrast (1787) as symbolic of this change, Kimmel argues that while Dimple and Manly dominate the play, it is Mr. Van Rough, the everconstant advocate of "the main chance," who "would come to dominate the new country in a new century." 25 So pervasive was this attitude, that even novelist Hugh Henry Brackenridge could admit to his son, "I have committed a great error in not attending sufficiently to the main chance." 26

Old power structures were also shifting, leaving many men adrift as they clung to increasingly untenable or irrelevant social hierarchies. As Emory Elliott has shown in Revolutionary Writers, the American Revolution and the postwar period dealt a staggering blow to American intellectuals. 
After the Revolution, the "learned clergy and the cultured men of letters, those who had exercised the greatest degree of intellectual and cultural influence in the prewar society, were left with little or no authority in America." ${ }^{27}$ Having rebelled against British social and political structuresagainst traditional forms of authority-during the Revolution, Americans continued to value liberty, individual choice, and intellectual freedom over guidance and dogmatism from the learned. This rejection of traditional forms of authority fueled the tension in the 1790s between the Federalists and the Jeffersonians, since the party of Adams and Hamilton was seen by many to be too aristocratic, too presumptuous in assuming that only distinguished gentlemen could exercise proper judgment.

Closely connected to this crisis of authority in the early republic was the aforementioned swerve toward manufactures. As merchants gained power, Elliott argues, they "found it to be in their best interests to discredit the intellectuals and ministers because theology and art often challenged the emergent precapitalist ideology upon which the new economy would be founded." ${ }^{28}$ Rather than have their business practices excoriated by ministers who preached that materialism was evil or have their social positions challenged by writers who expressed skepticism toward and raised questions about marketplace values, businessmen opportunely undercut the power of intellectuals, leaving a vacuum to be filled by pursuit of the main chance.

Authorship also had to adjust to marketplace values, but it did so at the cost of the same traditional forms of authority identified by Elliott. Grantland S. Rice argues that, for New England Puritans, "public writing was a political activity both ideologically and materially." ${ }^{29}$ By the end of the eighteenth century, however, the reduced threat of persecution by church and state transformed "printed texts from a practical means for assertive sociopolitical commentary into the more inert medium of property and commodity." ${ }^{30}$ In short, the postwar generation viewed authorship as a way to engage the marketplace, with books becoming commercial items. This shift, according to Rice, bodied forth not just a new meaning of public writing, but also "new literary forms and aesthetic practices" that attempted to respond to market forces. Such works as Crevecoeur's Letters from an American Farmer (1782), Hugh Henry Brackenridge's Modern Chivalry (1792-1815), and seduction novels like Hannah Webster Foster's The Coquette (1797) all looked back toward traditional forms of authorship as civic commentary and forward toward the book as commodity. ${ }^{31}$ The change in the status of authorship from political to economic act contributed to the struggles encountered by authors like Charles Brockden Brown who aimed to be "moral painters" 32 and speak "truths," but who, at the same time, needed to make money to survive. 
These political and economic transformations occurred simultaneously with social ones which redefined patriarchal authority, gender relations, and the status of marriage. In terms of patriarchal authority, Jay Fliegelman points out that the relationship between parents and children altered significantly in the eighteenth century. According to the old model of patriarchal authority, respect, deference, and obedience were due a parental figure simply because he or she was a biological parent. Moreover, as Fliegelman notes, "filial obedience had the time-honored sanction of Scripture as well as nature." ${ }^{33}$ Thus, a sin against the earthly father, according to The New England Primer, was a sin against God. By Brown's era, however, this model of authority had been replaced by a newer model with its origins in Locke and Rousseau. Rather than seeing them as due filial respect and obedience, this new model suggested that parents were responsible for raising their children to become independent citizens. Where the old model fostered tyrannical parents (as Britain had been called throughout the crisis of the Revolution), the new model begot eventual equals. Environment, not biology, assumed a central role in the relationship, for "true parents" were those individuals who fostered growth and independence. ${ }^{34}$ Thus, parents and children expressed disinterested benevolencethey served each other not because they were related, but because such service was the right thing to do and brought its own rewards. As Fliegelman puts it, "Benevolence as its own reward invalidates any concept of the debt of nature." ${ }^{35}$ While such a relationship based upon affection, education, and independence must have provided Brown with the latitude to disappoint his father in his pursuit of the law and in his marriage to a non-Quaker, it must also have created a degree of anxiety by destabilizing yet another traditional source of authority-social change of this sort does not come without a price.

The position of women, too, altered immediately after the Revolution, ${ }^{36}$ for as Mary Beth Norton aptly puts it in the 1980 preface to Liberty's Daughters, "the [American] Revolution had an indelible effect upon American women." 37 She argues that "the 1780s and 1790s witnessed changes in women's private lives-in familial organization, personal aspirations, self-assessments." 38 These private alterations had an impact on gender and marital relations; husband and wife were negotiating new definitions of their roles in marriage. In short, traditional male gender roles were in transition after the Revolution in part because the war had altered assumptions and perceptions about women's abilities and social position. Linda K. Kerber reaches similar conclusions, but she sees the changes wrought by the Revolution in more public terms. Laws governing coverture 
and divorce as well as attitudes toward female education all changed in women's favor, if only slightly sometimes. Such social negotiations concerning public voice and private life culminated in what Kerber calls "Republican Motherhood": a social position defined by actions within the home (such as child rearing) but which allowed such domestic activities to have a public impact (a well-raised child becomes a good citizen). ${ }^{39}$ Both Kerber and Norton agree that the changes they identify had a significant impact, but they also recognize that while women in the late eighteenth and early nineteenth centuries had more freedom within the feminine sphere, they could not leave that sphere completely.

While Kerber and Norton discuss changes within women's personal and public lives, Nancy F. Cott and Lee Virginia Chambers-Schiller identify the post-Revolutionary period as the origin of two significant nineteenthcentury phenomena. Cott looks to the period of the 1780s and 1790s as the point of origin for the ideology surrounding separate spheres-the notion that men and women move in distinct worlds with separate purposes. Following the changes that occurred during the Revolutionary period, Cott argues, came the belief that the domestic world was a refuge from the public (soiled) world of politics and the marketplace. The home became a place defined by work that was unique to women, by disinterested love that was separate from marketplace values, and by religious piety. Like Kerber and Norton, Cott concedes that women still faced social restraints, but she also points out that domesticity and separate spheres represented a form of advancement. While the seventeenth and early eighteenth centuries gave men sole authority in the home and in the public world, separate spheres produced a female-dominated world in which women could be empowered and be recognized as predominant. 40

Chambers-Schiller approaches the period from a different perspective: the changing role of the spinster. The post-war period witnessed a steady increase in the spinster population and an alteration in the ways such women were perceived and valued. As Chambers-Schiller notes, the "number of spinsters in the colonial population was very low-never more than a few percent." But, she continues, this "percent began to rise in the last decades of the eighteenth century and continued through the nineteenth," reaching its peak of eleven percent just after the American Civil War. ${ }^{41}$ Chambers-Schiller contends that the decision to remain single was "rooted in the desire to pursue autonomy, to explore the self, to expand intellectual and personal horizons, and to serve God and the community through the development and application of individual talents and abilities" 42 This increase in the number of single women and the removal of the 
stigma surrounding spinsterhood was a contentious social change-not everyone thought liberty was a better husband for women.

It would be easy to assume that a single white male from a middle-class merchant family of the early republic would occupy a stable place of privilege, but Charles Brockden Brown had a wide field for his anxieties. The unstable political situation stemming from the American Revolution and continuing into the early republic displaced traditional notions of leadership and deference, thereby leaving citizens like Brown without social forms by which to conduct themselves. The loss of intellectuals' authority left a vacuum, which Elliott argues writers, Brown among them, tried but failed to fill. The changing economics of the early republic also left Brown at a loss, for traditional forms of economic patriarchy were in flux. Moreover, by choosing authorship rather than shop keeping, Brown was exchanging an understandable, financially stable profession for less accepted, economically unstable work. He was implicitly rejecting Van Rough's advice to mind the main chance, the growing ethos of the economically self-made man, and the redefinition of republican virtue as self-interest. In short, he was positioning himself outside the economic mainstream. Furthermore, the profession itself was changing, moving away from the type of writing Brown seemingly aimed at: authorship as moral authority, as "useful." Instead marketplace values dominated, and while writers retained the claim to literature's usefulness, Grantland Rice points out that this was merely the remnant of the old-style writing of civic authority, that novels like The Coquette were accommodating the marketplace more than they were speaking from the same authorial position that someone of Cotton Mather's generation enjoyed. Despite rejecting the chase for the main chance, Brown found himself embroiled in it.

As a gendered being, Brown found his position equally unstable. While masculinity has frequently defined itself against femininity (something, that is, to be warded off), Brown also found his position as a man destabilized by new relationships between father and son, as Fliegelman shows. More importantly, while femininity might still be something men of the early republic were to avoid, they could not but face new relationships between husbands and wives, new courting rituals, new definitions of the good husband. Brown himself, by the time he was writing his novels, had courtship and marriage on his mind. He pursued several women before his wife eventually accepted him, and all his novels involve marriage, even if only peripherally. In a society where marriage was valued and single-living devalued, Brown had to confront his own marital status and its impact on his sense of identity.

Furthermore, despite the words of the founders, socially speaking not all men were equal in the early republic. Power does not just define 
difference between the genders; it defines difference between men as well, valuing some men over others. R. W. Connell lays out this concept in his notion of "hegemonic masculinity":

Hegemonic masculinity is constructed in relation to women and to subordinated masculinitics. These other masculinitics need not be as clearly defined-indeed, achieving hegemony may consist precisely in preventing alternatives gaining cultural definition and recognition as alternatives, confining them to ghettocs, to privacy, to unconsciousness. ${ }^{43}$

Connell goes on to argue that the "most important feature of contemporary hegemonic masculinity" is heterosexuality and its close relationship to marriage. Homosexuality then becomes a subordinated masculinity over which to wield power. He shows, too, that differences in power can exist between young and old men. Looking at labor, he points out that young workers frequently "recalled their apprenticeships in terms of drudgery and humiliation" but that once they mastered their trades they became equals ("brothers" in Connell's term) and wielded power over other young apprentices. ${ }^{44}$ This same notion of power differentiation among men is laid out in David H. J. Morgan's Discovering Men. Drawing on two personal experiences in which other men attempted to intimidate or exercise power over him, Morgan concludes that "patriarchy is also about the dominance of men by men as well as the dominance of women by men" 45 and that his examples are consistent with Connell's notion of hegemonic masculinities.

As a single male who, though mindful of courtship, was not yet married, Brown occupied a social position similar to Connell's apprentices, one defined by a difference in power. As Mark E. Kann has argued in On the Man Question and even more extensively in A Republic of Men, young bachelors were at a great disadvantage in the early republic. Rather than holding an equal social position as citizens, bachelors were typecast as socially disruptive, lumped with criminals and other social outcasts, marginalized and made sport of until they married. Howard P. Chudacoff concurs with such an assessment not just for the early republic, but for much of American social history. ${ }^{46}$ In his The Age of the Bachelor, he notes how the "social status of bachelors as akin to that of immigrants or a minority group made unmarried men 'others' in the male-oriented society dominated by married men." 47 Attempts to control such unmarried "outlaws" or "deviants" in the colonial era ranged from a Maryland tax on unmarried men over the age of twenty-five (levied to raise money to fight the French and Indian War) to a 1619 Virginia law "decreeing that all men in the colony were to dress according to their social rank and marital status." ${ }^{48}$ Like 
Maryland, many New England towns taxed bachelors for indulging in "the selfish luxury of solitary living" 49 or mandated that they live with legally constituted families; failure to do so could mean facing legal charges, as Plymouth, Massachusetts, residents Thomas Henshaw and Thomas Hall discovered in 1762. Moreover, the idea of the bachelor as rogue and scoundrel was applied to married men as well. A sort of "inner child," bachelorhood allegedly lived submerged in married men, its worst traits only awaiting an opportunity to resurface; thus, the stigma attached to bachelors also aimed to keep married men from "degenerating" into single men. Brown's novels show that he was keenly aware of power structures in the early republic, and the different values attached to single and married men did not escape his notice any more than the racial and feminist issues so central to his work.

Part of the concern over the single man stemmed from his ambiguous social status. Chudacoff defines colonial and nineteenth-century bachelors as "straddling two worlds." On the one hand, "unmarried adult males held membership in the family into which they were born," which carried with it some obligations such as attending family gatherings, visiting and corresponding with relatives, and exchanging money or services with family members. ${ }^{50}$ On the other hand, bachelors were also unfettered, for their time was their own. They could roam as they pleased, take on or put off responsibility as they chose, and occasionally create trouble for the rest of the citizenry. ${ }^{51}$ Katherine V. Snyder reaches similar conclusions about the ambiguity inherent in the status of the unmarried man. In her study of bachelor narrators, she notes how in the eighteenth century, just as the word "bachelor" attained its current usage, middle-class masculinity was equating itself with professional occupations. ${ }^{52}$ While bachelorhood did not qualify as an occupation, "such phrases as the 'freedom, luxury, and self-indulgence of a bachelor's career' suggest something like a substitute or alternative vocation, even while gesturing toward the bachelor's violation of the norms of bourgeois masculinity, especially with respect to an ideal of male productivity." 53 Clearly, a degree of ambiguity and liminality has historically defined the single man's status within social and economic circles.

But while Brown was writing his novels, he was also editing his Monthly Magazine and American Review, a periodical established by the Friendly Club, of which Brown was a member. In addition to printing submitted articles, pirated pieces from England and France, and reviews of newly printed books, the Monthly Magazine featured some of Brown's fiction. Most famous among the fictional pieces are a fragment from his novel Edgar Huntly and the entire text of his novella Memoirs of Stephen Calvert, 
spanning over 200 pages. ${ }^{54}$ Chronically short of material, Brown himself penned many of the columns and reviews, having overestimated the support a periodical in the new republic could sustain and the generosity of Friendly Club members, who had pledged their support if Brown undertook the editorship. ${ }^{55}$ Given Brown's intricate relationship with his periodical, the magazine would seem central to his career.

So what have Brown's critics had to say about the Monthly Magazine and American Review as a whole? The few book-length studies ${ }^{56}$ of Charles Brockden Brown focus primarily on his fiction, many times giving exclusive attention only to his four "major" gothic novels-Wieland (1798), Ormond (1799), Arthur Mervyn (1799-1800), and Edgar Huntly (1799). Moreover, unless they are biographies, these studies de-emphasize the beginning of his career and his involvement with his three periodicals, including the Monthly Magazine and American Review, even though he edited it in the middle of his most intense period of creative output. (He began his editorship just after the appearance of Ormond and the first part of Arthur Mervyn; continued it while he wrote Edgar Huntly, Stephen Calvert, the second part of Arthur Mervyn, and several short pieces; and discontinued it shortly before the 1801 publication of his penultimate novel, Clara Howard.) Furthermore, when critics do consider Brown or his fiction-in article-, chapter-, or booklength discussions - they tend to overemphasize psychological approaches to Brown's texts, almost to the exclusion of other critical approaches.

Two of the earliest studies of Brown are descriptive and consider Brown's influence on and place in American literature. Martin Samuel Vilas's Charles Brockden Brown: A Study of Early American Fiction (1904) focuses on Brown's life and his novels. ${ }^{57}$ For each novel, Vilas outlines the plot and then considers the book's weaknesses and strengths; once he examines all six novels, he briefly discusses those writers who influenced Brown and those whom Brown influenced. Brown's editorship of the Monthly Magazine receives only passing mention in the brief biography Vilas supplies. Forty-six years later, Lulu Rumsey Wiley's The Sources and Influence of the Novels of Charles Brockden Brown (1950) covers much of the same ground as Vilas but in much more detail. As part of Brown's life story, the Monthly Magazine warrants the attention of three paragraphs, but according to Wiley, while the periodical "contains the customary, conventional departments," it is the review section, "which was Brown's idea, [that] became the most characteristic and important department," because the "Review critic showed keen insight into the literary problems of the day and, by masterful, fearless, patient, wise criticism $|\ldots|$ endeavored to create and promote native literature." ${ }^{58}$ Wiley passes no judgment on the contents of the magazine section of 
Brown's periodical. Two biographies by Harry R. Warfel and David Lee Clark also appeared about the time of Rumsey's book, the first published in 1949 and the second in 1952. Both Warfel and Clark discuss the Monthly Magazine at some length. Unfortunately, neither Warfel nor Clark moves beyond the realm of mere description, and they expend more space stating what appeared in it and how its contents compared to other periodicals of the time than they do reading the articles critically or investigating what they reveal about Brown-attentions which they do extend to the novels. Warfel, nevertheless, does pass judgment on the periodical as having "deserved to live," 59 apparently approving of its structure and content.

Nearly another fifteen years would pass before further studies of Brown appeared. Donald A. Ringe's Charles Brockden Brown (1966), for Twayne's United States Authors Series, and Arthur Kimball's Rational Fictions: A Study of Charles Brockden Brown (1968) have two things in common: they follow the lead of Warfel and Clark by reading Brown's fiction from a psychological point of view, and they both virtually ignore the Monthly Magazine. ${ }^{60}$ Ringe's book would seem to offer a natural opportunity for discussing Brown's editorship, for the Twayne series aims to present overviews of authorial careers, yet Ringe barely mentions the periodical. ${ }^{61}$ Kimball's study, too, would seemingly offer an invitation to discuss at least Brown's short story contributions, but Kimball focuses exclusively on situating the novels within Lockean discourse.

In the early 1980s, two significant, albeit limited, studies appeared. In The Coincidental Art of Charles Brockden Brown (1981), Norman S. Grabo decides "to risk a good deal of New Critical close reading" and to "follow a psychological interpretation in large part." 62 This methodology, Grabo believes, will elucidate how Brown's use of coincidence in his fiction "may function as the foundation of the stories themselves," 63 how "coincidence is necessary" to Brown's works. ${ }^{64}$ Searching out this pattern in Brown's novels will ultimately reveal, Grabo contends, that "they reflect both a complex mind and a sophisticated art," 65 capacities with which Brown, up to that time, had not generally been credited. In his study, Grabo is focused only on the lengthy works of fiction. He does turn to Stephen Calvert for an extended discussion, but since he aims primarily to explicate Brown's long fiction, he briefly mentions only one short story from the periodical and generally ignores the Monthly Magazine as a topic. The second of these studies from the 1980s is Alan Axelrod's Charles Brockden Brown: An American Tale (1983). While previous studies had at least incorporated all of Brown's longer fiction into their focus, Axelrod admits at the outset that he is strictly interested in the four "major" novels. Despite this admission he strikingly 
claims that all of Brown's novels "occupy the emotional, intellectual, and cultural territory of Janus, looking forward into the darkness of the private self and backward into the public light of society; ahead into the wilderness and back into civilization; west toward the New World, east toward the Old." 66 (28). Like Ringe, Kimball, and Grabo, Axelrod makes no effort to investigate the significance of Brown's editorial projects, either in terms of challenging his book's thesis or of supporting it.

Stephen Watts astutely updates and details what we know of Brown's life and times in his The Romance of Real Life: Charles Brockden Brown and the Origins of American Culture (1994). His research led him to "a broad, two-pronged argument." 67 First, the gothic novelist "embodied many of the social and psychological pressures resulting from the wrenching development of market relations in the post-Revolutionary decades." ${ }^{68}$ Such developments, according to Watts, caused Brown to delineate, in his public and his private writings, "a fragmented personality type as the ultimate expression of a liberal capitalist society increasingly separated by economic interests, gender expectations, moral values, and political organization."69 Second, he argues that "Brown, partly by way of compensation, became an exemplary and pivotal figure in the articulation of an American 'culture' in the early years of nationhood." $70 \mathrm{He}$ believes the "long-term thrust" of Brown's career was toward "a bourgeois creed of genteel self-control."71 Though Watts claims to discuss Brown's entire career, he ignores the Monthly Magazine almost entirely, providing extended discussion of only a few of its short pieces of fiction and Stephen Calvert. Given the biographical nature of Watts's book, it is strange that he should omit a significant slice of Brown's career, especially since he does consider the later Literary Magazine and American Register at some length.

Another study from the last decade is Bill Christophersen's The Apparition in the Glass: Charles Brockden Brown's American Gothic (1993). Like his predecessors, he ignores the Monthly Magazine, and like Axelrod, he discusses only the four "major" gothic novels. He sees Brown's work as "dramas of the soul and psyche first." 72 He contends that the "truths they tell and the questions they ask about the human heart, the nature of evil, the reliability of the senses, the dubiousness of appearances and of absolutes such as God, virtue, benevolence, truth, reason, and self-knowledge need no anchor in national concerns or character." 73 Christophersen's purpose, however, is not to offer up another ahistorical psychological reading of Brown's gothic novels but instead to show their "Americanness." $\mathrm{He}$ argues they are "American tales because they revolve psychological, philosophical, moral, and sociopolitical dilemmas central to turn-of-the-century 
America." 74 He contends that Brown was "a product of various tensionspolitical, religious, philosophical, social-of his time."75 These observations are in line with what I will argue in later chapters. However, since Christophersen makes no claim to a comprehensive view of Brown's career, he ignores what I consider a rich vein for understanding Brown in his historical context-exactly what an examination of the Monthly Magazine, seen as a whole, accomplishes.

The most recent study solely dedicated to Brown's work is Private Property: Charles Brockden Brown's Gendered Economics of Virtue (1997) by Elizabeth Jane Wall Hinds. Like Axelrod and Christophersen, Hinds investigates the "major" novels, giving only bare mention to Brown's other fiction and citing pieces from the Monthly Magazine to support her larger thesis about property and virtue. Hinds argues that "while the concept of virtue was changing for men, beginning to accommodate a liberal capitalist ideal of speculative behavior built out of 'portable' property of cash and credit, virtue for women took on, for Brown, decidedly domestic contours, looking more like a classical Republican, conservative, and especially property-owning system of morality." 76 Her focus, while incorporating an investigation into gender, relies primarily on the fiction and Brown's awareness of the market economy. It looks mostly to Brown's treatment of the marketplace rather than his subject position in it.

If so many critics have passed the Monthly Magazine and American Review over as (apparently) unworthy of notice beyond using its materials to support their theories about Brown's attitudes toward fiction and authorship, the extent of his engagement with his culture, or his observation of events of the 1790s, why bother to examine it more closely as a whole? The answer lies in Connell's argument about hegemonic masculinities and Kann's description of bachelorhood in the early republic. Brown edited the Monthly Magazine and American Review just at the time when he was feeling the greatest pressure from his family about his profession and, more importantly, his marital state. Shortly after giving up authorship as his vocation, Brown would join his merchant brothers in their business and would marry. I argue that the Monthly Magazine betrays his engagement with the issue of masculinity-particularly bachelorhood-as it was viewed and voiced in the early republic. The audience of the Montbly Magazine as Brown envisioned it, I contend, was primarily male, and through the editing process Brown attempted to establish a space where single men could find validation of their unmarried status and where married men who shared the nation's attitudes toward the bachelor would find their beliefs challenged and their notions of married life subverted. 
Chapter two provides a historical overview of magazine publication at the end of the eighteenth century and places the Monthly Magazine in the context of its contemporaries. It then moves to examine a selection of the various short columns, features, and dialogues printed consistently throughout the Monthly Magazine's run. I show how many of these pieces belittled women and actively discouraged them from reading Brown's magazine. The editorial process, I suggest, was geared toward constructing and maintaining an audience of men. These short pieces, rather than being of interest only for their historical value or ability to support literary theories about Brown's longer fiction, actually reveal how Brown imagined his audience. Continuing the focus on audience and gender in the short features found in the Monthly Magazine, chapter three examines how Brown imagined his male readers and what the periodical offered to them. I argue that Brown used the columns in his periodical as a vehicle to challenge assumptions about bachelorhood, validate it as a viable lifestyle, and show that single men could contribute positively to early republican society. Simultaneously, these pieces also support Brown, for they reinforce his belief in his own bachelorhood and choice of career. In addition, the columns set an important context for examining the fiction that appears in the Monthly Magazine and the novels that chronologically surround the magazine. In these articles, Brown establishes an environment that mirrors the one in which his fictional characters operate. Reading the articles opens up interpretive opportunities for a reconsideration of Brown's major and minor fictions. Chapter four looks closely at the "major" short fiction by Brown which appeared within the pages of the periodical. Placed in the context of the magazine's nonfiction, these stories have much to say about single and married men, all of it challenging the social stigma attached to bachelorhood and the valorization of marriage in the early republic. While seemingly about mob violence ("Thessalonica"), murder ("The Trials of Arden"), marital deception ("A Lesson on Concealment; or, Memoirs of Mary Selwyn"), and headstrong disobedience (Memoirs of Stephen Calvert), these stories actually confront the stereotypes surrounding men and marriage, breaking them down in order to establish a space for the bachelor-hero. They explore what "good" the bachelor is capable of and how young single men can easily be misrepresented by hegemonic masculinity. Chapter five, the conclusion, offers some prospects for integrating the Monthly Magazine into Brown's career as a whole, for seeing the periodical as deeply connected to Brown's other work (fictional and nonfictional), and for applying this study's discussion broadly to the early republic and its literary output. 
This page intentionally left blank 
Chapter Two

\section{Women Need Not Read On: Magazines in the Early Republic and the Gendered Audience of the Monthly Magazine}

Using the New York Magazine, or Literary Repository ${ }^{1}$ as representative of late eighteenth-century American magazines, David Paul Nord asserts that "magazine reading in this era seems to have been a more broadly democratic activity than has usually been supposed." ${ }^{2} \mathrm{He}$ initially acknowledges that "the magazine's content would seem to be evidence of rather an elite audience," but by looking at the content in conjunction with the subscriber list, he contends that the reading public included not just the George Washingtons, John Jays, and Noah Websters of the period, but a larger readership that expanded well into the middling classes, excluding only those at the lowest rungs of the economic ladder. This swath of readership also included at least some women. Seven women subscribed in their own names to the New York Magazine, and Nord believes the readership was "heavily female." 3 Several women also contributed, one of whom wrote to praise the magazine's efforts and wish it success. Moreover, Nord points out that roughly " 11 percent of the articles in 1790 either had a woman as the main character or had a clearly identified female author, and many more were obviously aimed at and probably written by women." 4 Though Nord's analysis is primarily class- rather than gender-oriented, he believes women readers contributed toward a democratization of reading not just for the New York Magazine, but for magazine reading in general.

Unfortunately, we do not have a subscription list or any comparable resource for Charles Brockden Brown's Monthly Magazine and American Review (1799-1800), ${ }^{5}$ and this regrettable gap in the historical record leaves 
scholars little choice but to rely on an examination of the magazine's content and on knowledge of the editor himself. What the articles and Brown's editorial choices suggest is that Nord's findings are not as sweeping as he contends. Rather than implying a "democracy of readers" from several classes and both genders, the selections found in Brown's periodical, with some exceptions, speak primarily to an audience of men and employ a discourse that not only functions to construct a community of male readers but also actively seeks to exclude (or at least strongly to discourage) female readership. Equally important, examining Brown's editorship allows for a revision of critics' perception of his personal life and professional career. The selections-not only the nonfiction and short sketches submitted but also the prose fiction Brown himself contributed-suggest his growing concern over his position as an unmarried man in a society that did not value single men. Editing and publishing the Monthly Magazine allowed him to make a useful contribution to the new nation by disseminating knowledge and stimulating intellectual discussion, thereby showing - at least to himself-that bachelors could indeed contribute to the general good of American society. Moreover, the nonfiction and short sketches provide a valuable context for reading the short fiction he included in the Monthly Magazine and for the novels he produced around this period.

Before proceeding, however, it is pertinent to provide a context for examining the Monthly Magazine by describing its structure and comparing it with its contemporaries. To start with, the overall organization of Brown's periodical remained constant throughout its run. Each issue contained eighty pages, with articles distributed among four separate categories. The first, "Original Communications," featured prose pieces of varied length and content. Though Brown's fiction also appeared here, this section typically dealt in nonfiction articles that ran anywhere from one to ten pages and were composed either by Brown or his local contributors. Not surprisingly, then, the section's length each month was a function of the amount of material Brown had on hand. Since the members of the Friendly Club (who had vigorously offered their empty promise of providing extensive material) and his local contributors frequently failed him, Brown was faced with either filling the section with his own compositions or shortening it altogether. $\mathrm{He}$ regularly resorted to both of these options.

The Monthly Magazine's index of articles further reveals the wide spectrum of material that appeared under "Original Communications." The articles consisted of brief opinion pieces and Addisonian essays, short anecdotes, dialogues, occasional puzzles or requests for information, scientific and mathematical enquiries, travel pieces, biographical sketches, and 
theatrical announcements. These pieces could discuss anything-the state of American literature, shark anatomy, hair powder, the nature of love, and applications of the name "Jack," to name only a few. Many of these articles frame their arguments by intertwining plot and dialogue with philosophical exposition, showing how the eighteenth century frequently blurred the distinction between nonfiction essays and short stories that today's readers take for granted. Such pieces were common to eighteenthcentury magazines. John Tebbel and Mary Ellen Zuckerman assert a clear line of descent from these "character sketches" and "fragments" to the traditional short story. ${ }^{6}$ As Alfred Weber makes clear, though, literary formats in the eighteenth century were loosely defined, and there was no clear theory of what constituted a short story. "Consequently," Weber writes, "such designations as 'tale' and 'narrative,' 'story' and 'history,' 'character' and 'portrait,' 'romance' and 'novel' were used indiscriminately." 7

Moreover, the twenty-first-century notion of literature as equivalent to belles lettres (fiction, poetry, drama) did not obtain in the eighteenth century. As Harry Warfel reminds us, "literature and learning were almost identical terms in the eighteenth and early nineteenth centuries," and "a plea for better literature therefore was usually a plea for better education or a better means of attaining correct information." 8 Brown, then, would have said that the "Original Communications" section was "literary," but by twenty-first-century standards, he only published five works of "literature" in this section-a fragment from Edgar Huntly; his short stories "Thessalonica: A Roman Story," "The Trials of Arden," and "A Lesson on Concealment; or, Memoirs of Mary Selwyn"; and his serial novella Memoirs of Stephen Calvert.

The second, third, and fourth sections of the Monthly Magazine are much more easily described than the first because their content is more uniform. While "Original Communications" produced a wide range of American efforts, "Selections" reprinted various overseas communications and extracts. Such a division was not uncommon to eighteenth-century periodicals. The Columbian Magazine and the American Museum employed a similar practice. The Monthly Magazine's "Selections" followed "Original Communications" in its variety of content, but to a more limited degree, and except for excerpts from accounts or memoirs of various British authors such as William Cowper, Hannah More, and Mary Wollstonecraft which twenty-first-century readers might consider "literature" or at least "literary," this section also avoided belles lettres. The third section-the "American Review" of the magazine's title-comprised only reviews of recent publications. Following eighteenth-century conventions for book reviews, Brown extracted large sections of text as examples of content and 
style, but unlike most of his contemporaries he also assumed the mantle of critic, evaluating and recommending some of the texts, deriding others. ${ }^{9} \mathrm{He}$ drew from a variety of (mostly) indigenous and (some) foreign publications of American and European books and occasionally produced insightful criticism, which Warfel characterizes as "among the most notable in early national American literature." 10 Here, too, readers would have found an unusual collection of subject matter under consideration, including Timothy Dwight's sermons, translations by Brown's friend William Dunlap, and a striking number of eulogies and elegies for the late George Washington. ${ }^{11}$ Rounding out each issue of the Monthly Magazine was a one- or two-page collection of poems, many of them contributed by the same poet-John Davis. One senses Brown did not think highly of the poetry he received or of what he printed, since it commands so little of the magazine's space and appears unobtrusively on the final pages of each issue.

Despite what would seem to today's readers to be an unusually eclectic collection of printed material, compared with its contemporaries, the Monthly Magazine was typical of its day. ${ }^{12}$ While twenty-first-century magazines frequently target audiences with specialized interests, in most eighteenth-century periodicals variety was king, ${ }^{13}$ especially since "magazine meant miscellany to most eighteenth century readers and, with certain notable exceptions, the magazines maintained that tradition." 14 Thus, like the Monthly Magazine, other eighteenth-century periodicals included medical, agricultural, and biographical articles in a single issue.

Yet while Brown followed other eighteenth-century periodicals in printing a range of articles, he diverged from standard editorial practices in several other ways. For example, while short fiction was relatively commonplace in many of the magazines of the time, the Monthly Magazine stands out for its paucity in this area. In its entire run of eighteen issues, the only pieces recognizable as traditional fiction are Brown's three short stories, the excerpt from Edgar Huntly, and the serialization of his Stephen Calvert. ${ }^{15}$ In this sense, Brown's periodical stood with Joseph Dennie's Port Folio (1801-1827) in eschewing fiction, but its absence placed these two periodicals in the minority.

How could a writer passionately engaged in writing novels include so little fiction in his periodical? Perhaps, since the era frequently equated fiction with frivolity and idleness, Brown might have been attempting to strike a more "serious" tone with his readers. While he was dedicated to providing a variety of reading material, most of the pieces he printed convey practical information. They consist largely of scientific treatises and articles on public works, biographical sketches and essays on American customs, not 
traditional prose fiction. The frivolity and idleness associated with fiction was, moreover, frequently linked to women readers. There were, of course, men who read fiction, but the market for fiction was strongly gendered feminine. Since Brown was already invested and doing poorly in the book market, he could very well have been seeking out a niche to provide the sort of financial remuneration of which he dreamt when he wrote his letter describing the thousands of dollars he might earn. Also pertinent is Tebbel and Zuckerman's observation that fiction "in the magazines continued to be considered disreputable by many people, including editors" and that "it had to struggle for general recognition in the magazine world, as it did with the public, because for so long it was lumped in with such amusements as theater, dancing, gambling, cockfighting, and horse racing." 16 As such, fiction would undercut the serious tone Brown aimed to produce. Finally, Brown's genre of choice was the novel. He wrote six full-length novels and one novella long enough to be considered a novel by some of his critics. Only the novella was short enough for serial publication, and it took up two hundred of the Monthly Magazine's pages. By comparison, the short stories Brown wrote constitute a small percentage of his total output. Simply put, he was not a writer of short fiction, and his novels were too lengthy for serialization (a practice which really did not come into vogue until well after Brown's death in 1810). Additionally, Brown had difficulty gathering enough material from local contributors for a single issue. It is quite possible that he received no submissions of traditional short fiction. And even if he did, he might have discarded them because they did not complement the Monthly Magazine's content or were hack works he deemed unsuitable for publication. While the writing of fiction was Brown's first passion, the periodical's content suggests he had a different vision in mind for it.

Besides printing very little fiction in the Monthly Magazine, Brown also departed from his fellow editors in his neglect of current events. While other magazines dedicated considerable space to the turbulent politics that characterized 1790s America, the Monthly Magazine actively avoided controversial political issues of national import. Brown also dedicated little space to the topic of women's education. This important social issue was frequently discussed and debated in other periodicals, usually focusing on what subjects were proper for women to learn and how much education women should acquire. The pages of Brown's magazine, however, were regularly silent on this topic. ${ }^{17} \mathrm{~A}$ third issue Brown occasionally but infrequently addressed in his magazine involved what Mott calls "The Paper War" with England and France-an ongoing debate over the quality of life and literature in the new republic. As Mott points out, Americans possessed "sensitiveness to criticism 
arising from a feeling that the republican institutions of which they were really proud were on trial before the world." 18 Frequent criticisms or misrepresentations of American culture in British and French publications sparked a defensive war of words that found an outlet in the nation's magazines. ${ }^{19}$ While the Monthly Magazine flirted with "The Paper War" and discussions of women's education, these issues did not command the extensive coverage found in other periodicals of the era.

Magazining was also very difficult in the early republic. Before 1794, there were never more than three magazines in print simultaneously along the Atlantic coast. ${ }^{20}$ Dennie's Port Folio was the first periodical to celebrate ten years in print, and that was in 1810, the year of Brown's death. Most periodicals were short-lived, some lasting only an issue. Though long-running by some standards, the Monthly Magazine's year and a half of life was ultimately quite typical of the years before 1820 . Quite possibly, Brown's publication survived so long because it was filling a niche, since the demise of the Time Piece; and Literary Companion (1797-1798) four months after the appearance of the Monthly Magazine left New York City without a literary periodical. While a few other periodicals began their usually short runs in the months after the birth of the Monthly Magazine, only the Medical Repository (1797-1824) ${ }^{21}$ remained steadily in print before, during, and after Brown became an editor.

A severe problem that faced those in the magazine business and that probably contributed to the short life of many periodicals involved payment for issues received. While today's magazines demand their money before delivery, no such system obtained in the eighteenth century. Thus, even such successful magazines as Mathew Carey's American Museum (1787-1792) and Isaiah Thomas's Massachusetts Magazine (1789-1796) were forced to print notices demanding payment from delinquent subscribers. With a yearly subscription rate of $\$ 4.50$, Brown's periodical was probably no different. Furthermore, the rate itself was extravagant for the time. Mathew Carey's American Museum cost $\$ 2.40$ per year, and it struggled to survive. While Dennie's Port Folio garnered $\$ 5.00$ for a subscription (rising to $\$ 6.00$ in 1804), he had the good fortune of immediate success, which probably sustained the high rate, and his selections were of the highest caliber, written by the best minds of the period. ${ }^{22}$ Though Brown printed no notices attempting to shame subscribers into paying, an article in the December 1800 issue of the Monthly Magazine announces the periodical is ending its run and cites subscriber payments as one of the contributing factors to its demise.

Magazine publishers and editors also faced the same problem that was confronting booksellers. As William Charvat points out in his classic study 
The Profession of Authorship in America, "a small and scattered reading public and poor transportation depressed the commercial value of all books" 23 and, one might add, of magazines. Toward the end of the Monthly Magazine's run, Brown must have reached the same conclusion, no doubt observing that in 1800 New York City was too small to support a periodical exclusively and that national distribution was only a distant dream. Internal improvements would come, but only a quarter of a century after the Monthly Magazine's run. A further hindrance to distribution of magazines came in the form of the 1794 Postal Act, which provided postmasters with the power to refuse the passage of magazines through the mail. Without the mail to carry magazines to subscribers, both the Columbian Magazine and the American Museum collapsed; only where postmasters took a lenient attitude toward magazines did periodicals survive. Like the problems with longevity and timely subscriber payments, the Postal Act and the dearth of internal improvements proved to be obstacles too difficult to surpass in the late 1790 s.

While it shared some traits with other magazines of the period and its editor confronted many of the same difficulties facing other editors, the Monthly Magazine did differ in one very significant way from its contemporaries. Many magazines reached out to women readers. Nord's eleven percent was not uncommon for some periodical publications of Brown's time. Boston's New England Magazine of Knowledge and Pleasure anticipated a female readership as early as $1758,{ }^{24}$ for example, and the Gentlemen and Lady's Town and Country Magazine (May-December 1784) was the first to recognize women readers openly. ${ }^{25}$ While the first major efforts to target them came after 1800 , consistent recognition and courtship of women readers had already become a central feature of magazine promotion and publication by Brown's time.

From the first, though, while not openly or aggressively hostile to them, the Monthly Magazine supposes a readership that excluded women, detectable immediately in the first article of the first issue (April 1799). Presumed by many critics to have been penned by Brown himself, ${ }^{26}$ "On Periodical Publications" 27 is an introductory piece designed to acquaint readers not only with the goals and projected content of the Monthly Magazine, but also with the difficulties of producing a periodical in the United States at the end of the eighteenth century. "Candidus," the "author" of the piece, claims that the editor has promised too much, that he is attempting to please too many diverse factions with the projected variety of materials to be published in Brown's periodical. As part of his discourse, Candidus supplies a list of expected readers: 
Each [reader] will look for discussions connected with his favorite pursuit-the politician for news, the merchant for St. Domingo revolutions, the poet for elegies and sonnets, the naturalist for non-descripts, the chemists for aerial and caloric speculations; and, ten to one but each will find you trite, brief, or superficial, and consign you to cobwebs and dust. (I: 1$)^{28}$

The list of occupations is key here, for it indicates not just the content of future issues, but the type of readers Brown expected to attract to the Monthly Magazine.

In the seventeenth century and especially during the Enlightenment, Victor J. Seidler tells us, a "language of reason, science, progress, and civilization had been appropriated as the exclusive possession of men." 29 Brown's contemporaries would hardly have expected or desired women to involve themselves intricately and publicly with politics, business, or science (the professions Candidus names), for success in such professions required the ability to reason well, a quality the culture thought women lacked. ${ }^{30}$ Nina Baym contends that by the antebellum period "it was far easier for a woman to pursue scientific interests as a consumer than as a producer." 31 But she also concedes that gender conservatives believed the subject was beyond women's intellectual limits. Some critics claimed women were "too immersed in detail" to comprehend "rigorous scientific abstractions," while others claimed women were "too fanciful to focus on science's gritty details" and too physically fragile to do the experimentation required (4). ${ }^{32}$ By citing the politician, the merchant, and the scientist, Brown, a product of the eighteenth century, is signaling that he expects his writers and readers to be men. Moreover, many members of both sexes held the belief that women would appear "unfeminine" were they to participate in politics or other "masculine" professions and activities. New Jersey provides a relevant example, for in 1790 it adopted a new election law that provided suffrage to men and women. While some men hailed the law as a triumph of republican principles, many greeted female suffrage with ridicule; William Griffith, for example, remarked that he found it a "mockery" and "perfectly disgusting" to watch women casting ballots. ${ }^{33}$ Obviously, some women did exercise the right to vote in the state, but the majority did not, and many were content to agree with Abigail Adams, who, as Mary Beth Norton puts it, "believed that a woman should express her political opinions only in private, rather than by taking part in public debates." 34 But Candidus makes clear that Brown's magazine purposely aimed to promote public critical debate about issues and events considered outside "woman's sphere." This declaration of principles and the professions Candidus lists, then, worked to exclude 
women readers who like Abigail Adams, advocated private discussion over public debate. In fact, the only category in the list Candidus supplies that might have been an acceptable female pursuit is poetry. While it was not by any means unheard of for women to publish poetry and become authors, even this "profession" was dominated by the likes of Philip Freneau and the Connecticut Wits, with much of the poetry by women circulating privately through letters and manuscripts, a more becoming and "feminine" way for women to have their material read. ${ }^{35}$

Candidus presumes that politics and philosophy will command many of the pages of the periodical, but, in what might seem an attempt to attract women readers, he also expects "fictions" to be a part of what readers will find upon opening an issue. But the Monthly Magazine gave most of its space to works dealing with science, business, and social commentary, not fiction. Brown's Memoirs of Stephen Calvert did take up roughly two hundred pages over eight issues, but this amounts to just under $14 \%$ of the magazine's 1,440 pages (18 issues total). Furthermore, the content of Stephen Calvert and two of the fictional pieces suggests a primarily male readership. While two of the three short stories deal in sentimental plots common to the popular novels of the time, a fragment of Edgar Huntly (printed in the same issue as "On Periodical Publications") and "Thessalonica: A Roman Story" also appeared within the periodical's pages. The former contained one of the novel's several bloody confrontations with Indians, the latter the narrative of a slaughter, hardly the stuff of interest to the white women who were the major consumers of sentimental fiction in the early republic. The plot of Stephen Calvert, too, resembles those found in Brown's gothic works more than it does the plots of The Coquette or Charlotte Temple-the bestselling works that women readers made popular. Focusing on a male protagonist rather than a victim of seduction or other sentimental heroine, Brown spins a tale about an allegedly lecherous young man who rebels against authority. Brown's Calvert is decidedly not the sentimental hero. Since women preferred the seduction novel to Brown's gothic works, there would be little in his novella that would attract them to the Monthly Magazine.

Though it provides an inkling of what Brown construed his readership to be, the introductory piece does not provide incontestable evidence that the Monthly Magazine was geared toward male readers. Other articles, however, bolster such a claim because they discuss topics likely to be of little interest to eighteenth-century female readers or represent women as foolish and unintelligent. The piece "On Almanacks" (May 1799) provides one such example. ${ }^{36}$ By calling up a personal experience, the writer aims to show "the abundance of useless and unintelligible learning which an almanack 
contains" (I: 86). In spite of this, he wonders why there is "scarcely a family, however ignorant and indigent, without one copy hanging constantly in sight, and yet there is no production which fewer understand" (I: 86).

It is not his overall goal for the piece that is of interest, however, but the writer's portrait of the "good woman" occupying the "hovel of a fisherman" (in which a storm forced the author to take cover). Looking for something to occupy the time, the author scans the family's almanac and then asks the "good woman" to what "use" she puts the almanac. Hesitantly she tells him "why-I don't know-it's an almanac." Upon further inquiry, she states "with an air of increased perplexity" that they "look at it now and then to-to-to tell us the day of the month" because "One likes to know what day of the month it is sometimes," especially if they are to pay their quarter rent. Further questioning reveals the woman's total unfamiliarity with some of the information contained in the book, including the names of the saints, of which she makes no use because, she asks, "What are these folks to me?" The author pushes her, asking what "Quinquagesima," "Epiphany," and "Ascension" mean. She replies: "La! suz, don't ask me." Finally, the man asks "what are these uncouth characters, squares, and circles, and crosses; and the words elongation, southing, apogee, Sirius and Arcturus, and Bull's eye, and Crab's foot? What did the almanac maker mean by giving us all that?" Not knowing what to say, she tells him, "I can't tell, not I. I looks for nothing but the day of the month and the times that the sun rises" (I: 86).

Now, of course, there are class and literacy issues here. One can hardly expect a woman living in a fisherman's hovel to be familiar with astronomical terms and mathematical symbols. Yet, in spite of this, the piece seems to imply that this woman knows next to nothing at all, that she can barely respond to the author's questions, that she appears no better than a dunce. Even the names of the saints seem foreign to her experience. ${ }^{37}$ Whereas the male author comes off from this encounter looking intelligent (presumably be knows what "apogee" and "epiphany" mean) and reflective (be considers how useless almanacs actually appear to be), the woman looks superficial and unintelligent, hardly the sort of portrait with which a woman reader would want to identify. And this is not the last time such a portrayal appears within the Monthly Magazine.

This assumption that women are unintellectual-or at least prefer not to read intellectual pieces-reappears in the second installment of "Dialogues of the Living," a piece published in a much later issue of the Monthly Magazine (February 1800). ${ }^{38}$ The piece apparently is designed (perhaps by Brown himself) as a defense of the editorial ideology guiding the selection process behind each issue of the magazine. 
William is reading an issue of Brown's periodical when his friend Edward approaches. William is highly critical of the periodical because its content is "grave," "sober," and inferior to that of London and Edinburgh magazines; Edward, on the other hand, defends the selection process and the shape the magazine has taken. ${ }^{39}$ This is clearly a "puff" piece designed to enhance the reputation and prestige of the Monthly Magazine's content and purpose while simultaneously repelling the criticisms of its detractors. Edward serves as Brown's spokesperson.

Within Edward's defense and implied promotion of the magazine, however, are noteworthy comments about women. To William's complaint that the magazine is too serious in tone and should contain more amusing and entertaining pieces, Edward responds thus: "But, really, after all, who would be gratified by this light and frivolous stuff? It would please women and children; and perhaps now and then serve to relax the muscles of a student, like yourself. For my part, I think instruction of more importance than amusement" (II: 97). Several of Edward's remarks are immediately significant here. To begin with, his statement sheds further light on the introductory "On Periodical Publications" and the audience of the Monthly Magazine. His claims that Brown's periodical lacks frivolous articles and that women favor such pieces implies that (some) women will likely not read the Monthly Magazine. Since Edward is presumably Brown's mouthpiece, Edward's comment suggests that Brown conceptualized his editing as unlikely to attract a female audience and that he conceived of the Monthly Magazine as a periodical geared chiefly toward men.

Ranking instruction over amusement is also in line with how Brown defined his authorial career. According to one biographer, "Brown conceived of fiction as a means of enforcing wholesome lessons." 40 Moreover, "Brown conceived the notion that ideas guide society, that most worthy of acclaim is he who directs the nation in correct ethical courses, and that of all writers the moralist is the most useful." 41 "Dialogues of the Living" places the same emphasis upon instruction, which suggests Brown conceived of the Monthly Magazine as on the same terms as his novels. Equating his fiction with articles in the Monthly Magazine also provided some much-needed self-promotion. By the time "Dialogues of the Living" appeared in print, Brown's career as an author was faltering. His novels were not selling, his lessons left unread and unlearned. Grantland Rice argues that novels were a cross between an earlier period's sense of publication as a form of authority and the late eighteenth century's conception of printed matter as commodity. By putting his novels and the Monthly Magazine's articles in the same category, Brown was attempting to reinforce his identity as an author. By showing in "Dialogues of the Living" how the periodical he edits carried 
substance, he implies that the novels he writes also put forth ideas of importance, not mere amusement. A reader purchasing the Monthly Magazine who is interested in serious literature should, correspondingly, also buy his books for further enlightenment. ${ }^{42}$

But "Dialogues of the Living" does more than just support the claims made in "Of Periodical Publications," for it also reinforces the equation of masculinity with reason and rational thought. Edward's statement concerning the Monthly Magazine's content equates entertainment with frivolity and frivolity with women and children. Such a syllogism brings us back to Seidler's point about the relationship between masculinity and reason. No "rational" creature would purposely seek out frivolity, but since women supposedly do, Edward suggests that they cannot be rational. At the same time, he manages a subtle dig at William, for by implying only women, children, and (occasionally) students desire the superficial, Edward attacks William's reason and ultimately his masculinity. Readers of the Monthly Magazine, it seems, ought to display a "proper" masculinity that is based upon reason and eschews frivolity.

The dialogue also firmly discourages women from reading Brown's periodical. While some women might have agreed that their peers can be frivolous, not all women would have considered themselves so. Mary Wollstonecraft, who died in 1797 , vehemently did not consider herself to be so and in fact blamed women's education more than anything for their attitudes. A Vindication of the Rights of Woman (1792) was not well received by much of the American reading public, ${ }^{43}$ though Wollstonecraft did have her admirers in America, Brown among them. Nevertheless, it is doubtful that women readers would have found the equation between frivolity and womanhood an enticement to read more of the Monthly Magazine's offerings. Worse yet, by claiming light entertainment is favored by "women and children," Edward places the two groups on equal footing with his choice of conjunctions-a common trope that maintained its currency well into the nineteenth century. Thus, women are equated not only with frivolity but also with childlike behavior. ${ }^{44}$ This is hardly complimentary. Moreover, Edward qualifies his remarks about students with "now and then," as if they partake of light reading, but not regularly and habitually. By doing so, he places students in a category apart from women and children, as if drawing a line between the intellectual activities of (usually male) students and those of women and children.

Perhaps too much is made of this one statement, yet Edward repeats his sexism when William claims to be disinterested in reading works of a "scientific and oeconomical kind" (II: 97). Edward is astonished, remarking 
that he had "expected this objection [that the magazine is "too solid and instructive"] from the giddy girls and the old women of my acquaintance, both in and out of petticoats" (II: 97, emphasis original), but he did not expect William to hold the same opinion. Again, there is an assumption at work here that women are not interested in texts containing facts and other "important" information; Edward suggests that women are uninterested in education or intellectual activity generally and accuses William of effeminacy-a serious charge against a youth that carried with it connotations not just of being "unmanly" but of harboring aristocratic notions rather than solid republican virtue (a strong insult in the new republic). Thus, again, there is not only a definite effort to dissuade women readers, but also a construction of readership that expects men to read the Monthly Magazine and to read it for its intellectual power rather than for any frivolity found in it.

Brown's periodical contained other unflattering portraits of women besides the apparently unintellectual woman with the almanac and the frivolous women Edward imagines. In the piece "Gossiping: A Dialogue" (June 1799), two women are sitting down to have a talk over tea. ${ }^{45}$ Their situation immediately sets them apart from the woman with the almanac, who was living in the "hovel of a fisherman"-that is, they occupy a higher social position, one which allows them leisure time for tea and gossip. Such a difference indicates that the lack of sympathy for women and the mockery to which they are subjected within the Monthly Magazine are not limited to lower-class wives of fishermen and stereotyped, nondescript female readers of frivolous publications.

The piece, not surprisingly, is designed to satirize gossiping as foolish, superficial, and time-wasting. With this goal in mind, it is significant, then, that the participants are women, perhaps implying that only women throw away their time in this way. ${ }^{46}$ Beyond the gender of the speakers, though, is the dialogue itself, which places the gossipers-and thus women themselvesin an unfavorable light. First, there is Mrs. L., the "primary" gossiper, the one who dominates the dialogue and conveys the most information about her neighbors and friends. Her conversation displays a range of interest in others' business. She discusses Sammy Wiffet's marriage to his rich cousin and their plans for the future; she relays the reaction of the couple's in-laws to the Calthorpes' removal to the country (ostensibly for Mrs. Calthorpe's health, but in reality because Mr. Calthorpe's business affairs are "quite deranged" [italics original]); and she comments upon the destabilized social situation of Dr. Bolus and his sister after his loss of a patient. Throughout the dialogue, Mrs. L. reveals she is less interested in the difficulties of her subjects' situations 
and what, perhaps, she can do to alleviate their problems than she is in merely passing word along to anyone who will listen. In other words, she eschews republican virtue and Christian charity, for she is more interested in making herself the center of attention than she is in attending to the needs of her neighbors and the community at large.

Moreover, for the sake of passing on information, she is not above breaking confidences; when discussing Mr. Calthorpe's financial difficulties, she tells Mrs. B. that the news "was whispered to me as a great secret, by Mrs. Pry, who told me not to mention it to anybody." Mrs. L further contends she "wouldn't [mention it], except to a particular friend who will keep it to herself" (I: 170). The context of her claim suggests the "particular friend" is not Mrs. B., so Mrs. L. has, apparently, told at least two people to whom she should not have said a word. How many other times has she repeated this "sleight of hand," apparently only telling a select few? How many other people know of Mr. Calthorpe's affairs through Mrs. L.? Though the text does not provide specific answers, the satire works to imply that Mrs. L. is generally untrustworthy with any information, particularly of a confidential kind.

Mrs. L. is portrayed not only as untrustworthy, but also as completely oblivious to the pain and suffering afflicting her neighbors and friends-a cardinal "sin" in an age valuing sympathy and sentiment. ${ }^{47}$ In the case of Sammy Wiffet's marriage, the bride is going to live with his parents, and his mother "has not the best temper in the world" and "is not heartily for the match" because "she thinks the girl and boy are too young for the marriage" (I: 169-70). While Mrs. L. does claim she pities the future Mrs. Wiffet, her sympathy appears as nothing more than a cliché thrown out in the course of conversation; a mere few sentences later, she has callously left the Wiffets' living arrangements behind and is talking about the ages of the wedding couple and the date of "her Jemmy's marriage." When she discusses the Calthorpes, she calls their rumored move to the country "prudent" and passes judgment on how he has handled his affairs: "To be sure, he's lived in quite too high a style since his marriage. His wife had no fortune; he married her a poor ga'al, an orphan, and living altogether on her aunt" (I: 170). She uses this information only as a springboard to verify her information, asking Mrs. B. whether she has heard anything of their affairs. A similar lack of sympathy is displayed during her discussion of Dr. Bolus's flagging social status and her speculation concerning the future of Betsy Bolus (the doctor's sister) now that the doctor is getting married.

Of equal importance is her lack of interest in Mrs. B. and her poor health. At the beginning of the conversation, Mrs. L. inquires how Mrs. B. is 
doing. Mrs. B. attempts to gain some sympathy for herself, but Mrs. L. interrupts the tale of how she came by her illness, in a complete non sequitur, with a discussion of the Wiffet marriage. In fact, each time Mrs. B. speaks, she rarely gets out more than a few words before Mrs. L. has interrupted her again, sometimes with subjects triggered by something Mrs. B. has said. Though Mrs. B. is apparently Mrs. L.'s neighbor and friend, Mrs. L. shows no interest in what her friend has to say or in her friend's condition because she is more interested in what gossip she herself has to convey. Even at the end, when Mrs. B. realizes it might rain and hurries off before she worsens her illness by getting caught in the downpour, Mrs. L. asks what her hurry is, oblivious to what Mrs. B. has just said about the weather and her health. By the end of the dialogue, Mrs. L. looks like a heartless and untrustworthy woman.

Unfortunately, Mrs. B. does not necessarily fare much better. While it is true that she appears deserving of some sympathy for her illness, she continually returns to it as a subject for conversation. On the one hand, having failed to gain any sympathy from Mrs. L., Mrs. B. may be searching for some acknowledgment of what she has confided to her friend-a perfectly understandable response. However, her repeated attempts also indicate a degree of egotism. It should become apparent to Mrs. B. after her first and second attempts that she will get no sympathy from Mrs. L., yet Mrs. B. returns to the subject a third and a fourth time. With one exception, each time Mrs. B. speaks she manages to turn the conversation to her health. When Mrs. L. breaks off from her monologue about the Wiffet marriage to ask whose coach is going by, Mrs. B. seizes the opportunity to bring up her cold: "I don't know; some upstart's [coach]. I dare say; but my cold's so distressing, and I have not been out of the house this five days, and havn't seen a soul at home" (I: 170). Her turn toward her cold is not unlike Mrs. L.'s non sequitur concerning the Wiffet marriage. Similarly, when asked about the Calthorpes' situation, Mrs. B. tries to relay some information, realizes she has forgotten a name, and then says "my cold's so troublesome that I don't remember nothing" (I: 170). This comment initiates a monologue about how she wanted to consult Doctor Bolus; of course, before she is far into her story Mrs. L. seizes upon the doctor and changes the subject entirely. By this point, though, the reader wonders if Mrs. B. wants to discuss anything but her cold. By the end of the dialogue, she appears so focused on her own condition that she, too, is oblivious to what her friend is saying, and the reader must begin to think that while Mrs. L. might be heartless, Mrs. B. is completely self-centered.

Besides the negative portrait of women presented in "Gossiping," it should also not be lost upon the reader that Mrs. L. and Mrs. B. are married, 
making the piece a subtle commentary about wives. In the early republic women were frequently stereotyped as superficial in their thinking and "naturally" unable to rise above their limited mental abilities. By including this piece, the anxiety-ridden Brown was perhaps not only discouraging women from reading the Monthly Magazine but was also reflecting on the benefits of single living, for himself and men generally. This piece suggests some unease about the sort of conversation to which Brown (or any man) would be subjected if he chose his spouse unwisely or misjudged her faculties. Marriage required that men center their personal lives in domestic duties, spending more time at home than at social gatherings. For a man like Brown this might also have meant giving up-at least in part-the time spent in intellectual exchange with male social groups like the Friendly Club. He would have to trade this circle of literary and scientific men for, perhaps, the superficiality of women's gossip. In short, this piece, like "Dialogues of the Living," equates women's interests with the frivolous, cautions men against marrying gossiping wives, and subtly valorizes single life.

Yet another piece which reveals an antagonistic stance toward women within Brown's periodical is "Anecdotes of Madame Du Barri" (June 1800)..$^{48}$ This article briefly retells the life of Louis XV's mistress. While the piece mainly aims to criticize the French and "expose" the corruption of the French monarchy, Madame Du Barri nevertheless maintains her own presence within the piece, perhaps even overshadowing the political message seemingly so central. Her rise to prominence and power is cited as "one of the many examples of folly and profligacy that produced the French revolution" (II: 401). Issues of class, gender, and race are all at play in this short piece, and Madame Du Barri is more damned with each "revelation." Central to her portrait is her close association with corruption, no surprise given the political import of the text and the stereotypes of the day. Vilifying the French and the excesses of the French Revolution was a national pastime for many Federalists and some Jeffersonians of the period, so an elegant French woman with such power was sure to draw fire. English Whigs, who held great sway in the political thought of the American Revolution and early republic, often portrayed women as a disruptive force within society that led to corruption. As Kann puts it, English intellectuals "regularly blamed women's unlimited selfishness and greed for driving men from virtuous agriculture to corrupt commerce and speculation and then into the clutches of inconstant female figures such as the enchantress 'Credit' who operated 'malignantly and irrationally." 49

Madame Du Barri's corruptive influence, in fact, knows no bounds. Besides having an undue influence on Louis himself, who raises her "from a 
brothel to a partnership in the throne" (II: 401), she also "infects" all those around her. For example, waking up one morning in the presence of the monarch and his attendants, "she ordered the pope's nuncio to hand her one slipper, while the grand almoner (an archbishop) put on the other!” (II: 401). The example and the exclamation point draw attention not only to how immodest she is (waking and dressing in front of others), but also to how her own "immorality" is so contagious that it even infects religious representatives, supposedly dedicated to rising above materialism and sensuality.

Closely associated with her corruption is the luxurious life she has led. For good republicans of Brown's era, luxury carried all the negative connotations that sin did for the Puritans. Readers are told, for example, that "her toilet was of gold, her jewels were more costly than those of any princess of Europe, and her villa, or as it was termed, her pavilion at Lucienne, was furnished at an expense equal to a German subsidy" (II: 402). She can also draw "on the royal treasury, to whatever amount she pleased, without the formality of the royal signet" (II: 402). All of this-her possessions and her habits-presents a woman who is corrupt and corrupting, and while the image is displaced onto the French court, the dearth of positive images of women in the Monthly Magazine makes Madame Du Barri stand out all the more. While women readers might have agreed that this particular woman ought to be vilified and that "her end was worthy of her life" (she was guillotined), it is doubtful that they would have seen her as representative of their sex; they would more likely have found little to emulate, and perhaps little reason for reading on.

Moreover, like "Gossiping," this piece might be making a statement about the battle between the sexes. Du Barri does, after all, have a sexual relationship with the King of France. They are not officially married, of course, yet their relationship involves some of the same obligations, including supporting her financially. Her life of luxury is a drain on Louis's resources, though he apparently pays willingly. While this piece might serve to discourage men from taking and supporting mistresses, because the relationship of mistress to man so resembles that of wife to husband, the article might also work toward validating single life. "Gossiping" offers up the common image of woman-as-superficial, but this piece provides another common notion, that of woman-as-spendthrift. To recall Kann, it was supposedly women who drove men to the marketplace, away from the virtues of agriculture. This sketch, then, also validates bachelorhood, at least until a man can find a woman who thinks critically and maintains republican virtue.

The negative portrait of Madame Du Barri does not cease, however, with her interchangeability with corruption. She "sins" with regard to social 
position as well, and this is at the heart of the anxiety represented in this piece. For one thing, Du Barri transgresses class lines. The writer makes clear that her origin is "obscure" (that is, likely of no consequence), despite the fact she "claimed a relationship with some of the first families of Ireland" (II: 402, emphasis mine). Obviously, the writer's choice of the word "claim" is meant both to mock the truth of her statement and emphasize her obscure origins, including her life in the brothel. What we have here is a woman who rises from a lowly birth to having the King's ear, seemingly a French version of the American Dream. But the class implications of her history would have been terrifying to Federalists, who were in a tight race with the Jeffersonians for control of the government, and to many Americans over all, whose memories of Shay's Rebellion and the Whiskey Rebellion (both class-driven) were still fresh. Citizens of the early republic frequently expressed fear of "mobocracy"-that is to say, of the political power of the lower classes. Madame Du Barri ultimately represented to Monthly Magazine readers a realization of their intense fear of fluid class positions in the early republic and what that fluidity might lead to.

This French woman is more than merely a class menace, though, for she also represents all the gender anxieties of the time. As Linda Kerber and Mary Beth Norton have shown, women did claim more rights during and after the Revolution than they had possessed before. The anxiety over this new gender dynamic appears in the amount of power Du Barri controlled and becomes quite evident when the "princes of the blood were treated by her sometimes with insolence, and at other times, with vulgar familiarity." The writer cites one example where a duke was arranging his marriage to another lady. Upon soliciting Madame Du Barri's interest in the affair, "she tapped him on the belly (he was a fat man), cracked a joke on his person, permitted him to solemnize the nuptials, and engaged to take all the consequences on herself" (II: 401, emphasis original). This is not just a class transgression. The italicized "permitted" is key here, for it indicates not just that a lowly prostitute/mistress can broker marriage deals, but that she presumes to allow a man to do anything. In theory, the duke does not need the permission of a woman to marry whom he wants, or to act in any way whatever. The italics contain all the outrage surrounding the notion that a woman could so upset the gender hierarchy and disrupt the "normal" order of things, whether in Revolutionary France or early republican America. English Whigs such as Algernon Sidney feared the tyranny of a woman's influence. ${ }^{50}$ For many men of Brown's era, with women quietly and not so quietly clamoring for realization of the ideals behind the American Revolution and the writing of the Constitution, Madame Du Barri represents a very real anxiety over loss of power. 
Lastly, Madame Du Barri transgresses racial boundaries. One of the many examples of her corruption involves her servant: "The chancellor of France, at her request, signed a patent, constituting her negro governor of the castle of Lucienne, with a pension of six hundred livres a year" (II: 401). A country of slave-owners, whose next president considered the poet Phillis Wheatley and her entire race inherently inferior to Caucasians, ${ }^{51}$ was certainly not ready to nod approvingly at raising a black servant to a position of power and wealth. For this, Madame Du Barri is later compared to Caligula, an obvious reference to the corrupt Roman Empire rather than the (alleged) noble Roman republic. The writer contends, with Du Barri in mind, that the "philosopher scarcely knows which most to despise, the Romans of one age, or the French of another" (II: 402). Presumably, any despising of the French includes Madame Du Barri expressly because she has made a black man a governor. In short, Madame Du Barri is not only a disruptive and corruptive influence-the worst nightmare of Kann's Whigs-but also constantly upsets supposedly inherent hierarchies of race, class, and gender. By the end of the piece, one of the most drawn out prose sketches in the Monthly Magazine, neither male nor female reader can see anything about her worth admiring. Not only would women fail to find themselves in this portrait, though they might find men's image of women in it, but they would also fail to find anything applicable to their own lives. There appears nothing to attract them to this piece, and, taking this article as in line with the editorial policy of the periodical, nothing for them in the magazine as a whole.

There are, of course, a few exceptions to the pervasively negative image of women in the Monthly Magazine. For example, in the "Selections" section of one issue appears a list of thirty-nine women authors that includes Charlotte Lennox, Hannah More, Lady Montagu, and Mary Wollstonecraft (May 1800). ${ }^{52}$ Each woman's name is given with a brief designation like "novelist," but no further commentary about their works or female authorship in general appears alongside. One could read the appearance of this list, perhaps, as expressing general approval toward at least these particular authors and their works.

Such an assertion is further evidenced by one of the very last articles to appear in the Monthly Magazine: "Memoirs of Hannah More" (December 1800). ${ }^{53}$ The piece initially remarks upon the "controversy respecting the intellectual talents of women, as compared with those of men," which has been "nearly brought to an issue" (that is, an outcome) by the current generation. This outcome, the writer of the piece suggests, is "greatly to the credit of the fair sex" because the "present age has produced 
a most brilliant constellation of female worthies." These authors "have not only displayed eminent powers in works of fancy, but have greatly distinguished themselves in the higher branches of composition." According to the author, Hannah More in particular has distinguished herself in the literary world through "several elegant, ingenious, and useful publications." Her life is laid out in the piece because it "will not only be amusing to those who have read her works, but will also be instructive to young persons in the way of example" (III: 465).

This is indeed high praise from Brown's magazine, given the many pieces that apparently aim to discredit women. Perhaps the praise for More emanates from the Monthly Magazine's thrust toward edification in every issue, since the "usefulness" of More's works is given some emphasis in the piece. Her high stature (the rest of the piece relates her life story) is reinforced by the generally positive review she received from Brown's American Review. She is, in fact, only one of a handful of female authors represented in the periodical's review section, which was predominantly concerned with male-authored works. Brown must have believed that More's works and life would be of some interest to the men he imagined were reading his magazine. Perhaps he thought those readers might pass this one piece along to female household members. After all, her life story appears as a positive example, in spite of her having authored books at a time when the culture still viewed female authorship as somewhat suspect. ${ }^{54}$ Perhaps, too, he envisioned the Monthly Magazine as a repository for information from Europe. Despite the calls for an American tradition of authorship, Europeand Britain specifically-was still the cultural center of the Atlantic world. Printing information about what the British were reading could then be construed as Brown's attempt to keep his readers culturally literate. Viewed in context, though, the praise for More is exceptional rather than commonplace, for the overwhelming emphasis of the Monthly Magazine was on male authors and readers.

In addition to More, there is, not surprisingly, also a piece written about Mary Wollstonecraft (August 1799). ${ }^{55}$ As many critics have acknowledged, Brown was an admirer of both Wollstonecraft and William Godwin, ${ }^{56}$ and the article in his periodical reflects this admiration to a degree. In the very first sentence, the author, L. M., refers to her as a "great character" and a few lines later compares her to a "dazzling meteor" (I: 330). The writer's admiration continues: "She discovered all the force of original genius, not only in detecting the errors of all former plans of instruction, but by devising new principles of education, sufficient to rescue the minds of females from the lethargy that has so long oppressed them. 
Hence I respected her, even to veneration" (I: 330). He further enumerates the points he admires: how she seemed elevated above "the common elements of life"; how the passions driving her "seemed all exalted into a pure ethereal fire"; and how "she was alive to all the sympathies of nature" (I: 330). The writer again reminds the reader of Wollstonecraft's "exquisite genius" (I: 330) and claims "the purity of her heart appears to be incontestable" (I: 331).

All of this is unquestionably high praise for a woman whose bookA Vindication of the Rights of Woman (1792) - attained an almost universally negative response in America, especially after William Godwin published her memoirs in 1798. Many Americans looked unfavorably upon the Godwins, especially because of their notions of morality and ideas about equality between the sexes. What we have in the piece appearing in the Monthly Magazine is a series of admissions with which many American men and women in the early republic would have taken issue. Wollstonecraft's reputation in America was more infamous than famous. To suggest that she had "genius" and that her plans for female education had value ran counter to popular belief. Moreover, the praise is rather extraordinary in a time when some men doubted that women could even exert reason or feel sincere friendship. ${ }^{57}$

Yet, despite these praises for Wollstonecraft, L. M. must repudiate his unqualified admiration and veneration for her. The result of his repudiation is a piece which presents Wollstonecraft as negatively as some other women are portrayed in the Monthly Magazine. Mary Wollstonecraft has an Achilles Heel: despite her intelligent views on female education, she also "seems to have given the wing to her imagination, indulged in all the enthusiastic reveries of a luxuriant fancy, and suffered life to evaporate in a rhapsody of sentiment" (I: 332). What does L. M. mean by this? In short, while Wollstonecraft might have shown great abilities as a thinker and philosopher, she allowed her emotions to overwhelm her good judgment. This is not unlike the stereotype explored in the sentimental novels of the time. In Hannah Webster Foster's The Coquette, Eliza Wharton lets her emotions get the better of her and becomes a "fallen woman"; so, too, with Mary Wollstonecraft. The author objects not so much to wild theorizing, but to testing out those theories through experience: “Her's [sic] was a wild and visionary scheme of uniting, in her own experience, the blissful confidence, and tranquil joys of connubial life, with those of inestimable privileges, and that perfect independence alone compatible with nothing but a single state" (I: 332). In short, she had premarital sex, and "This it was that became the source of all her misfortunes; and this it was that precipitated her to the 
brink of destruction" (I: 332). While L. M. dedicates a considerable amount of space to discussing Wollstonecraft's genius and admirable qualities, he spends significantly more on her downfall, leaving the article ambivalent toward its subject at best, but almost wholly negative at worst. The criticisms of Wollstonecraft's life choices take over and become the centerpiece of the article. What began as a positive discussion of her abilities closes with a regret over her extreme independence from social conventions; as a positive portrait of a woman, like the ones noted before, this one of Wollstonecraft fails.

Despite his apparent, though qualified, sympathy for women's rights in Alcuin and his admiration for Godwinian ideas, Brown obviously did not refuse to print articles that participated in his culture's sexism by mocking and degrading women. Such content-from the piece spotlighting the apparently empty-headed woman and her almanac to the discussion of Mary Wollstonecraft-probably did little to generate interest among women in Brown's magazine. More likely, it discouraged them altogether from reading the Monthly Magazine and American Review. 


\section{Chapter Three \\ Constructions of Masculinity and Brown's Male Reader}

Charles Brockden Brown's Monthly Magazine and American Review contained little that was of compelling interest to women or that was immediately relevant to their lives, and the repeatedly unsympathetic portraits of women suggest that Brown might have aimed to discourage women readers. But the magazine must have had some readers; otherwise it would have gone the way of one of its contemporaries, Thespian Oracle, which lasted for all of one issue in 1798. If women likely were not reading the Monthly Magazine, men, at least must have been. What did Brown offer men beyond derogatory pieces about women? How did he imagine his audience, and how did he use his periodical as a vehicle for exploring and constructing early republican masculinity?

For one thing, Brown's projected male reader was a man of science. That the Monthly Magazine reported on scientific achievements is, to be sure, not unusual for eighteenth-century periodicals. William Bradford's American Magazine (1757-58) published pieces on inventions, natural history, and other sciences, and Mathew Carey's Columbian Magazine (1786-92) regularly published weather observations. Brown's lifelong interest in geography is also well known to his critics. But the Monthly Magazine was not just a repository for geographical information, nor were its scientific essays necessarily for the layperson. The articles and extracts Brown selected suggest that he had an elite audience in mind. For example, Brown apparently thought that astronomy was of particular interest to his readers. Pieces on the subject are to be found scattered throughout the run of the periodical, and Brown's handling of the subject took various forms. Several times under "Selections," for instance, Brown reprinted information from his European competitors in order to keep his readers abreast of the latest scientific developments, and 
these articles assumed readers possessed a substantial degree of learning. In the very first issue (April 1799), ${ }^{1}$ it was not enough, for example, to acknowledge that a new comet had been spotted in the sky, but that "It was small, had no tail, and was not visible to the naked eye. Its orbit has been calculated by Zach. It was in its perihelion on the 14th of December, at 15 hours $32 \mathrm{sec}-$ onds, mean time at Gotha. Its distance then from the sun was 0,22 " (I: 54). Though not common to all the discoveries extracted from the Journal de Physique, the information found here presumes the ability to locate celestial objects through exact scientific measurement rather than merely approximating locations through the use of familiar constellations. The inclusion of measurements such as these supposes a well-educated audience, the type most likely to be found among men rather than among women. The article requires that readers know how to decipher the information to understand exactly where to look for the new comet, and the ability to decipher these measurements ultimately becomes an expression of one's manliness. Such detailed information also projects onto readers a desire to investigate this new discovery further, which is in keeping with the Enlightenment notion of scientific practice as a "gentlemanly pastime" within "polite culture." 2 As cultured men, Brown's readers ought to want to search the sky precisely as part of a masculine code of behavior.

A similar assumption about readers' knowledge underlies reportage of a debate over the surface of the moon. This extract, also printed in the April issue and taken from the same French journal, sets the reader in the middle of the discussion and conveys only the latest information: "The volcano of the moon has been seen several times by the naked eye [....] It resembled a brilliant spot less sensible than the greatest satellite of Jupitor [sic], but larger. Its existence therefore can no longer be doubted" (I: 54). Two assumptions underlie Brown's selection process here. First, the fact that the piece stipulates the volcano's existence can no longer be doubted assumes an audience that is already familiar with the controversy surrounding this issue. Brown expects his man of science to know of the debate, its origins, and its developments. Second, the piece claims the size of the volcano, relative to a view from Earth, is larger than Jupiter's largest moon. In order for such a comparison to be effective, one would have to know how large this moon appears and its luminosity, since the volcano is "less sensible" than the moon. By publishing pieces like these two, Brown constructed a notion of manhood that demanded his male readers command a minute knowledge of astronomy - and by implication, of all science.

As he constructed him, however, Brown's reader did more than just keep abreast of scientific advances; he contributed to them. While the extract 
from the Journal de Physique merely reports recent theories, discoveries, and scientific activities, "On the Inequalities of Solar Light" (from the "Original Communications" section of the May 1799 issue) depicts the author "B" considering observed phenomena and posing his own thoughtful theory to explain these occurrences. ${ }^{3}$ While it should be noted that William Herschel posed the same theory three years earlier, B elaborates on Herschel's suggestion, turning the essay into more than just a reiteration of the Englishman's idea. B introduces his essay with a two-paragraph philosophical consideration of how humans must "conjure" a property (that is, posit a theory) because they are not "contented with the facts as they are noted by our senses" (I: 81); he also includes a two-paragraph description of observed phenomena concerning varying temperatures on Earth, especially when comparing specific seasons to their predecessors (e.g., winter 1799 to winter 1798). What follows afterward is B's theory of a variable quantity of rays emitted from the sun to explain why one winter, for example, can be bitterly cold and last long while another can be mild and produce an early spring.

What is important here is that $\mathrm{B}$ is participating in the debate itself and thinking through the problem to account for observed phenomena. B goes on to compare our sun with other stars, some of which also vary in their luster. If our sun is a star, B asks, "Why then may we not infer from the visible changes in the latter [other stars], the probability of similar changes in the former [our sun]?" (I: 82). In order to support his argument all the more, B goes on to consider that "The order of nature seems to require that there should be progress and mutation in this, as in all things" (I: 83). Here B moves well beyond Herschel's initial theory, producing not just scientific facts, but observations about the nature of existence itself; a variable output of rays from the sun conforms to life as we know it. After all, B asks after speculating that the sun might suddenly go out, "Why should this sun be imagined exempt from revolutions equally abrupt and memorable?" (I: 83).

By the end of the essay, B is so fully engaged with his subject that he has left far behind his explanation of varying temperatures on Earth. Staying with the possibility that the sun's light may some day vary, B asserts that heat may become "totally withdrawn or dispensed in portions considerably different from the present"; as a consequence of shifts in temperature "much havock must be made among the species that now exist, and new chains of being commence" (I: 83). "An inquisitive mind might amuse or terrify itself," B suggests, "by imagining the consequences connected with this changeable property in the sun's lustre" (I: 83), but he assures readers that certain constants like gravitation would be unaffected and that "there is no reason to suppose that intelligent beings would be fewer or less happy than 
at present" (I: 83). ${ }^{4}$ Such changes, B decides, are a part of history and could perhaps explain ancient observations heretofore unexplained and previous ages of humankind. What ultimately begins as a mere scientific explanation of differences in temperature, though, turns into a brief treatise that examines the consequences of the theory of variable light from the sun. This suggests that Brown imagined his male readers not just gleaning facts from his periodical and schooling themselves through the diffusion of knowledge, but also actively engaging transatlantic scientific debates. Readers should decide for themselves who has proposed the most accurate scientific theory, or look at the world themselves and present their own theories regarding the nature of their environment.

Such an engagement with science is furthered by a piece excerpted from the Royal Society and printed in the Monthly Magazine's "Selections" section. Probably to complement B's essay in "Original Communications," Brown elected to extract Herschel's original theory on the sun, which B footnotes in his essay. Herschel first presents his theory that "our sun has been sometimes more and sometimes less bright than it is at present," but then "challenges" others to pursue the theory through experimentation. He suggests that a

method of ascertaining the quantity or intenseness of solar light might be contrived by some photometer or instrument properly constructed, which ought probably to be placed upon some high and insulated mountain, where the influence of various causes that affect heat and cold, though not entirely removed, would be considerably lessened. (I: 138)

He goes on to suppose that a thermometer by itself might be enough and directs the reader to a Mr. Mayer, whose work may be of further use. There is no hint in the paragraph that Herschel himself will conduct these experiments, but that readers should instead follow his lead. By excerpting this section, Brown, perhaps, suggests the same for his readers. His imagines that his male readers will consume the information in his magazine, and that their reading will spur them to great scientific heights. They will investigate the universe and report back the findings in order to make a contribution to human knowledge and society.

The same is true of another piece, "On the Temperature of the Planetary System" (December 1800), where the author attempts to disprove the belief that temperatures vary greatly from planet to planet. ${ }^{5}$ For this piece, one requires a degree of expertise, for the author speaks of how water, turned into vapor, takes on "a temperature similar to that of surrounding objects; or, in other words, free caloric is rendered imperceptible, or fixed, 
on the passing of liquids into the state of elastic fluidity" (III: 419). The author's basic argument is that the more water evaporates, the heavier the atmosphere of the planet is, but the heavier the pressure, the less evaporation occurs, ensuring "a perfect equilibrium is kept." This conclusion leads the writer to exclaim, "Such is the wonderful economy which exists in nature!" (III: 420). Like B, this writer is trying not only to educate readers but also to make a contribution based on an understanding of science and observation. $\mathrm{He}$, too, is actively engaging his subject matter, thus contributing to Brown's construction of his readers as scientific men. To make a contribution to human knowledge is also equivalent to showing patriotism. Observations and experiments that move human knowledge forward could only bring laurels to American "genius." Brown might not have engaged openly and regularly in the "Paper War" with Europe, and while this piece makes no overt sally, it implicitly suggests that a substantial scientific contribution would further the American cause.

While Brown's editorial choices regarding astronomy offer insight into how he constructed his readership and American masculinity, they also provide an important context for reading the stories he published in the Monthly Magazine. It would be easy enough, too easy, in fact, to assume that Brown used his fiction as "filler," since he was chronically short of material. If this were the case, he could have serialized any one of the novels he was writing at the time, especially since he had considerable material on which to draw. While the Monthly Magazine was in production, Brown completed and published Edgar Huntly (1799) and Arthur Mervyn (1799-1800), and he was already composing Clara Howard (1801), which he published roughly six months after the periodical ended its run. To have serialized any of these novels, though, would have involved a serious breach with convention. While short stories did appear in periodicals with some regularity, novel serialization did not come into general practice until the nineteenth century. Furthermore, while Brown might have been willing to expand the role of the critic and to avoid several popular topics, he still selected the content for and structured his magazine according to eighteenth-century conventions. I contend that Brown consciously chose these short stories because they matched the content of the magazine better than some of his other fiction. The previous examples provide an interpretive starting point. The power of keen observation is key to the pieces on astronomy. Science requires a desire to pause and watch, to note details, to interpret. The same is true of several of the characters who appear in Brown's fiction. Both Edgar Huntly and Dr. Stevens require such skills to decipher the mysteries surrounding Clithero and Arthur Mervyn, respectively. Close observation is also integral to the characters in 
the short fiction. Stephen Calvert is the most prominent example, for his observations make him the only one willing to defend Cleilia Neville from false accusations. This quality is also present in characters found in "The Trials of Arden" and "A Lesson on Concealment." Like those men reading Brown's scientific articles, the men-the bachelors-found in these narratives must pause, observe, and think critically. In this there is a key connection between the stories and the short pieces. If Brown's fictional bachelors have to pause and observe, they then have to break their alleged self-indulgence, their pursuit of pleasure. And if they must, single men reading the Monthly Magazine must do the same in order to participate in scientific discussion, undermining the notion that bachelors are interested only in what affects them directly.

Brown's republication of several pieces on mathematics provides similar insight. The same sort of expertise Brown requires of his readers in science recurs in the articles concerning mathematics, perhaps even more so. ${ }^{6}$ Like the essays about science, variety plays a central role, for there is a mix of factual and applied mathematics articles. Judging from the essays, Brown's male reader obviously was supposed to possess proficiency in mathematics as well as astronomy. Under the "factual" category falls "The Family of Lines" (August 1800). ${ }^{7}$ The writer sets out to define basic terms of geometry, but he also prefaces his definitions with remarks concerning the need for such an article. In a late conversation, he says, "there was occasion to use the word line with more distinctness and precision than is customary" (III: 89). Having found this need, "though no mathematician" (III: 89), he decided to acquaint himself with geometric terms.

Both the situation prompting his resolution, and his reasons for assuming readers might need him to submit a piece for publication are telling. The writer found himself in a conversation-though he is no mathematicianwhere a precise definition of a line was required. For so precise a definition to be in demand, the conversation had to involve complicated, perhaps even theoretical geometry. What other discussion would require this? Such a situation reveals that Brown's writers, and, as he imagines them, his readers, regularly converse on subjects outside of their professions. That is, they appear to need to be broadly lettered and to possess a range of intricate knowledge (offered, of course, by the Monthly Magazine) which they can bring into play. They require depth as well as breadth of learning. Brown's male readers apparently need such knowledge in order to function within American society, even if they are pursuing professions that have little to do with science on a daily basis. Such a conclusion is backed by the writer of the article himself, who states that the "things denoted by them [mathematical terms] so constantly recur to the imagination, and are so often necessary 
to be mentioned, that there are few who have not accidentally picked up some of them" (III: 88 ).

The writer goes so far as to suggest that knowledge of these terms is a matter of general cultural literacy, for "not to know them," he claims, "becomes, in some sort, equivalent to ignorance of our native tongue" (III: 88). He believes that at some point there is "no one but who sometimes finds himself bewildered and distressed for want of this knowledge [of the precise definitions]" (III: 88). From his remarks, it becomes clear that he believes his late conversation is not unusual, that men of the early republic frequently require such definitions and should thus read the rest of the piece for their own edification. Naturally, to gain other "useful" knowledge, they should also read the entire issue and continue to subscribe to the Monthly Magazine. The writer ends his opening remarks by noting that his article may be useful not only to non-geometricians but also to those who "may not disdain to have their memories refreshed by a simple and perspicuous, and, perhaps, a somewhat new elucidation of the subject" (III: 89). Brown's reader ought to have a knowledge of this material, not only for its own sake but also for its application in everyday life. ${ }^{8}$

Also significant here is the writer's curiosity, his desire to look into subjects more closely than he had previously, a quality he assumes his readers share. Like the need for keen observation, curiosity and inquiry are central components to all of Brown's fiction. It is what drives Carwin and Edgar Huntly, and it plays a central role in the short fiction appearing in the Monthly Magazine. The narrators of "The Trials of Arden," "A Lesson on Concealment," and Stephen Calvert all demonstrate their propensity for critical inquiry and express a curiosity which drives them to find answers to questions they have. Like Brown's readers, they find out answers for themselves, sometimes at the cost of public ridicule and suspicion. Moreover, if Brown is connecting his fictional bachelors to his readers via these short pieces, then he is again challenging the stereotypes concerning bachelorhood. Single men in the single-minded pursuit of pleasure would not stop to inquire into mathematical definitions anymore than they would astronomy.

Brown also chose to print pieces on applied mathematics. Like the pieces on astronomy, the application of mathematic principles appears as an essential skill for the reader. This time, in place of the transatlantic discussion of solar light, we find an investigation initiated by a United States citizen. A Mr. Dudley Saltonstall has suggested the possibility of a universal system of measure, and "S. M. H." is bringing Saltonstall's "discovery" to light (June 1799). ${ }^{9}$ Three things are significant about this piece with regard to Brown's construction of masculinity. First, it shows that Brown's male 
once again requires an in-depth education of mathematics to be a useful citizen. The author of the piece does not simply bring attention to the discovery; he shows how Saltonstall's standard should be construed as "correct." S. M. H. lays out his evidence not only in text form, but also in geometric diagrams. The evidence in the text appears thus: "Let $\mathrm{C} \mathrm{C}$ be a double cone ... of which cone, the greatest angles formed at the point $\mathrm{C}$, shall be of a fixed quantity" (I: 177). A student of mathematics will recognize the language in this statement as that found in geometric proofs. Nearly the entire piece, in fact, is in proof form. Brown's reader would have needed at least a basic understanding of geometry and mathematical proofs to comprehend the significance of the article, which naturally required not just a high level of education (the sort available only to men), but an ability to follow the logic behind the proof to decide if it is indeed correct.

Second, S. M. H. (and thus, as editor, Brown) is participating in a discourse of sharing knowledge. That is, the writer is bringing forth a seemingly important discovery not necessarily for self-glorification, but perhaps with the best interest of everyone in mind. Brown's male is a public servant, diffusing important knowledge to keep the public informed. Such a stance would seem to situate the article firmly within the public sphere Michael Warner delineates. ${ }^{10}$ The author is relatively anonymous (though some locals might recognize his initials) and seeks to encourage public discussion. But by printing such pieces, Brown's magazine also shares some characteristics of Grantland Rice's novel writers. Rice argues that the novel is civic discourse in the form of commodity. Like Foster's The Coquette (Rice's example), Brown's magazine is a mix of fiction and nonfiction, designed to educate and sell magazines simultaneously. His magazine attempts to play all sides of the (male) reading public by, as Candidus phrases it, pleasing everyone, thereby selling itself (and thus knowledge) to all. The initials are also of import. By not using a pseudonym or remaining fully anonymous, the author seems to speak from a sense of authority that is closer to Rice's novelists than to Warner's public sphere. Yet the author does retain some of his anonymity, for he publishes only his initials, making himself known to a select number of friends and associates. Since many of the pieces either appeared anonymously or with the writer's initials, Brown's magazine provides further evidence that public discourse was shifting from a sense of the public sphere as an ahistorical place for public debate to a notion of writing as commodity. Brown's magazine, it seems, is caught in the midst of the transition and tries to accommodate both authorial stances, not just by presenting itself as a commercial item, but by carefully treading the line between authority on high and public debate. 
Third, and perhaps most important, by sharing the knowledge, S. H. M. initiates a debate over the validity of Salstonstall's discovery. Unlike the transatlantic discussion concerning solar rays, this one is carried out among "native" Americans, for Saltonstall, S. H. M., and those who join the debate are all United States citizens. By bringing forth the discovery, S. H. M. and Brown stimulate the "genius" of America, contributing to the nation's "rising glory." Despite the laments that the new nation had put forth few men worthy of international respect for their accomplishments, Brown's magazine presents itself as interested in helping to produce such men. Moreover, by stimulating discussion among some readers, perhaps more will take to reading and learning so that they, too, can participate better in public pursuits in science and mathematics. At the same time, they will express a degree of civic responsibility and patriotism by adding to the reputation of the United States.

This knowledge of mathematics and the civic responsibility that goes with it recurs in the request "Adam Workman" makes of the readers of the Monthly Magazine. ${ }^{11}$ In the July 1799 issue, he appeals to the editor and readers of Brown's periodical "to do something for me which I cannot do for myself" (I: 263). Apparently Workman has sunk a well and requested payment for services rendered to persons " $A, B$, and C." They want to proportion the payment so that those living closer to the well pay more for the work, but neither Workman nor his clients can figure out who pays how much; thus, Workman has yet to receive his wages. Such a request relies on the civic mindedness of Workman's fellow citizens. That is, Workman has done something useful for A, B, and C, and his appeal is grounded in the notion that others will be willing to help him receive his due out of their good nature, their desire to help their fellow citizens. It also appeals to the mercantile interests of the Monthly Magazine's readers. Capitalism, as Joyce Appleby has shown, was adding new dimensions to old terms like civic virtue, and making money via independent efforts like Workman's was surely something to which New Yorkers could relate. In other words, by helping Workman, readers accomplish two significant goals. First, those who respond to Workman's query encourage others to aid their fellow citizens when a problem arises, fostering a sense of national (or at least regional) unity-the achievement of which was a crucial goal and a chief anxiety of the early republic. By so doing, they also provide a degree of security for themselves should they ever be in need of aid. Readers can count on their fellow citizens, which also enhances a sense of unity. Second, such aid also leads to a sense of self-satisfaction, not only in helping a fellow citizen but also in exercising good citizenship. Workman's request for help, then, is not an individual's quagmire, but a community issue. 
Workman's problem does indeed spur a debate much like the discussion Saltonstall's universal standard undergoes, with several parties weighing in. Workman's initial request appears in July 1799, but as late as May 1800 the best solution to his problem is still being debated. "Too impatient to wait for the solution" (II: 345$)^{12}$ and perhaps frustrated with the initial lack of response, Workman reports that he has consulted with "Mr. Standard" (August 1799), who believes A, B, and C should call in arbitrators (persons $\mathrm{X}, \mathrm{Y}$, and $\mathrm{Z}$ ); they will solve the problem for Workman and his clients. Workman's response takes on a touch of satire, though, once the initial division is accomplished, for there are "four trifles" left due to Workman which Mr. Standard determines amount to "nothing" and since "nothing" cannot be divided, he encourages all parties to retire; A, B, C, and Workman agree, receiving "a smile of contempt" from the arbitrators for being such simpletons as to believe Standard's answer. It is, of course, this last bit that actually spurs the debate, though the correct payment for Workman always hovers about. Finding the August piece by Workman "entirely false and absurd" (II: 84), George Baron (presumably not a pseudonym since he includes his New York address) briefly proposes his own solution to the problem in the February 1800 issue. ${ }^{13}$ In what must surely be a touch of humor, Workman defends his solution the following month, which naturally garners a serious response from Baron (complete with complex mathematical equations) in the April 1800 issue. What is important here is not the accuracy or inaccuracy of the respective solutions but the public debate itself. Workman's original request carries a tone of sincerity. ${ }^{14}$ The serious response of George Baron may be overkill, but the response itself exemplifies what sort of man Brown was constructing in his magazine-someone willing to contribute to public debate in order to benefit his fellow citizens. ${ }^{15}$

This work of civic mindedness carries over into more significant tasks to be completed to "improve" the new nation. In the June 1799 issue, "B" (probably as in Brown) discusses the Philadelphia waterworks, which he contends "cannot be too much admired or too zealously imitated" (I: 181). ${ }^{16}$ In the article, B describes at great length how water is supplied to the city and discourses about the many benefits of having a good water system. Among the benefits from a sound waterworks are the "abridgement of labor" and the cleansing of the streets. Moreover, "if pleasure may be considered separately from usefulness," B claims every courtyard may have a reservoir and every chamber a bath, and "personal impurities of every kind may be hourly washed away" (I: 181 ). In addition, good water translates into aesthetics: an ample supply means city beautification in the form of tree-lined streets. Finally, and perhaps most importantly, the "experiment" 
of supplying fresh water has its origins in the yellow fever epidemic, which would have been particularly important to Brown since he had lost one of his best friends-Elihu Hubbard Smith—to it just the year before. The author speculates that the waterworks will uncover "whether it [yellow fever] be capable of being washed away; whether water and shade, in addition to the strictest law of quarantine, will shut out this enemy" (I: 182). The significance of this piece lies in its opening statement about other cities pursuing the same course Philadelphia has chosen. By bringing the waterworks to the attention of New Yorkers (and presumably whoever else encounters the Monthly Magazine outside of the city), Brown encourages residents to undertake such an experiment. In other words, he and his magazine proffer solutions to problems plaguing New York and other cities by circulating knowledge of the Philadelphia experiment. He performs a civic duty here, displaying his good citizenship by acting for the good of all the citizens. Such an action shows a disinterestedness necessary for classical republicanism, but by encouraging such projects, Brown also encourages the sort of republicanism defined by Appleby. To design and build a waterworks requires workers and capital. Such a project has the potential to put money in many pockets. Internal improvements such as these were not just for the benefit of the community; they were an opportunity to "mind the main chance," in Van Rough's terms. Engaging in such a project, then, provided for both schools of republicanism, disinterest and self-interest.

Brown repeats this performance in a discussion about road building, found directly after the piece about the Philadelphia waterworks. ${ }^{17}$ In "Remarks on the Erection of a Turnpike Road" (June 1799), an unnamed author reports on the project of building a turnpike from "Fort Schuyler, on the Mohawk River, to Geneva, in the county of Ontario," what the full title calls the "Genesee Country" in western New York State (I: 182). The writer begins with a brief but detailed history of the project and what has heretofore been accomplished. In so doing, the writer demonstrates that he has been keeping apace of current civic projects, essentially taking an interest in the well-being of the country. The writer's knowledge and a reader's willingness to absorb it in the Monthly Magazine is basically the phenomenon William J. Gilmore describes in Reading Becomes a Necessity of Life, in which he argues that after the American Revolution the act of reading metamorphoses into a crucial skill for residents of the new nation. ${ }^{18}$ Information and its distribution are central to a citizenry about to exercise civic rights. The author of the turnpike piece is showing not only that he has done his duty by becoming well-informed, but also that he is aiming to educate his fellow citizens so that their own reading allows them to act on good information. 
In the turnpike article, the author argues that the residents, though eagerly building an initial road for greater ease of travel, still require state aid to finish the job, especially in light of recent westward expansion into the Genesee region. By stipulating that an "object which affords such general benefit ought to be executed by general means" (I: 183), the author lays out a theory of government in line with Alexander Hamilton's advocacy of internal improvements and investment. The author elaborates on this point further, noting that the New York legislature is "doubly interested," for it is "their duty to forward every measure on which the general prosperity of the country depends; and, in the next place, they are bound to foster those who have settled, and purchased lots immediately from them" (I: 185). Advocacy of the turnpike is interlinked, then, with a theory of good government, reasserting the author's authority on current events and projects.

The author also demonstrates his understanding of the economic benefits: "The advantage a country derives from an improvement of this kind is in proportion to the greater speed you can travel, and the additional weight of bulky articles you can carry to market with the same force, and with less tare [sic] and wear" (I: 183-84). This same point is underscored later in the piece, when the author observes that the

trade of these western countries is now considerable, and must increase and be of great importance. A gencrous conduct on the part of these two cities [New York City and Albany] will effectually secure this trade to them; which, by putting it in the power of the farmer to send his produce to market with advantage, will afford the merchant an opportunity to receive in pay such articles as the industry of the farmer will produce: and the roads being brought to such a state of perfection as will enable him to carry his own produce to market, is a clear saving to that industrious class of men. (I: 187)

Obviously, the economics of road-building are complicated and have farreaching effects on the public. ${ }^{19}$ The author nevertheless shows a mastery of his subject, an intricate knowledge of public affairs, and an understanding of his civic duty. He also presents a plan to pay for these internal improvements, demonstrating intricate knowledge of tolls, profits, and stock shares. While the author clearly is advocating the building of this turnpike, the detail of the piece suggests that, like the Philadelphia waterworks, this article aims to demonstrate good citizenship, disseminate knowledge, and smooth over opposition by showing that clear plans already exist for the "easy" completion of this project. It also does not hurt his cause that the project "minds the main chance." 
Printing such pieces would seem, on one level, to be counterproductive, given Emory Elliott's assertion that the public distrusted intellectuals and the power of authority they once wielded. Are not the authors of these articles-and perhaps even Brown-positioning themselves as people more knowledgeable about such issues and therefore in a better position to speak about them? Not exactly. While several of these articles are rather erudite, their appearance in a periodical is a crucial distinction. Unlike the sermons produced by the clergy and the pamphlets or tracts published by intellectuals, Brown's periodical is designed to sell well and circulate widely. In short, it is a commodity of the type Rice describes, not a sermon or tract. The very way in which these articles came into the hands of the public differed significantly from the way the disestablished clergy and intellectuals put forth their opinions, positions, and views. The authorship of these articles is also of significance. While not every piece printed was anonymous, many of them were and therefore fit into the public sphere defined by Jürgen Habermas and elaborated upon by Michael Warner. These articles are meant to stimulate debate in a context free of personality and historicity. They were entirely in the public's hands, and readers were free to respond to them, which leads to another difference between Elliott's intellectuals and the authors writing for the Monthly Magazine. Since these articles were meant to spur public debate rather than act as pronouncements on high, what readers concluded was entirely a matter of private judgment. They could find themselves in agreement, seek to respond with a dissenting opinion, or consign their copy of the Monthly Magazine to the trash. The tone of these articles, though argumentative, does not indicate that these authors believe they possess the final authority upon the subjects they are discussing. They write with the expectation that some debate will ensue. Is this not, after all, what ultimately happened with Saltonstall and in the solution to Workman's problem? Brown and the magazine, then, carefully distance themselves from authors who presume to speak from authority and place issues in the private judgment of those who make up the public sphere.

These articles-the mathematics discussion, the solution to Workman's problem, the pieces on the waterworks and road building-also provide an important context for Brown's fiction. They all advocate taking on civic responsibility and performing acts of good citizenship, goals that inform the short stories within the magazine. All the stories appearing within the Monthly Magazine's pages_"Thessalonica," "The Trials of Arden," “A Lesson on Concealment," Stephen Calvert, and even the extract from Edgar Huntly-portray characters who are trying to act in a civically responsible manner. In "The Trials of Arden," for example, despite pressure from the 
community to convict, Loveden votes to acquit because he has been assured of Arden's innocence and wants to see justice done. In Stephen Calvert, the titular character rushes into a burning building to rescue a trapped woman. Furthermore, many of these characters trying to "do good" are, not surprisingly, bachelors. In some cases the characters act for the betterment of society as a whole. "The Trials of Arden," for example, deals with capturing and bringing a murderer to justice. Other problems, however, have private implications. Both "A Lesson on Concealment" and Stephen Calvert deal with ensuring that justice is served in the personal lives of the characters rather than in the public realm. Moreover, just as keen observation and curiosity help define masculinity and undercut negative bachelor stereotypes in Brown's periodical, so, too, does the portrait of civic responsibility. Good citizenship, maintaining order, and serving justice were allegedly anathema to the single man. According to Kann, the Founders advocated early marriages, and immediate establishment in a career would tie men to the community at large, would provide them reason to prevent civic disruption as well as participate in civic improvement. Both of the pieces on civic responsibility that complement Brown's fiction and the fiction itself undercut such notions.

In addition and closely related to civic responsibility, patriotism also plays a role in the Monthly Magazine. Citizens of the early republic thought of bachelors as more concerned with themselves than with the nation. Thus, "patriot" and "bachelor" were considered by many to be mutually exclusive terms. Kann notes that one way to channel the selfish passions of single men in a positive direction was the military. Service would discipline and contain disruptive bachelors; at the same time, it would allow such men to display patriotism toward the United States.

Calls to patriotic action were not unique to the Monthly Magazine, and expressions of pride in the communities along the Atlantic coast preceded the Revolutionary crisis and the emergence of the United States. William Bradford's American Magazine, for example, took a strong procolonies stance, and as the Revolution materialized, many periodicals openly and vehemently took up the colonial cause. Similarly, once the new nation was born, the American Museum displayed its love of country by reprinting John Trumbull's M'Fingal (1775) and Thomas Paine's Common Sense (1776), and by publishing for the first time selections of Benjamin Franklin's Autobiography (then still in manuscript). Brown's periodical offers an alternative way to express patriotic fervor. Like the civic-mindedness behind the waterworks and roads, writing allowed one to be patriotic. Calls for a distinctly American literature were nothing new in the early republic. Many bemoaned the state of the nation's literary output or expressed a 
desire for a literature to complement the nation's independence from Britain. The article "On the State of American Literature" (by " $M$ " and from the April 1799 issue) addresses these concerns, making an explicit connection between writing and patriotism: ${ }^{20}$

I am an American. I feel a strong partiality in favor of my native country; and, perhaps, approve of many things merely because they are American. The principles of government prevailing among us, are substantially such as I admirc. The more equal distribution of property in the United States than obtains in most other countries, is also a circumstance which highly pleases $\mathrm{mc}$. I feel a degree of pride in contemplating the bold, enterprizing and independent spirit of my countrymen; nor does it give me less satisfaction to observe the plain republican manners which prevail, especially at a little distance from our seaport towns, in which it must be acknowledged the opposite evils have made too much progress. Taking all these things together, perhaps it may be said that the American character, making allowance for its youth, ranks with the most respectable and dignificd on the globe. (I: 15)

The pride and patriotism in this lengthy first paragraph are obvious. The author hits the major points that have become staples when praising the nation-its form of government, the opportunity to acquire property, the innovative and industrial character of the American people. $M$ establishes himself as a patriotic person in order to gain credibility with the audience. Calling attention to a defect in the nation, which $M$ is about to do, seems less like a criticism than a patriotic call for reform, for righting a serious national wrong. $M$ takes issue with what "learned foreigners" remark: "that THE LITERARY CHARACTER OF AMERICA IS EXTREMELY SUPERFICIAL" (I: 15). He goes on to offer an analysis as to why this is a just, albeit embarrassing, truth about the United States.

Not too surprisingly, $M$ cites the "love of gain, which in a very remarkable degree, pervades the United States" (I: 16). Authors have long been lamenting the nation's preference for business over intellectual pursuits. ${ }^{21} \mathrm{M}$ goes on to note that such a state is "humiliating to the moralist" and that the "natural and necessary influence of such a state of public taste and public sentiment, must be in various ways highly mischievous." $M$ is drawing on classical republican virtue here, which taught suspicion of mercantile interests. Yet he is also sensitive to the transition virtue was undergoing in the 1790s as a political philosophy. As Joyce Appleby has demonstrated, the notion of republican virtue was undergoing a change which would allow for some desire for wealth without necessarily invoking charges of luxury and vice. Rather than eschew gain altogether, republican virtue called for the 
accumulation of wealth as long as it protected the individual and his family but did not harm the public good.

What $\mathrm{M}$ finds pernicious is when people find "wealth is everything" and "nothing can atone for want of property" (I: 16). Then, "we may expect to see most men bending their whole attention to this object, and neglecting the cultivation of their minds" (I: 16). Key here is the example M presents: "Hence, when a young man of active and enterprizing [sic] talents comes forward, instead of studying to distinguish himself in the paths of literature and science, in which he is so well calculated to make a figure, he reads and improves himself no more than will qualify him to pursue the main chance" (I: 16 , emphasis original). ${ }^{22}$ The patriotism expressed here is two-fold. First, such neglect of intellectual pursuits is bad for the nation, for lawyers and physicians abandon their books the minute they find themselves in possession of enough knowledge to succeed financially. This trend creates a set of ill-prepared men who presumably endanger the nation at the worst and bring it no international laurels at the best. But a second key point is the author's emphasis on the "young man" who acts thus. Implicit in this argument is the notion that a young man, with proper perseverance, could make a contribution to the new nation. Writing literature becomes a patriotic duty for young (possibly unmarried) men. This will bring reputation to a nation supposedly lacking it. Such an alternative vision of bachelorhood is antithetical to the period's prescriptive literature which condemned young men as destabilizing to the community and who must be married off as soon as possible. If they are not married off, then they ought to be put into positions that either lead to marriage or, like the military, discipline their ungoverned passions. $M$ is suggesting a third way outside of marriage and military service that will serve the republic and allow bachelors to express patriotism.

The entire column about the state of American literature, in fact, becomes a sort of patriotic call to arms to rescue the country from the defects the author identifies. From "the main chance" the author moves to the nation's colleges and the imperfect education they provide, which is offered as "another reason for the superficial literary character of America" (I: 16). While he is not opposed to a college education, $M$ sees the proliferation of colleges as spreading talent and funding too thin. Thus, "professors wretchedly unqualified for their station" inhabit these universities and "are incapable of making thorough scholars" (I: 16). Worse yet are the "trustees and governors" of these institutions, who, destitute of a liberal education themselves, cannot properly judge what a strong curriculum of study requires. They, too, add to the problem. $M$ uses his friend's experience in administration to demonstrate his point: 
[The trustees] had prescribed such modes of teaching for the professors, and had so tied up their hands, that it was impossible for them to do tolerable justice either to themselves or their pupils. They were under the necessity, in order to comply with these prescriptions, so to contract, hurry over, and fritter away the systems which they undertook to teach, in order to get the boys ready for graduating at a fixed time, that science was disgraced, and those who had the name of being instructed in it were deccived. (I: 17)

Such an education has consequences reaching far beyond the "superficialities" of American literary production. Implicit here is nothing more than the security and prosperity of the republic itself. The "poor" education these "boys" are receiving endangers the nation because these students are not prepared to exercise their civic rights, engage in public debate, or even practice their professions. The students in college in 1799 are the same men who will shortly be running everything from the federal government to the local law office. If, as the rhetoric of the Revolution and the Constitutional debates made explicit, the United States was a nation of law, ${ }^{23}$ then that very foundation was crumbling in the universities. Likewise, Americans would never be able to "compete" with Europeans when it came to the sciences and other professions, let alone writing.

The little competition faced by those scholars who pursue authorship and the small remuneration they receive compound this problem. Without strong competition, Americans cannot hope to improve their literary output, for good literary output requires a challenge and knowledge of the productions of other nations. Thus, with scholars so widely scattered, there is little possibility for intellectual exchange. But there are also few scholars because they gain little reward in this country for their efforts. No one wants to engage in a profitless pursuit when families need feeding.

If Brown imagined a male audience of scientific, virtuous, and patriotic readers who benefited by absorbing the values showcased in his magazine, what did he have to gain from editing the Monthly Magazine and American Review? Quite a bit, in fact. Anxiety characterized most of Brown's life, but this was particularly true for the period he spent as a professional author. He had already been disappointed in love several times, most recently by Miss Susan A. Potts. According to one biographer, "Parental objection to their marriage, possibly because Miss Potts was not a Quaker, caused relations to be broken off forcibly." 24 Though Brown put on a good face, "without doubt his feelings had been rudely shocked by the attitude of his family, particularly that of his mother whose intervention finally forced the issue." 25 In this spirit, Brown entered his most productive 
eleven months-having already published Alcuin, Brown would shortly release Wieland and his three other "major" novels, and just under a year later he was editing the Monthly Magazine. The episode with Miss Potts, coupled with at least his earlier disappointments in love, left Brown an unmarried, unattached male in a society that did not seem to value single men.

Moreover, having firmly committed himself to authorship, Brown must have felt considerable anxiety over his very social position as a man. As Robert A. Ferguson notes, Brown's concerns over his masculinity did not begin with the publication of Wieland, but with his abandonment of the law. An exchange between Brown and a fellow student of the law, William Wood Wilkins, makes Brown's predicament clear. Responding to his friend's complaints about unhappiness with the study of the law, Wilkins upbraids Brown: "Renounce then, I entreat you, your allegiance to fancy! . . Despise the distressing power of her wand, but bow in manly submission to the sceptre of reason." 26 Wilkins "traces Brown's problem to literary self-indulgence," according to Ferguson, and "Brown's unwillingness to follow such advice leads to censure of his moral code, masculinity, and patriotism." 27 Surely, Brown must have thought, there is some way to bolster his sense of place in the early republic.

The key to shoring up his citizenship and his masculinity lay in editing the periodical. If authorship of imaginative literature committed him to fancy, brought into question his masculinity, and engaged him in a largely feminine marketplace, editorship served to counter all these effects. As Jay Fliegelman makes clear, editorship in the eighteenth century amounted to more than collecting materials for publication. The roles of author and editor were not so well defined in Brown's time as they are, perhaps, now. According to Fliegelman, these two roles had long overlapped. They were only beginning to separate in the early nineteenth century, when, to use his example, Jefferson stood accused of plagiarizing the Declaration of Independence because it was more a compilation of previous thought-from legal precedents, the Continental Congress, and the Declaration's drafting committee-than it was an "original" composition. Jefferson, Fliegelman claims, was working under the older rule of authorship: "The overlapping of those roles [editor and author] had long provided a protective context for authorial agency and articulated an older understanding of the role of the author, not as the creator of original thoughts but as a disseminator of information, as one who applied the accumulated wisdom of others to new circumstances." 28 Thus, Fliegelman concludes, "editing was far more than a 'humble act of compiling' that stood in opposition to the assertion, validation, and fashioning of self supposedly peculiar to authorship. In the scientific culture of the second half of the eighteenth 
century, which linked power with the organization of knowledge, editing, especially editing that made multiple abridged texts available in one volume, was a proprietary, interpretive, appropriative, and often imperial act."29

The role of editor, for Brown, brought some of the prestige that authorship of imaginative literature lacked. As editor, he would be able to participate in the scientific and cultural discourse of the time and be able to make the sort of contribution he sought as a "moral painter" in his novels. Authority, then, was at the heart of Brown's project as editor, authority for an unmarried author of fiction in a republic which did not value whatever contribution he felt he was currently making. As Emory Elliott notes, the "poets who lived through the American Revolution felt an obligation to use their talents to fill the moral and spiritual void left by a declining clergy, to present the social and political ideals of their nation, and to enlighten and inspire their readers with visions of the human condition in a new age and new world." ${ }^{30}$ Central to Elliott's argument is the idea that the writers of this period wrestled with a crisis of authority; they aimed to wield significant cultural influence, but they fell short of the impact they hoped to make. Although left unaddressed by Elliott in his chapter on Brown, the Monthly Magazine was part of Brown's attempt to gain this authority.

Similarly, Mark R. Patterson notes that critic Lewis P. Simpson "suggests that Federalist writers hoped to create a 'Republic of Letters,' thereby instituting a link to the political republic that would aid in stabilizing the nation." 31 Building on Simpson's point, Patterson argues that for men of the early republic "writers and reviewers could wield power equivalent to the executives and judges of the republic; as the government enacted laws and dispensed justice, the writers too might encode and constitute the as yet incomplete powers of literary practice and interpretation" 32 Thus, for Brown, "authority and authorship are closely allied," 33 and if Fliegelman's point about the dynamic between authorship and editorship is added to this equation, we find Brown's editorship meant a good deal in establishing cultural authority at a time when his personal life and the choices he had made were viewed as culturally invalid. Moreover, if Brown were to edit the periodical wisely, he must master the discourses and controversies of the times. The Monthly Magazine became, then, a way for Brown to validate his social position in spite of his bachelorhood and his authorship of imaginative literature.

This cultural authority then carried over into his readership. As Patterson also argues, privatization of judgment placed a good deal of cultural authority in the hands of readers. Brown understood this, and as Patterson puts it, writers "were faced with creating and instructing the ideal reader." 34 Authority was transformed "from public performance to private 
judgment." 35 Thus, while Brown was able to validate his own position, his subscribers, by reading, judging, and interpreting what appeared in his magazine, were also able to find validation of their social positions as single men. Or, if they were married, they found their hegemony under attack, their stereotypes called into question. Brown, then, not only cut out a space of his own, but he also helped other single men validate their lives and forced married men to recognize positive, albeit alternate forms of masculinity outside of marriage.

Virginia Lee Chambers-Schiller argues that the eighteenth-century "spinsters" of her study were, in a sense, pioneers. They had no unmarried women to look to as models, and they had to establish their own patterns of life outside of marriage. But these pioneering women became models for subsequent generations of women who chose to remain single, especially as the number of single women rose steadily during the nineteenth century. The same demographic pattern can be found among the bachelor population, so much so that Howard P. Chudacoff calls the nineteenth century the "Age of the Bachelor." Brown and his periodical stand, ultimately, at the forefront of a trend: the validation of bachelorhood as a viable form of masculinity. The editor of the Monthly Magazine eventually abandoned the single life for marriage, but for the time that he remained unmarried, he helped to establish bachelorhood as a valid lifestyle.

Brown found personal validation in editing his periodical, but this theme of challenging bachelor stereotypes and the cultural hegemony of married men carried over into his fiction. The stories he chose to include in the Monthly Magazine reflect his concerns in the articles he chose to publish. These stories, to which this study now turns, show the bachelor in quite a positive light and challenge the stereotype of the honorable married man and upright citizen articulated so clearly by the Founders. 


\section{Marriage and Bachelorhood: Fiction in the Monthly Magazine}

Brown found personal validation in editing the Monthly Magazine and American Review, in constructing masculinity in terms of civic mindedness, patriotism, and reason, and in challenging bachelor stereotypes and the cultural hegemony of married men. These concerns, reflected in the articles Brown selected, carry over into the stories he chose to publish. Why did Brown decide to include fiction in his periodical, and what cultural work ${ }^{1}$ did this fiction perform with regard to his readers?

There are some easy explanations for Brown's use of his own fiction. His position as editor allowed him to bring his fiction to a wider audience than his novels had hitherto received. He took up editorship of the Monthly Magazine in part because he could not make a living from book sales alone. Harry R. Warfel notes Brown's "dreams of affluence" with regard to sales of the periodical. ${ }^{2}$ More exposure might translate into better sales for Wieland and Ormond, as well as for his forthcoming novels Edgar Huntly and Arthur Mervyn. This would be especially true for Wieland, since T. and $\mathrm{J}$. Swords were the publishers of both this novel and Brown's periodical, and though Brown never put his name on any issue of the Monthly Magazine, it is entirely possible that the Swords brothers promoted both simultaneously as Brown products. Increasing sales and maintaining a steady audience would allow Brown to succeed as a professional author and to resist his family's pressure to join his brothers in business. Brown was also notoriously short of material from issue to issue. As biographer Warfel notes, Brown discovered that "issue after issue had to be lifted either from foreign periodicals or composed by himself alone." 3 Though sponsored by the Friendly Club, the magazine saw but few of the members' promised contributions, so Brown was continually scrambling for material to fill each month's eighty 
pages. A short story of considerable length could fill a fifth of the magazine's space, and serialized fiction like Memoirs of Stephen Calvert could continue for multiple issues. (Stephen Calvert ultimately filled two hundred pagesthe equivalent of two and a half issues.) Quite probably, by including some fiction among the wide variety of material he selected for the Monthly Magazine, Brown also thought he was fulfilling the standards Candidus set in the first article of the first issue, "On Periodical Publications": "By the variety and multiplicity of your objects, you seem aware that the approbation of the few will not answer your purpose, and, what is much more questionable, you seem to think that the taste of all may be gratified" (I: 1 ). Following this claim is a lengthy list of projected readers that includes "lovers of literature and poetry" as well as the expectation the editor will "exercise, by turns, the pencils of Richardson and Tacitus" (I: 1). (In other words, Candidus expects the Monthly Magazine to reprint excerpts from these and other famous or popular authors.) Brown's fiction certainly met the expectation of finding belles lettres in the Monthly Magazine and thus fulfilled the prospectus laid out by Candidus.

Yet such tidy reasons are not so tidy. If Brown aimed to reach a primarily male audience with his periodical, he surely had to be aware of fiction's demographics. As Cathy N. Davidson observes in Revolution and the Word, women are "the implied reader[s] of most of the fiction of the era," 4 and for the sentimental novel in particular, they are "young, white, of good New England stock, and for the most part unmarried.".5 While Davidson documents that men were clearly part of the reading community for Susanna Rowson's Charlotte Temple and other novels, ${ }^{6}$ she also notes that "the male novel reader must have felt somewhat defensive about enjoying a form often implicitly and explicitly feminine."7 Furiously engaged in the literary marketplace by the time he began editing the Monthly Magazine, Brown would have been well aware of the early republic's "feminization" of fiction.

He also must have known that many men were opposed or outright hostile to fiction, and not just because it was gendered feminine. For some "men of power and prestige [ . . ] the novel, more than any other literary genre, was seen as the sign of a time when their authority was being called into question." 8 While Brown enthusiastically presented Wieland as a gift to Thomas Jefferson and the future president replied politely, Jefferson also betrayed misgivings over novel reading as a way to spend one's time. Critics of fiction tried to reassert their authority in order to keep people in their proper places. ${ }^{9}$ Ministers, too, attacked fiction because it undercut their authority and authorized readers to be interpreters, thus dispensing with ministerial intermediation. ${ }^{10}$ Given these circumstances, what could Brown mean by 
intermixing fiction with the Monthly Magazine's more "masculine" pieces on science and public works? Did these stories speak in some way to his implied audience? And what did they say?

While Brown constructed his imagined audience for the Monthly Magazine as primarily male, he seems far from imagining them as a homogeneous group. In his own life, he was acutely aware of the hierarchy among men. Though he studied law for five years, a course endorsed by his family as a means to wealth, status, and financial stability, he abandoned the pursuit of what Christopher Looby describes as "the preeminent respectable career of his time" 11 to become a professional author. Looby goes on to note that in the "Series of Original Letters" printed in The Weekly Magazine in 1798, Brown's lawyer character "holds the other young men with whom he lives (a tailor, a clerk, and an usher in a school) in contempt"12 rather than viewing them as republican equals. While the lawyer's contempt originates from pride in his own profession and from a sense of class superiority, it is also important to recognize that these men are not all created equal. As Looby notes, a legal career was preeminent and would raise those men above other men. So it was, too, with Brown's merchant brothers. His family constantly pressured him to give up his scribbling and join his brothers in business, a career they thought far more legitimate. As a professional author, Brown's respectability sank, and pursuing a career that afforded little chance of economic success and social prestige and that many men gendered "feminine" put his manhood in question.

While Brown might have felt the social power of lawyers and merchants to his disadvantage, as a single male in his late twenties, to some an age by which he should long have been married, he must also have understood the advantage married men had over him. Socially accepted and valued, married men held more power than single men. As Mark E. Kann argues, the bachelor in the early republic was related to but better than violent criminals and those "engaged in lawless conduct associated with itinerancy, vagrancy, pauperism, and frontier anarchy."13 Such men were destabilizing forces in the community because they upset the social order. While not necessarily guilty of criminal activity, the bachelor was allegedly licentious and sexually ungoverned. He produced bastard children by indulging his sexual appetites and then abandoned them to the public's care. The republic's Founders believed the bachelor had to be contained in order to maintain civic order. ${ }^{14}$

By contrast, the married man was valued far above the bachelor, according to Kann, because he was a stabilizing force in the republic. Having a wife and children, the Founders felt, stabilized a man's behavior and coun- 
tered the bachelor's disorderly conduct. A family also forced him to recognize he had a stake in the community and that it was in his best interests to uphold the social order. Joyce Appleby argues that republican civic virtue, which demanded placing the group's concerns above one's own and avoiding the pursuit of unnecessary wealth and luxury, evolved into an acceptance of the pursuit of wealth for purposes of self-interest and safeguarding one's family. Such acceptance obtained as long as self-interest and the pursuit of wealth did not impinge upon the community's best interests. While Kann and Appleby are pursuing separate lines of historical inquiry, they both agree that a man married with children was central to the republican project. Under these circumstances, the married man held more power and influence than the single man, a fact Brown was undoubtedly aware of, since his married merchant brothers found more family favor than he did. Clearly, there were disparities in how the early republic valued its male citizens, and Brown recognized the power differential. What his fiction in the Montbly Magazine accomplishes, I argue, is to challenge the power structure of the hierarchy among men and to raise the bachelor to a higher status than he had been allocated.

One of the first stories to appear in Brown's periodical was "Thessalonica: A Roman Story," which he published in the Monthly Magazine's May 1799 issue. ${ }^{15}$ Occupying roughly seventeen pages and situated between an article about Elizabeth Inchbald's translation of Kotzebue's Remarks on Lover's Vows and the beginning of the "American Review" section, "Thessalonica" was the lone short story appearing in the May issue. Surrounding it were articles typical of the variety characterizing the Monthly Magazine. Since its setting is ancient Rome, the story fit well with "Description of the City of Morocco," Park's "Journey into Africa," Brown's review of Description of the Settlement of the Genesee Country in the State of New York, and excerpts discussing Lima, Paris, Peking, and Portugal-all pieces focused on places equally as remote as ancient Rome. ${ }^{16}$ Social and cultural practices also received some attention in this issue, with a commentary on the practice of switching residences in New York City every May Day and one contributor's proposal for a book on the use of hair powder. Aside from the book reviews, intellectual interests were met through a discussion of Hume, Gibbon, and Robertson and through several pieces on agriculture and science, including articles on preserving seeds, converting weeds to manure, removing the taste of garlic from milk, and observing an insect "prejudicial" to the apple tree. Of the pieces discussed in previous chapters, "On the Inequalities of Solar Light" fronted the May issue's "Original Communications," "On Almanacks" 
appeared only pages later, and British astronomer Herschel's observations were excerpted in "Selections."

As for "Thessalonica," the story itself does not valorize bachelorhood or attempt to redefine it as a valuable social position-this, we will see, Brown does elsewhere. Rather, Brown uses this story to call into question some "positive" forms of manhood in the early republic. "Thessalonica" is a seemingly superficial blood-soaked story of how one man's drunkenness initiates a chain of events that escalates into a state-sponsored near genocide of the city's residents. Replete with social unrest and soldiers on a mission to restore order, the story appears to be more an allegory of social turbulence in the early republic-Shay's Rebellion and the Whiskey Rebellion come to mind-than it does a commentary about masculinity. Yet close inspection reveals details overlooked by focusing too narrowly on the story's political overtones.

In "Thessalonica," married men have a significant impact upon how events in the story unfold. Let us turn, for example, to the catalyst of the bloodbath that ensues. At the beginning of the story, the city of Thessalonica is hosting one of its "public shows," and Macro, one of the city's citizens, attempts to enter the arena through a gate that is reserved for the Senate. The narrator tells us that "order had long since established distinctions in this respect, and every class of people enjoyed their peculiar seats and entrances" (I: 100). The sentinels refuse entry, a scuffle follows, and Macro is injured; enraged, the by-standers attack the guards, and more troops are called in to restore order and exact "fitting" retribution. What is crucial to the story but is easily overlooked is why the scuffle between the sentinels and Macro occurs in the first place. "It seems that," Brown's narrator tells us, "when he [Macro] came to the circus, he was intoxicated with wine, and had mistaken one entrance for another" (I: 108). So inebriated was he that "in the confusion of his intellects, he neither listened to, nor understood the objections of the centinels" to his "claiming a privilege which he regarded as justly his due" (I: 108). Macro's drunkenness seems relatively unremarkable, but reading his social position in terms of Brown's era makes it important. The narrator also reveals that Macro has a wife, immediate family (though whether this includes his offspring is not made clear), a residence, and a trade. By all respects, except for his public drunkenness he is a model citizen. But he is also the antithesis of what the married man of Brown's era was prescribed to be. As Kann argues, according to the Founders' "grammar of manhood," marriage was supposed to prevent such debauchery and licentiousness. Macro's actions are that of a disorderly bachelor, not a respectable citizen. By providing Macro with a wife and trade-his stake in the community and reason for maintaining social 
order-Brown undercuts the "grammar of manhood," revealing what many no doubt already knew-that married men do not suddenly cease to indulge their bad habits once married. ${ }^{17}$ In this light, Macro is no better than the disparaged bachelor.

This is not, by far, the only place where Brown undercuts the marriage ideal. Married men in "Thessalonica" are also prone to violence and riot, hardly displaying a desire for social order. Rather than grouping the rioters together under a nondescript term like "mob," Brown provides minute, albeit easily overlooked, details of the group's composition. Readers are told that during the "needless and wanton" execution of citizens by a small group of soldiers attempting to restore order, the "father had seen the death of his son, and the son had witnessed the agonies of his father" (I: 103). The key descriptor here is father. Involved in the riot are unruly young men and supposedly community-minded married men who should be doing everything in their power to restore social order, even, perhaps, joining the soldiers in reasserting control over their fellow citizens and family members. Brown reinforces the point when his narrator states that, upon hearing a rumor that the soldiers have been ordered to massacre all the citizens, each "fled to his house, and imparted to his family the dreadful tidings" (I: 103). Readers are also reminded of the rioters' families later in the story as the "kindred and friends of the dead" seek to recover bodies for funeral rites and "women hung over the bodies of their husbands, fathers and sons" (I: 108). While Kann notes that bachelors were supposed to be the ones who disrupted the community, Brown shows that family men were just as prone to social unrest and that the stigma attached to bachelorhood was, indeed, unfair. ${ }^{18}$

Rioting, however, is not the only way the ideal of the family man is undercut. According to Kann, a young man was expected to "prove his manhood by governing a woman," without becoming a tyrant over her. ${ }^{19}$ But in marriage, the "challenge was to ply a narrow pathway between the Bachelor's slavery to passion and a husband's potential subordination to his wife." 20 Not all men lived up to this ideal, a point emphasized in "Thessalonica." During the riot, Botheric, a favorite of the emperor, is killed. Botheric had formed a political alliance with Rufinus, who hoped to ride Botheric's coattails into the emperor's favor and eventual power. The death of Botheric demolishes his expectations. Although he is disappointed, he is not moved to stir the emperor to revenge until Botheric's sister, his wife, speaks with him: "Her grief gave place to revenge, and she used the most powerful means to stimulate the zeal of her husband in what she deemed the cause of justice. Rufinus was sufficiently disposed to avenge the blood of her kinsman, in that of the rebellious city" (I: 112). The pronouns here are most 
significant-her grief gives place to (her) revenge, she stimulates her husband's zeal, she deems what is just. The result is that Rufinus is manipulated into "extort]ing] from him [the emperor] a sanguinary edict" (I: 112) against Thessalonica. While the grammar of manhood Kann identifies calls for Rufinus to govern his wife, clearly he does not. Brown is pointing out that this ideal obviously does not exist in reality. Plenty of wives unduly influence-govern-their husbands, as Botheric's sister does Rufinus. Before his wife stirs his zeal, Rufinus seems given over to disappointment, which might have led to accepting the loss of Botheric's influence and repositioning himself to take advantage of the situation politically. He might even have used his reason to turn the tragedy to his advantage. While this is only speculative, until he talks with his wife, readers are given no indication that revenge is on his mind. In short, he fails to govern his wife and to live up to the ideals set forth for husbands of Brown's era.

In addition to the early republic's professed ideals concerning marriage, Brown also tackles attitudes toward the military in "Thessalonica." Lance Banning states that "every Anglo-American knew that standing armies were the classic instruments of liberticide." 21 Kann concurs, noting that early Americans "honored the republican militia as an exercise in men's civic virtue" and "detested standing armies as an invitation to corruption." 22 Yet he also notes that this attitude was in flux at around the time Brown was producing his fiction. Men first accepted the Continental Army, then the volunteer regular army, and later the modern conscript army. ${ }^{23}$ Eventually, a mythology grew up around military service and civic virtue. The attitude toward military service shifted from distrust to a belief that "exposure to military virtues would transform unruly young males into predictable, productive middle-aged adults who could be trusted to exercise individual rights without fostering anarchy or tyranny in society." 24 While this shift in attitude occurred over time and became most firmly entrenched in the nineteenth and twentieth centuries, its origins were concurrent with the nation's birth. In The Jeffersonian Persuasion, Banning documents the debate in the 1790s over a standing army. While he concurs that both Federalists and Jeffersonians held standing armies in suspicion, he also argues that one of the significant conflicts between the two parties concerned the Federalists' growing acceptance of a standing military. Strongly attuned to his culture, Brown investigates the nascent belief that military service could produce better young male citizens. The army in "Thessalonica" is clearly a standing army, and its actions could thus be considered symbolic of the corruption and liberticide citizens of the early republic feared. I suggest, however, that Brown is not so much concerned with military service itself- 
be it in a militia or an army-or with the possible connection between corruption and standing armies. The story itself suggests as much since the narrator does not criticize standing armies, and the commander, Botheric, is clearly a figure of reverence. Brown instead undercuts the notion that the military can produce virtuous, single, young men ready for the responsibilities of full citizenship.

"Thessalonica" contains several places where the growing connection between military service and good citizenry is questioned. At first, it would appear that the figure of Botheric, the only fleshed-out military figure in the story, acts as a symbol of manly virtue: the emperor selects Botheric for his post because of the soldier's "valour, fidelity, and moderation" (I: 99). Brown's narrator goes on to describe the commander at some length:

The temper of Botheric was generous and impetuous. He was unacquainted with civil forms, and refrained, as much as possible, from encroaching on the functions of the magistrate. His education and genious were military, and he conceived that his commission required from him nothing but unwearied attention to his soldiers. His vigilance was bent to maintain order and obedience among them, and to prevent or to stifle dissention between them and the citizens. For this end, he multiplied their duties and exercises, so as to leave no room for intercourse with the people. (I: 99-100)

Though charged with maintaining civil order, Botheric is nevertheless conscious of his soldiers' propensities and the possible dangers of interaction with the citizenry. He is not a figure of corruption as citizens of the early republic saw members of standing armies and would seem to undercut any sort of critique of the army. His lack of refined manners also distances him from the courtly manners associated with corrupt monarchy and perhaps conjure the ideal of the Jeffersonian farmer. Yet it is crucial to remember that he is one of the earliest to fall victim to mob violence, effectively erasing his presence from the story so that the remaining soldiers take center stage, and it is upon these men that Brown's critique focuses. Botheric becomes the exception rather than the rule, the virtuous soldier among passionate, violent young men-the type of men military service was expected to reshape into good republican citizens.

Botheric represents the even temper that military service was supposed to produce, but his soldiers are exactly the disorderly men the Founders wanted to contain. Before the bloodbath begins, for example, some crowd members desire to bring the soldiers who injured Macro before a military tribunal, but the soldiers refuse to listen to reason from those who "endeavored 
to gain their end by expostulation and remonstrance" (I: 100). Later, during the riot, Botheric's personal guards become butchers who determine "to open a way [through the crowd] by killing all that opposed them" (I: 103). When news spreads to the garrison that Botheric and his company are under siege, the soldiers there are thrown into confusion, and when no marching orders come forth immediately, they "threatened to march without permission," which "conquered the reluctance" of their superiors, who called out five hundred men (I: 105). Hearing of Botheric's death, all of them mourn, and many, "in pursuance of their vow not to survive their leader, stabbed themselves, and died upon the spot" (I: 106). Others vow vengeance against the civilians. Later, the soldiers are determined to hold obsequies for Botheric on the spot where he fell, but the Senate fears that this

was likely to exasperate the grief of the soldiers, all of whom would be present and partake in it. Some fatal impulse of indignation, some inauspicious rumour or groundless alarm, might unscasonably start into birth. The night would lend its cloak to purposes of cruelty, and, before a new day, the city might be wrapt in flames, and ten thousand victims might be offered to the shade of Botheric. (I: 110).

These are not men being trained in reason, civil discourse, and republican virtue. These are passionate, zealous killers who, one would expect, hardly will become good citizens once their military service is at an end. Moreover, they appear little better than a street gang or mob, symbolic of the anxiety felt about civic disorder.

The skepticism concerning the virtues of military service mounts when Brown introduces Eustace into the story. Unluckily, Botheric had just punished the man with "stripes and ignominious dismission from the service" (I: 102). Accordingly, the "treatment he suffered could not fail to excite resentment," though "the means of vengeance were undigested and impracticable." Furthermore, his "cowardice and narrow understanding equally conspired to render his malice impotent" (I: 102). Eustace is hardly a man whose passions have been disciplined by military service or civic virtue. Rather than putting aside his own narrow view of his punishment and respecting his treatment as a necessary means of discipline, he pursues solely his own self-interest. For classical and liberal republicanism alike, this is a grave $\sin$, and in the story it has tragic consequences. Once the rioters flood the streets, Eustace is near the center of the action, having "a heavy stone in hand, with which he had armed himself, from a general propensity to mischief, and a vague conception that it might be useful to his own defence" (I: 102). Instead of self-defense, however, Eustace uses the stone as the means 
to attain his revenge against Botheric, striking the man square in the chest just as he is attempting to calm the crowd. This strike is precisely the catalyst that heightens the violence, leading directly to the death not only of Botheric at the hands of the crowd, but of the multitudes who are slain by his soldiers as they make their way toward a safe haven. Again, military service is supposed to discipline the bachelor's passions, and by the time of their discharge, men ought to be prepared to take their places in the republic and safeguard its social stability. The example of Eustace shows that this is not the case when soldiers regain their civilian status. It could be argued that Eustace, as a miscreant who was dishonorably discharged, is an exceptional case, that military service produces a sizable majority of good citizens. Yet, rather than assuming self-possession through reason, his fellow soldiers also allow themselves to be dominated by inordinate grief and passion. They also look to a narrow self-interest of vengeance and anguish rather than to the consequences of their actions for the citizenry.

"Thessalonica" stakes out an ideological position contrary to prescriptions set forth by leading citizens of the republic. By undercutting the ideals surrounding marriage and military service, Brown challenges his readers' assumptions about both. In so doing, he establishes a realm of doubt that clears the way for him to present bachelors in a more positive light in later stories. For his single readers, "Thessalonica" must have carried some resonance, especially for those who, like Brown, were not inclined toward military service or were content to remain single for some time in order to pursue their own interests.

In Brown's case, this pursuit was authorship, and the story reflects his own anxieties regarding the pressures he was under from his family. While he had a circle of support from the Friendly Club and other acquaintances, his family kept urging him into business because it was a more useful, profitable and stable activity than a career in letters. No doubt they thought that a business demanding great portions of time would steady this man of unsteady work habits and occasional outbursts of ungoverned feeling. In short, the family's perspective of business was akin to the view many held of military service. By disrupting the stereotypes involved with military service, Brown could subtly claim that a career pursuing the "main chance" might also fail to accomplish its ends. He might become no steadier a worker by joining his brothers than he was as an author, and his general unhappiness could fuel any future outbursts. "Thessalonica," then, though primarily a piece concerned with social unrest and standing armies, challenges dominant images of masculinity, and read in this context reflects Brown's own life and worries. 
The short story also has resonance for single men other than its author. If Brown could undermine the mythos surrounding military service and citizenship as a way to reject his brothers' career path and bolster his own choice of authorship, surely the story could perform similar cultural work for its readers. They could equate military service with whatever cultural pressures were pushing them toward supposedly acceptable forms of masculinity that they would rather reject. In place of the Browns' mercantile firm could be apprenticeships in trades in which young men shared no interest, lives spent only in political and public service, or years spent in domestic duties to support the household. Such a subversion of acceptable forms of masculinity would initially appear to be a destabilizing force that could provide only for disorder and social fluidity. Brown's politics, ${ }^{25}$ though, suggest he was strongly committed to the notion of American freedom, even as his Godwinism diminished and his Federalist sympathies grew, and the story itself demonstrates that he deplored social disorder. Rather than creating social chaos, the cultural work of "Thessalonica" actually helps to fulfill the ideals set forth in Jefferson's Declaration of Independence-life, liberty, and the pursuit of happiness. Surely a happy citizenry pursuing careers of their own choosing and crafting is a far more stabilizing force than channeling young men into early, perhaps unhappy, marriages and careers they would rather reject. The story's disruption of the military ideal-however fledgling in the early republic-has far reaching consequences for acceptable forms of masculinity and social cohesion.

Once Brown shakes the foundations of marriage and military service, he can confront his readers with men who are single and protagonists. One such story, "The Trials of Arden," appeared in the July 1800 issue-well after "Thessalonica." 26 A piece concerned with European claims to America and a brief letter to the editor concerning "oxygenated muriatic acid" immediately precede the sixteen-page "Arden," while another letter to the editor on the "submersion of swallows" and "Friendship: An Original Letter" follow it. The July issue emphasized rational inquiry-especially into linguistic and cultural phenomena- to a considerable extent. Among other articles printed in "Original Communications" were investigations into schemes for an American language and for describing American manners, a discussion of whether Christianity would ever become universal ("yes," says the author), a reflection upon the difference between felicity and happiness, and a brief essay on applications of the name "Jack." Thoughts on a taste for the picturesque and spouses who act in too reserved a manner toward each other have a place as well. This issue also features some significant and familiar names-James Madison's oration on Washington's death and an 
appendix to Jefferson's Notes on the State of Virginia ${ }^{27}$ are discussed in the "American Review" section, and among the "Selections" is an extract from a work concerning Washington's private life. Some of the other "Selections" continued to reflect a variety of interests-methods for extracting turpentine and for preparing Parmesan Cheese, observations on the North American climate, and an inquiry into the relationship of cats and rats, including an anecdote about how a cat raised a rat to adulthood. The July issue continued the practice of avoiding the major political issues of the day. Among this collage was printed Brown's "Arden," which forwarded his ongoing engagement with issues of masculinity and bachelorhood.

In "The Trials of Arden," single and married readers found a hero with whom they could sympathize. Elizabeth Barnes and Julia Stern have investigated the importance of sympathy to the late eighteenth century. As Barnes notes, a key document was Adam Smith's The Theory of Moral Sentiments (1759), which states that people can understand how others feel only "by conceiving what we ourselves should feel in the like situation." 28 Smith's notion is crucial to Brown's project because "Sympathetic identification-one of the foremost elements of sentimental literature-works to demonstrate, even to enact, a correspondence or unity between subjects." ${ }^{29}$ By providing upstanding bachelors with whom the audience could identify, Brown could simultaneously validate the beliefs of those men-single and married-who already understood bachelorhood as an alternative form of masculinity and challenge the preconceptions of those men who had accepted the culture's valorization of marriage.

Readers of "The Trials of Arden" find their sympathies immediately engaged by the title (a narrative of trials) and the story's opening sentence: "The sympathy of mankind for great sufferers, is the liveliest of their passions" (III: 19). Immediately, the expectation arises that a kinship will grow between the readers and the protagonist, Arden the sufferer, fated to a lot "the most disastrous, the most intolerable" (III: 20). Arden's misfortunes stem from his arrest for, but eventual acquittal of murder; despite the court victory, his New York neighbors refuse to accept his innocence, and a mob drives him from town. Like "Thessalonica," this story would seem to be about social disorder within the republic-murder, mobs, economic boycotts of the jurors, criminality-but both stories rely upon the details the narrator conveys about the characters rather than the overall plot. Arden comes to Manhattan from Europe, "under thirty years of age, unrecommended, unknown to anyone" (III: 20-21). He is completely unfettered, without any commitment to the community and region, without a stake in its success. Despite the fact Arden is "destitute of visible means of support" 
(III: 21), he makes a friend, who finds him "modest, reserved, serious in deportment, endowed with much knowledge of men and of books" (III: 21) and who alerts him to a tutoring position with the Finches. Despite his initially unfettered position, Arden seems on the social and economic rise, pursuing the main chance, as Tyler's Van Rough advises, by taking on respectable work (unlike, for example, authorship). He appears ready to assume the mantle of citizenship.

What gets Arden into trouble is not social ostracism or financial failure but his bachelor status. The Finches have a daughter, Harriet, whom they expect to marry off to Wingate, son of another wealthy family and recently returned from Europe "expressly to solemnize the marriage" (III: 22). Her refusal to marry immediately raises questions about Arden:

The father's suspicions, and the lover's jealousy, naturally imagined to themselves a rival; and the youth, dignified deportment, and mental accomplishments of Arden, could scarcely cscape surmises on this occasion. Arden and Harriet had lived, for months, in the same house; the young lady never concealed her respect for the tutor; they were oftener together, under pretence, however, of something to be learned, than rigid discretion would permit. (III: 22)

It is because Arden is single, sexually attractive, and a stranger that suspicion falls on him as the reason for the girl's refusal. The fact that he is a newcomer is unstated but central to their surmises. Since Harriet expressed no reservations before Wingate left, the father's attention leaps to Arden because his presence is the only thing different about the household. Why is Arden's position as newcomer important? As a stranger he represents the same fluidity identified by Chudacoff that a bachelor demonstrates with regard to his family responsibilities. Just as the bachelor can leave or take up family responsibilities as he chooses, so Arden can come and go as he chooses. Outside of his employment he has not yet established significant ties to the city, and his past is a relative blank. Naturally, then, when Mr. Finch and Wingate learn that Harriet has disappeared, Wingate immediately suspects she and Arden have eloped. When the girl's lifeless body is discovered, Arden's declaration the previous day that he will leave Mr. Finch's service makes him the primary suspect of the murder, a charge reinforced when he asks if the girl's body was found in the grotto (which it was).

Arden's fluid position also suggests certain unease with developing capitalism. Unlike farmers and landowners who are tied to their property, any man could set himself up in business or gain employment in a community to which he has no ties. How could a man develop the sort of disinterested 
attention that republicanism called for? Appleby's reconstituted civic virtue expects self-interest to stop where the good of the community commences. But a man who has no formal ties to his community other than his job lacks an important incentive to civic-minded behavior. He could exploit the community and then move on, as the Finches at first suspect Arden of doing, since they believe he and Harriet have eloped. From this perspective, though, her death is different only by degree from her supposed marriage. Arden still stands accused of extracting what he wants from the household-Harriet's companionship and perhaps her chastity-while returning nothing.

At first, since it appears that Arden is quite guilty, Brown would seem to be reinforcing the stereotype surrounding the young unmarried man. As Kann points out, "Early American fiction was filled with morality tales about selfish bachelors who schemed to conquer girls' chastity and acquire their fortunes." ${ }^{30}$ As a real-life example, Kann cites the young George Washington, who, attempting to discipline his sexuality, "sought to live 'retired from young women' that he might bury that 'troublesome passion in the grave of oblivion or eternal forgetfulness." 31 Kann argues that the Founders "saw males as inherently passionate creatures whose sexual propensities were emblematic of their overall inability to resist temptation." 32 The circumstantial evidence in the case of Arden would seem to support just such a supposition. It appears that, governed by his sexuality, he had attempted to convince (or force) Harriet to elope with him, lost control of his passions when she continually refused, pursued her to the grotto, and murdered her. Since Arden had turned in his resignation the previous day, he also appears to believe he will win her hand or perhaps, governed by his passion, is already meditating murder.

Moreover, this scene presents Arden as subject to sudden, ungovernable actions. From Mr. Finch's point of view, Arden's resignation is a "sudden resolution" (III: 22). The narrator states that Arden "was willing his design should seem unreasonable and unaccountable" (III: 22). Arden also has no plan directly in mind, for he refuses to give "any account of his future motions" (III: 22). Finally, "it was plain that some weight hung heavily on Arden's thoughts, his countenance was troubled, and his accent sorrowful," such emotions coinciding with his "evident reluctance and embarrassment" when he entered the room (III: 22). While Arden initially appears focused on building his fortune and establishing himself, his sudden decision to quit his job presents him as given to whims, unstable, undependable, a rambler, all things bachelors were supposed to be. To clinch the stereotype, Brown also includes the fact that Arden had steadfastly and vehemently refused any entanglement with Anna Brudenel, the sister of the 
man who first befriended him. Though the match would seem to be a good one, Arden rejects it.

The crucial turning point comes, as if "The Trials of Arden" were a Brownian version of Twelve Angry Men, when a single juror refuses to convict Arden of the crime and turns the remainder of the jury to his way of thinking. The mob does not accept the jury's verdict, attacking Arden when he is released, driving him from town, and then turning its wrath on the jury members. Fearing for themselves, the eleven jury members declare that Loveden, the Henry Fonda of the jury, prevented Arden's conviction, and so the mob attacks and ostracizes Loveden.

Despite the initial uproar and Arden's flight, Brown turns the story so that assumptions and stereotypes about the bachelor fall away as the truth of Arden's case is gradually revealed and the actual murderer caught. First to go is the suggestion that Arden is a slave to his passions, that he murdered the girl when he could not gain her hand-in seduction or marriage. As it turns out, the situation between Harriet and Arden is not at all what Brown's readers would expect, what even readers of seduction novels would expect. Via the correspondence between Anna Brudenel and Arden it becomes clear that Harriet "had been favourably impressed by the accomplishments of Arden" and "had made various advances to familiarity and confidence" (III: 31). She acts "with much temerity and indiscretion, flowing from inexperience and a sanguine temper, and from certain defects, which were mingled plentifully with her good qualities" (III: 31). Contrary to expectations, Arden is not the corrupt, seductive bachelor seeking to undo the poor heroine of a sentimental novel. He is, initially, the pursued, and it is his reaction which undercuts and challenges assumptions about single men. Arden keeps his distance, partly out of "concern for the happiness of Harriet herself" (III: 31). The narrator also states that Arden

easily discovered what views her family had entertained respecting her; the claims of Wingate, to whom she was $[\ldots$. $\mid$ betrothed; the prejudices of her father, who would never stoop to an alliance with his children's tutor. To these obstacles were added the inconveniences likely to arise from the disastrous situations in which Arden himself was placed. To accept the hand of Harrict, without parental approbation and knowledge, without the means of supporting her in that luxury, and ease, and dignity in which she had been educated, could not be thought of. (III: 31)

Rather than representing Arden as a single man committed solely to his own interests and passions, this passage reveals him to be thoughtful and considerate of Harriet, her family, and his own circumstances. Despite his own attraction to Harriet, he does not dishonor her by turning her into a fallen 
woman or condemning her to a life of (possible) poverty by marrying her without the consent of her family. Furthermore, readers are told that upon Wingate's return and her refusal to accept him, Arden's "pity, his honour, his affection, were all engaged on her side" (III: 31 ). Crucial here is the fact that his emotional response is measured, tempered by sobriety and sympathy under his control.

Just as important as Arden's self-control in the face of his affection is his refusal to abide by Harriet's suggestions. According to Kann, the Founders "degraded" the bachelor "for his unmanly selfishness and slavery to desire." ${ }^{33}$ Supposed barely able to resist temptation, the bachelor submerged himself in licentious behavior. Yet in Arden we see a different bachelor under the yoke of temptation. Where Arden argues they would live in poverty, Harriet "was unconvinced by his arguments," for "Poverty was not to be dreaded" because "she possessed a sufficiency" (III: 31). Moreover, she claims her "father's choice was not her's [sic]"; she believes that "in this case she only was entitled to judge of the means of her happiness" and that by using her father's love for her, she could "make him acquiesce" (III: 31). Finally, turning the seduction novel's plot on its head, Harriet argues that a "private marriage would reconcile her duty to her inclination, since then there would necessarily be an end to Wingate's hopes and importunities; and if her family should prove irreconcilable, still union with Arden would be the least evil of the two" (III: 31-32).

Arden, readers are told, "fluctuated, wavered" and sometimes agreed to Harriet's plan, only to retract his promises later. Eventually, though, "he wrought himself up to the resolution of making her his wife" (III: 32). Readers' expectations of bachelor Arden appear to be on the verge of fulfillment, only to have Brown undercut these expectations unexpectedly when "an event happened which restored all former obstacles, and inspired Arden with a resolution to shun all further contests and struggles, by abruptly retiring from New-York, and burying himself in some remote obscurity, wither it would not be possible to trace or follow him" (III: 32). In one stroke, Brown has shown the bachelor to display the qualities thought to be the purview of the married man. Not only does Arden resist the temptation of sexual attraction and consummation by refusing Harriet's offer, but he also decides to remove himself from her society, thereby destroying possible future opportunities to give in to temptation. Moreover, Arden's actions undercut the belief that bachelors are weak and effeminate. By refusing her offer, he refuses to be ruled by a woman, demonstrating a quality men supposedly learned in marriage: good governance. First, by marrying, a man masters his vices by giving up bad habits, and then, through marriage, he learns to 
govern his family wisely. ${ }^{34}$ When they meet in the grotto, Arden displays that he has mastered himself and his passions, and rather than seduce Harriet, he refuses to marry her and announces his honorable withdrawal.

Another crucial moment in the text occurs when Mayo, the actual murderer, is introduced. His appearance in the story occurs just after Arden has been acquitted by the jury, indicted by the mob, and forced to flee the city. The juxtaposition of the two characters seemingly calls out for a comparison. Acutely aware of how undervalued bachelors were in the early republic, Brown could also have been drawing on how, as Kann reports, the Founders saw bachelors as not far removed from "other disorderly men" like criminals. Such disorderly men "indulged their desires to criminal extremes. They were guilty of sex crimes such as rape and sodomy or engaged in lawless conduct associated with itinerancy, vagrancy, pauperism, and frontier anarchy." 35 Though perhaps few in number, such men demonstrated a spirit that was allegedly contagious and "poisoned the minds of many," destroying "the bands of society." 36

Mayo's capture quickly brings his criminal character to light. Since he is already sentenced to be hanged for burglary, he confesses to Harriet's murder. He had spent fifteen years "in a series of frauds and iniquities, seldom to be paralleled." Mayo "formed some acquaintance with Finch, and being specious and addressful, insinuated himself into Finch's confidence." Eventually, he was "impudent enough to aspire to the daughter's favour," which, coupled with "some sordid pranks in which he chanced to be, at the same time, detected," destroys his reputation with the Finches. Mayo, then, was motivated by "malice and revenge, and the desire of concealing a violence previously committed on this ill-fated girl" (III: 27$).{ }^{37}$ His motivations, in particular, harken to the image of the bachelor, and a few paragraphs later, he is described as "innured to every species of guilt" and "the slave of flagitious passions" (III: 27). Such a close comparison serves Brown in a couple of ways. First, it undercuts any propensity to group the bachelor's actions with the uncontrolled passions and extreme behavior of other disorderly men. Second, it displays the bachelor in an even more favorable light; while Arden's "goodness" (III: 24) is mentioned and displayed frequently throughout the story, it is illuminated to blinding brightness by comparison with Mayo. No reader can help but sympathize with Arden, discover common stereotypes of bachelorhood undermined, and find the married man's hegemony subtly challenged. Perhaps, the bachelor and the married man are more alike than readers at first assumed.

Readers are further challenged to revise their estimation of bachelors directly after Mayo's confession, for they are in some ways like the crowd- 
too quick to condemn. Once the truth about the murder is revealed, "the memory of Arden revived":

The hatred he had formerly met with was changed to compassion. The incidents so unfavorable to him were now recalled; but since they no longer justified the belief of his guilt, they gave birth to ncw perplexities and new inquiries. The fiercest of his persecutors now repented of their fury, and longed for an opportunity of compensating his sufferings. (III: 28)

Like Arden's persecutors, heretofore unsympathetic readers ought to re-evaluate their preconceptions not just of bachelorhood as a life stage but of the actions of bachelorhood. Perhaps, by mistrusting single men, citizens of the early republic were twisting into sinister purposes actions that were, in truth, innocent. Thus, the bonds of sympathy between reader and character which Barnes discusses are here enacted. Similarly, for single readers, the trials of Arden should, if only metaphorically, appear familiar. While much of the private correspondence and belles lettres of the period demeaned the bachelor, Brown has presented an alternative vision with which, perhaps, single men could sympathize. They could see themselves in Arden and disassociate themselves from being pigeonholed as disorderly non-contributors to society.

While the characterizations of Arden and Mayo hold a central place in the narrative and the story's point, the sole juror who held out against the majority should not be overlooked when examining the text. Loveden, too, is a bachelor and was a one-time courter of Miss Brudenel. As Loveden's role unfolds, it becomes clear that he and his actions also serve to undermine the bachelor stereotype. Having had his suit to gain Miss Brudenel's hand end unsuccessfully, he "concentered all his thoughts in the improvement of his fortune" (III: 30). Immediately Loveden's good character is set before the reader. Rather than act the rogue by immersing himself in selfish pleasure, becoming a disruptive force in the community, forcing himself on Miss Brudenel, or turning his amorous attentions to a woman easily seduced, the still-single Loveden takes on the role of the married man, seeking to engage the community, serving a useful purpose through business, and working for the good of the nation. He is, to use Joyce Appleby's terms, acting like a good republican of the $1790 \mathrm{~s}$, for as the market economy developed in the early republic, the virtuous citizen was the self-interested businessman. Thus, Loveden immediately appears as the virtuous republican.

Loveden is also of interest because he risks fulfilling another aspect of "bad" masculinity-effeminacy. Answering Miss Brudenel's message, he learns that she wishes him to work toward Arden's acquittal. The dynamics 
of this scene are key, for one of the ways that married men "proved" their manhood was by "governing a woman." 38 A married man was to master the family, albeit without turning into a tyrant, and "modern norms of republican manhood indicated that male dominion could be fortified if men practiced a hegemonic masculinity that mostly relied on kindness, consideration, and respect to win a wife's consent to her own subordination." 39 What we have in the case of Loveden, however, seems to be the reverse. Like Rufinus's wife, she is attempting, through argument and persuasion, to subordinate him, if only for this situation. Moreover, she is asking him to trust her judgment without presenting undeniable proof of Arden's innocence. Her conviction of Arden's innocence is "founded on proofs that were all-sufficient; but such as were only known to Arden and herself, and such as could not be imparted to another" (III: 30). She implores Loveden "to evince [his] generosity; to prove the truth of that affection which he formerly avowed for her, by believing her assertion, that Arden was innocent, without demanding the proof on which that assertion was made" (III: 30). He must put his whole faith in her judgment and act as she directs. Loveden, not surprisingly, objects to sacrificing "every thing dear to the heart of man." At stake is his "reputation, his fortune, and, indeed, his conscience, since he was called upon to acquit him whom the strongest evidence pronounced guilty" (III: 30).

This passage suggests that Loveden believes Arden guilty-his conscience, after all, is at stake-but it also does not foreclose the possibility that Loveden is open-minded, willing to entertain Arden's innocence, for nowhere does it state Loveden pronounces Arden guilty; only the evidence does. Loveden once again shows his republican citizenship, though, both in his counterarguments and in his eventual acquiescence. He asks Miss Brudenel "to excuse him from an act which might irretrievably ruin him here and hereafter" (III: 30). No doubt thinking of his business and his prosperity, Loveden invokes the republican self-interest that has guided him since Miss Brudenel's rejection of him. But this self-interest obtains only if the community is not harmed, and a miscarriage of justice would certainly harm the community. Loveden must put aside his self-interest for the sake of the republic, even if it does mean his ruin. Despite the appearance that Loveden is somehow putting himself under a woman's yoke, once the secret of his obstinacy is revealed it becomes clear that he has actually exercised virtuous citizenship. The narrator confirms as much when he states that Loveden's decision "denote[s] as powerful an impulse of affection and disinterestedness as can be felt by man" (III: 30, emphasis mine). Loveden, a bachelor and by social convention a potential rogue, shows himself to be not just a faithful lover but a good and virtuous citizen. Like Arden, Loveden works in the text to undermine and 
challenge assumptions about what role bachelors can play in the republic. Rather than acting as disruptive forces, though they might appear so at first, Arden and Loveden show themselves to be models of behavior. For Brown, this story works to validate his own position as author and to ward off charges of idleness and effeminacy. What is Loveden, after all, if not a truthteller, as Brown aspired to be through his fiction? If Loveden appears manly, so does Brown for his role in the republic.

Given the omnipresence of these positive images of bachelorhood, surely they were not lost on all of Brown's readers as well. Noticing fictional representations is only one half of the equation. What were his readers supposed to do with this information other than store it away? What cultural work might "Trials of Arden" have accomplished? Brown's commitment to ideals of equality and his debt to Godwin's radical politics are well-noted and gave birth to Alcuin, his dialogue on women's rights. Like Alcuin, "Arden" points out the discrepancies in American liberty. Not all men are treated equally because of unfair assumptions, and some men are treated unjustly. "Arden," then, aims to create a more perfect union. Readers should not just read the story; they should absorb its message and act on its ideals. The positive images of single men in "Arden" probably had an empowering effect, encouraging bachelors to continue their disinterested acts of civic virtue or to excel toward even more public participation. They could prove their critics wrong, just as Arden undercuts bachelor stereotypes held by his persecutors. Through the examples of Arden and Loveden, Brown's story works to enhance and enrich the citizenry of the new nation.

So, too, is it with married readers who are prejudiced toward and working to preserve their hegemony over bachelors. While a story like "Arden" might change some minds, unless readers act on their new-found beliefs, undercutting stereotypes becomes an innocuous pursuit. Married readers (and really anyone who held the bachelor in contempt) needed to overcome their prejudices and realize the inequalities among American men. In some ways, this is the most subversive cultural work that the story accomplishes, for if readers recognize the inequalities in power among white men, perhaps they will also recognize the inequalities the American system fosters towards gender and racial others as well. Such a project, then, brings Brown's editorial practice right back to Alcuin and to a February 1800 article from the Monthly Magazine predicting the eventual termination of slavery. Clearly the valorization of marriage is not the only thing at stake in these short stories.

"The Trials of Arden" establishes a pattern of character development and a theme Brown repeats in his longer fictional treatments of bachelorhood-in Memoirs of Stephen Calvert and Edgar Huntly-but he also 
employs it in the last of the short stories to appear in the Monthly Magazine, namely "A Lesson on Concealment; or, Memoirs of Mary Selwyn." 40 This story appeared in the March 1800 issue, situated between one of Adam Workman's essays about his billing dilemma and the beginning of the "American Review" section. Aside from Stephen Calvert, this was the longest piece-fiction or nonfiction-to appear in the Monthly Magazine, taking up a full thirty-four pages (out of the standard eighty for an issue). This issue contains few "Original Communications." Brown may have been printing fewer pieces because "Lesson" occupies a considerable amount of space, but it is also possible that he was suffering from a dearth of material and that he used this story at this time because it is so long. The other pieces in the March issue nevertheless maintain the continuity of Brown's editorial program. He selected two articles on the French Revolution (the destruction it has caused and the new political nomenclature to which it has given birth), two puzzles (one linguistic, the other mathematic), and another article from Adam Workman. Other than the "Selwyn memoirs," perhaps the most interesting piece is from a correspondent (Brown?), who laments that Stephen Calvert has ceased its serial run. Regardless of whether Brown wrote the letter himself, the piece certainly promotes his fiction, for while the article states that Calvert was initially boring, it grew more interesting with every issue, and the correspondent regrets that serialization has broken off before the story's denouement - a situation Brown rectifies by printing the remainder of part one before his magazine ends its run. This issue is also remarkable for its omission of the "Selections" section-again, maybe due to the length of "Lesson"-and to the seven reviews of works concerning Washington's death (one oration, one discourse, one elegy, and four eulogies). Clearly, "Lesson on Concealment" dominated the issue's pages. ${ }^{41}$

As its title indicates, Mary Selwyn's "Memoirs" are about the detrimental consequences of concealment and deception. It relates how a wife's secret-a previous marriage and an adulterous affair-emerges once she comes into contact with a youth who has learned her story from her seducer, and how that secret destroys her marriage and herself. Like "Trials of Arden," Brown's "Lesson on Concealment" appears on the surface to establish the bachelor as a disruptive force within a peaceful domestic setting. Molesworth, Mary Selwyn's second husband, seems to imply as much when he writes to Henry Kirvan, the bachelor and primary narrator: "It was only after your admission to the house, that smothered grief, mournful thoughtfulness, were ever visible in her [Mary's] demeanour" (II: 175). Molesworth has only fragmentary knowledge of what was bothering his wife, and as the story unfolds readers have only his perspective by which to guess the mystery. 
But Brown is setting his readers up by providing misleading and circumstantial evidence which seemingly supports the assertion that Henry has been the disruptive force. Before Molesworth allows Henry to return to his house, the mysteries of Mary's death and Henry's actions must be "settled," further leading readers to suspect that Henry had something to do with Mary's death. Such a suspicion is reinforced by Molesworth's own account of Henry's actions:

You could not but be aware of the effect which some mysterious appearances in your behavior, for a few days before you left us, were adapted to produce in me. I saw troublc in your countenance; your cyes betrayed some little reluctance to meet mine. This alone was not much $[\ldots]$ but my uneasiness would have been transient, if the effect had not been aided by the deportment of my wife. (II: 174)

Something has obviously been troubling Henry, but "what?" readers must ask. Almost inevitably they must conclude at this early stage that Henry's conscience is bothering him, a conclusion that pushes readers to wonder about his character. His bachelor status and fluid residency (which are also strikes against Arden) must factor into readers' suspicions.

While in his letter Molesworth never openly confronts Henry about what this grief-stricken husband is thinking, Henry and the readers of the Monthly Magazine undoubtedly comprehend the subtext. Returning from the country, Molesworth abruptly enters a room containing his wife and Henry: "My entrance, it was plain, was unexpected to you both. It createdWhat shall I say?" (II: 174). Leaving his question unanswered and suspicions unstated, Molesworth continues to paint a picture of deception: "My wife was disconcerted. She had been weeping. I never saw before traces of deep sorrow. Never did she meet me before with marks of confusion or terror" (II: 174). Molesworth had clearly interrupted some momentous tête-àtête, and though he claims not to have suspected his wife's "integrity," his letter does not bear this out. He wonders why she feels free to weep in front of Henry but cannot confide in her husband. He argues that "This terror, this concealment, this duplicity, is not due to an husband such as I have been" (II: 174). All of this suspicious behavior-the concealment, the discomfort both feel in Molesworth's presence, the weeping, the "terror" obvious upon Molesworth's entrance-suggests Henry and Mary share some intimate secret between them. Having been caught unexpectedly and embarrassingly together in close contact, what else could Molesworth be hinting but that Henry and his wife had become lovers? Perhaps the weeping even indicates pregnancy. 
Molesworth's relation of the next day's events seems to confirm this. He confronts his wife, but by then she has become feverish and soon dies, despite her husband's pleadings to share her secret. Narrating her end, Molesworth sees that "Serenity" had "resumed its place in her heart, in proportion as she felt the certainty of death" (II: 175), as if her death is somehow a result of her actions. Immersed in the sentimental culture of the late eighteenth century, readers would surely have recognized the implications of her death, especially in the context of her and Henry's suspicious behavior. Like her predecessors-Samuel Richardson's Clarissa Harlow, Susanna Rowson's Charlotte Temple, Hannah Foster's Elizabeth Wharton, ${ }^{42}$ and scores of others-Mary stands as the fallen sentimental heroine who has been seduced and apparently abandoned, paying for her sin of adultery with her death. Henry, of course, must be her seducer, and the scene interrupted between them must have been either a meeting to assess the damage done by their crime (with her tears and his avoidance of eye contact signifying that they both feel guilty for their intimacy) or a last meeting between them as bachelor Henry leaves to seek out new sexual conquests (with her crying over her sin and abandonment and his avoidance of eye contact indicating perhaps pity or laughter for the cuckolded husband). Molesworth's and readers' suspicions ultimately coincide, and the rest of "Mary Selwyn" should be an exposition of events leading up to Mary's "fall" at the hands of a vile bachelor seducer-a Lovelace, a Lieutenant Montraville, a Major Sanford.

Brown, however, was only drawing on the conventions of the sentimental seduction novel, and the story he unfolds through the voice of Henry is intended to challenge how young single men have been portrayed in Clarissa, Charlotte Temple, and The Coquette. His young man turns into the sympathetic, almost tragic hero rather than the licentious bachelor out for luxury and sexual conquest. In this light, Brown's use of conventional sentimental tropes-seduction, concealment, betrayal, the dying heroine-makes more sense in a magazine aimed primarily at male readers. Men were, of course, readers of sentimental novels, but as Brown was certainly aware and as Cathy N. Davidson confirms, the audience for novels consisted mostly of women. Moreover, his failure to write typical sentimental novels-to write what the marketplace demanded-led directly to the poor sales his books achieved. ${ }^{43}$ While "Mary Selwyn" might at first appear to be a "woman's story," Brown's ultimate project is no different than it is in "Thessalonica" and "The Trials of Arden": the undercutting of married men as virtuous in all senses of the word and the raising of the bachelor as an acceptable, noble, and honorable alternate form of masculinity. 
In unpacking "A Lesson on Concealment," it is fitting to begin with Mary's seducer, one Haywood. As Henry unfolds Mary's past to Molesworth, readers learn much about her seducer. Haywood was married at a young age, which, as Kann notes, was a positive step toward assuming the role of good citizenship: "Samuel Williams applauded 'the wishes of parents to see their children settled' into early marriages and set in 'the way of virtue, reputation, and felicity." 44 Similarly, "William Byrd recalled, 'The Spartans had so much regard for marriage that they enacted a law by which they condemned all old bachelors about the age of 24 to be whipped publicly." "45 While there were no Spartan whippings of bachelors in Brown's time, it was also not long ago that New England maintained laws prohibiting bachelors from living alone, and the notion of taxing bachelors for remaining single still held currency into the early nineteenth century. The younger a man married, the sooner he would settle down and rid himself of the stigma and sins associated with a bachelor's life. Haywood's marriage, then, is significant because by the time he begins living with Mary's family, he ought to be settled, to be focusing on the future-establishing his livelihood so that he may support his wife and, eventually, children.

Yet, despite the professed virtue of marriage as a steadying influence on men, when Mary tells her story, she describes Haywood as "the prey of an hopeless passion" (II: 195) and "consumed by unsatisfied desires" (II: 197). Reflecting upon his relationship with Mary, Haywood himself admits to "one moment of infatuation" and "the intoxications of a momentary passion" (II: 180). In short, marriage has failed to steady Haywood's passions, has fallen short of forging him into a citizen of circumspection and foresight. The absence of such virtues recurs as the relationship between Haywood and Mary develops. She states that she "listened [to him read] and found no satiety," that "his tones and looks" while reading "afforded new and exquisite gratification," and that his absence left her "in languor and impatience" (II: 192). "In this state of things," she concludes, "it was impossible that proofs of confidence should not be mutually exchanged" (II: 192).

Though Mary does not say so, surely some of her feelings were outwardly visible so that Haywood ought to have been able to recognize what was happening. Instead of recognition, however, Haywood feels no uneasiness over exchanging confidences with a married woman and claims to be "contented with the enjoyments of friendship" (II: 193). He is just as blind to his own feelings and the duties they entail. But outward signs of "pensiveness and discontent" eventually appear; he begins to withdraw himself from her without explanation, an action which only increases her desire for his company. Physically deteriorating, Haywood eventually confesses his passion to 
her, which opens her eyes to her own situation and replaces her sense of innocence with an understanding of their improprieties. Upon his recovery, and given their mutual attraction, the course of action seems obvious: Haywood, like Arden, ought to leave the house and end their interaction so as to prevent an illicit sexual encounter from occurring, especially since Mary resolves to dare the evils of ruining her father's peace, her brother's hopes, and her husband's happiness and to suffer "the loss of fame and of friendship" (II: 197). Haywood does eventually resolve to leave, but only after many days and after making Mary understand that his happiness could only be secured through her sexual surrender, in spite of the fact their coupling would for Mary "blot my name, awaken enmity in all that loved me, and bring down inexpiable vengeance on the head of my seducer" (II: 197). It is in the instance of Haywood's leaving that a chance encounter brings them together and they commit the adultery they had attempted to prevent. At no point does Haywood demonstrate the thoughtfulness and morality expected of the married man who aspires to good citizenship.

The result of this coupling, not surprisingly, is pregnancy-a standard development for an eighteenth-century piece of fiction. Mary's condition, of course, will eventually reveal her adultery to her then-absent husband, so she flees her home, seeking shelter in a distant Connecticut town. She details her experiences there for Henry: the "untimely birth of my offspring," residency in an "obscure abode," the "indigence" flowing from her flight, owing "subsistence to my labour," and the unstable reputation from a "change of name and the ignorance of my neighbors respecting my true condition" (II: 199). Driven to despair by her double life, Mary attempts suicide twice, first by drowning, then by hanging. She ultimately spends two years in her "gloomy reverie" so that "Joy was flown from my heart, smiles from my lips" (II: 199).

The key fact in this entire affair is that throughout her wrenching tale of her baby's premature birth (and implied death), struggle to survive, plunge into depression, and eventual attempt at self-destruction, Haywood is never mentioned. His actions have destabilized an entire family-Mary's father is consumed in grief, her husband dies, and her brother spends the rest of his life seeking revenge against Haywood-yet, rather than taking responsibility for their act, Haywood has abandoned Mary to her fate. At a time when the family unit was undergoing immense pressure - from Fliegelman's revolt against patriarchy to Robert Gross's "epidemic" of premarital sex and conception of illegitimate children ${ }^{46}$-and when the Founders were praising family as a source of social order, Haywood undermines that stability, both for the family as a unit and for the republic as a whole. Though a married 
man, he is acting just like the bachelor the Founders feared, one who "seduced women but refused to recognize his offspring." 47 Haywood, then, though a married man and expected to be (or eventually become) a good citizen by virtue of his marriage and business, acts instead like the unruly bachelor who destabilizes the republic and undercuts good citizenship.

If this be Brown's portrait of the "respectable" married man in "Lesson on Concealment," what of the bachelor? Brown provides two very significant counterweights to Haywood's depravity. One of these is Mary's second husband Molesworth. His friendship for and courting of Mary stands in stark contrast to the treatment she receives from Haywood, and he betrays none of the licentiousness of Mary's former lover, despite his young age. His good reputation, in fact, precedes his first meeting with Mary, and the praises bestowed on him are confirmed by her own observations. When he first seeks out her friendship, she notes that he "solicited permission" to take walks with her, keep her company, and amuse her by reading aloud. Rather than imposing himself, he respects that she has lately been a creature of solitude. As Mary goes on to note:

This man was, indeed, widely different, in character and person, from Haywood. I need not mention [ . . ] his noble and expressive features, his eye beaming with benevolence and vivacity, his refinement of taste and variety of knowledge. His deportment was tender and pathetic, but was untinctured by that impatience and moroseness which flow from compunctious recollections and unsatisfied wishes. He pursued no sinister ends, treasured up no illicit wishes, and contemplated no consequence but the cheering of my hours and the promotion of my happiness. (II: 200)

The differences in temperament and conduct between Molesworth and Haywood are obvious here, especially in the last sentence. Rather than viewing her as sexual prey, Molesworth instead treats her with "disinterested kindness" (II: 200). Readers versed in the classical republicanism of the Revolutionary and post-Revolutionary periods would immediately have focused on the word disinterested, for republican virtue was by definition disinterested. Molesworth's attentions to Mary, then, immediately place him in the discourse of the virtuous citizen rather than the virtueless and selfish bachelor so often satirized in the early republic and represented in the form of the married Haywood.

Molesworth also demonstrates virtuous citizenship-of the classical kind-in his desire for a profession and stable living. Rather than remaining idle (though his family would seem to have the means for him to remain so), he resolves to become a physician. The choice of profession is significant. 
What better way to practice virtuous citizenship than by helping people reclaim their health so that they can become productive members of the republic again? Moreover, as Christopher Grasso notes of Yale University, more men were entering the law and medical professions than ever before, with growth in the latter due to the lucrative nature of doctoring. ${ }^{48}$ The number of doctors in New Haven County, Connecticut, for example, increased 300 percent between 1756 and 1790 while the total population grew only 55 percent. ${ }^{49}$ Also, to separate themselves from fraudulent practitioners, medical men moved to professionalize doctoring by forming associations, publishing medical journals and treatises, and attempting to control the certification and regulation of medical practitioners. ${ }^{50}$ For Molesworth to become a physician, then, meant he was entering a profession of growing respectability that will yield a steady income and allow him to exercise civic virtue.

Beyond this, Brown's republican readers would also have been attuned to Molesworth's choice of residence. Ending his visit to his relatives, he determines to return to the city and set up his practice. Correspondence with Mary reveals to her "new excellencies in my friend" (II: 200). He writes to her of his "schemes of benevolence and fortune" and aims to "shun the pits and quicksands to which his safety was exposed in the midst of a luxurious city" (II: 200). This portrait of the city was nothing new to citizens of the early republic. As J. G. A. Pocock has demonstrated, Americans drew on the court and country ideology of Britain. Believing the court (that is, the city) to be a den of corruption, virtuous citizens retreated to the country to steady their moral compass and become better servants to their nation. Readers would have seen Mary's passing reference to the city as a common trope and a sign of Molesworth's good character.

This initial suggestion of his character is reinforced by his symbolic return from the city. Readers are told that "Weary of the turbulence and vices of the city, and disappointed in the hopes which he had formed of professional employment, he resolved to take up his abode in his native town" (II: 201). His reasons for returning firmly establish his good character, one who can be a trusted citizen, for he is shunning vice in favor of the country virtue Pocock defines. Moreover, though his expectations of an urban practice have failed, presumably he will not stop practicing medicine and will instead hang his shingle in his native town, continuing to help his fellow citizens. All of this, of course, characterizes a single man who, in the prejudices of the period, was alleged to be vice-ridden and a danger to the stability of the republic.

Finally, as one last instance of his respect for Mary, once he offers himself as her lover-that is, her suitor-and is rejected, he acquiesces in her decision. Though disappointed, he withdraws "none of his benevolent 
attentions and services" to her (II: 201) and does not press the issue as one determined to seduce her (as, for example, Major Sanford and Montraville do); he merely continues his friendship with her. Similarly, when the subject arises again, he in no way appears in the guise of a seducer. He instead describes the origin and steady growth of his interest in her, the reasons behind its continuing to mature, "the immutable foundation of his esteem," and the steady observation of her conduct (II: 201). The rather lengthy paragraph which lays out his argument serves to show that his regard for her is not the momentary passion evidenced in Haywood, that it is grounded firmly in who Mary is rather than in a transient sexual attraction. Like his virtuous citizenship, his courting of Mary undercuts the stereotype of the bachelor as a man solely in pursuit of his own pleasure. The qualities which Molesworth possesses are in evidence before he even meets Mary; they are not the result of a woman's steadying influence upon him but are already part of his character.

Having established Molesworth as an example of a bachelor who possesses a good character and exercises virtuous citizenship, Brown also peppers the narrative with evidence of Henry Kirvan's positive attributes. Though on the surface he might appear to be the disruptive force that destroys Mary, he is, in fact, the chief example that bachelors are not the fiends they have been made out to be. On the surface of the story, Henry would seem to be the cause of all the tragedy that occurs in the Molesworth household. Having been introduced into their home, Henry eventually identifies Mary as Selwyn's sister and Haywood's paramour. With her past unexpectedly invading her present, Mary takes ill and dies, leaving behind a griefstricken and confused husband whose only recourse is to plead with Henry to reveal the secret of his wife's past and the reason for her sudden death. Seemingly, had bachelor Henry kept silent or left the house immediately, the Molesworths would not have suffered this tragedy.

Yet, upon closer inspection, it becomes clear that while Henry might have triggered these events, his actions actually serve to reinforce the positive image of single men that Molesworth establishes. For example, readers find hints as to Henry's good character even before he enters the Molesworth household. According to Henry, since Haywood treated him with "familiarity, and almost with tenderness," he "was not deficient in fidelity and gratitude" (II: 176-177) Besides providing Henry with employment prior to the duel with Mary's brother, once Haywood is found out, he trusts Henry with personal information and entreaties to his "candour [ . . ] to put the best construction on my conduct" and to his "gratitude and good sense" to show him "the duty of concealing from the rest of mankind" 
conjectures concerning Haywood's actions (II: 179). Fidelity, candor, gratitude, good sense, duty-these are words reputedly alien to the bachelor's code of behavior, for they require a leap beyond self-absorption and interest in the plight of others. Henry, however, possesses these qualities, and as the protagonist of the tale, he commands readers' sympathy.

These early hints recur and are developed throughout the story. For example, "let loose on the world," Henry admits that "Haywood's generosity had enabled me to be idle, for a time, without beggary" (II: 181). While the idleness suggests a lazy streak in Henry and would certainly have raised eyebrows in a society that defined civic-mindedness as its highest virtue, also of importance is the fact that he actually had tasks to perform. Henry might define his employment under Haywood as idleness, but it was not. He did do work, but his duties also left him with a significant amount of time to himself. Moreover, even if he commanded a degree of leisure time, Henry acted so without beggary. In short, he differentiates himself from those on the streets without land, employment, or purpose who, no doubt, "engaged in [the] lawless conduct associated with itinerancy, vagrancy, pauperism, and frontier anarchy." 51 The juxtaposition of these quotes makes clear that Henry was not classifying his idleness with the disorderly type citizens of the early republic feared. Finally, instead of seeking to retain this lifestyle, Henry aims to become a doctor, a decision he acts upon once he meets Molesworth and a plague sweeps the city: "I was not startled by the approach of the late terrible pestilence, and cheerfully engaged to assist you in your benevolent endeavors to disarm this pest of some of its horrors. In resolving to become a physician, I had formed a sort of tacit contract to stand forth the adversary of disease, in all its forms" (II: 181). If idleness might have raised some eyebrows, Henry's dedication to medicine would have gained approving nods, for here is the civic virtue thought to be the foundation of the republic. Not only does he take on the job, but he also "cheerfully" attends the sick. He attempts to imitate the "benevolence" manifest in Molesworth while taking a public stand against not just this plague but all illnesses. His presence benefits the community, not disrupts it.

Henry's character, then, is far more complex than simply the destroyer of family peace. If anything, once the crisis is upon the Molesworth household, Henry is the chief proponent of good. He does not fit the bachelor stereotype in other ways as well. A penchant for introspection, for example, is another of his qualities, for it is his reverie which reveals Mary's identity to him. One engrossed in his own appetites is not going to be prone to selfreflection. Once the notion that Mary is Selwyn's sister occurs to him, he 
decides he must act cautiously, "with vigilance and circumspection" (II: 182) in order not to betray Haywood or disrupt the household. In this same scene, Henry appears as rational a creature as any man of the eighteenth century claimed to be. He does not act impetuously on his insight but instead reasons out all the consequences and implications of his knowledge. A desire to protect Mary from any strong shock motivates him to conceal his insight while looking for an opportune moment to verify his conjectures.

As he explains how he revolved these thoughts, another of his qualities becomes clear: his honesty. He states that while he wants to ascertain the truth, "Circuitous methods of arriving at the sentiments of others were new to me. I was not qualified by habit, to employ them with skill. They involved some degree of falsehood, and from this I shrunk with strong repugnance" (II: 183). Arthur Mervyn, of course, makes similar claims to his honesty, but the novel's complexity of narration and sequence of events serve to draw his professions into question. In "Lesson on Concealment," however, Henry's honesty is not complicated by events or the opinions of others. He truly attempts to act for Mary's good without bringing her pain or suffering.

Once he accidentally ${ }^{52}$ reveals his secret insight and the crisis is upon them, Henry continues to act in the same level-headed way. He first considers flight:

What a pity, I exclaimed, that I had not died before I entered this house! That the benevolent exertions of this woman have rescued me from the grave one to whom he will owe the death of her hopes! But the evil has not yet come. Let me shun another interview by flying from this roof. Let me hide myself forever from their inquiry, in the remoteness of the desert, and let my fatal knowledge be buried with me. (II: 185-86)

Clearly, Henry is aware of his debt to this woman and her husband, and he would prefer to ruin his own happiness rather than spoil theirs. Though he ultimately decides that this course "was conceived in a moment of imbecility" (II: 186), it nevertheless shows how much he values retaining domestic tranquility and family harmony. Once he does meet with Mary, he attempts a compromise between this course and retaining his position: he offers her his silence to secure her happiness. He, in fact, goes beyond this by asking her to "Impose upon me any task; you cannot impose upon me any inconsistent with virtue, and the task shall be performed" (II: 186-87). By placing himself at her disposal-within the limits of virtuous action-he betrays his ability for self-sacrifice. This offer also makes clear that he is not the sexual animal bachelors supposedly were, for he does not threaten her with blackmail or extort sexual favors from her in return for his silence. His chief 
motivations here are gratitude for her kindness and sympathy for her situation. These are key to Henry's character.

Finally, there remains his conduct throughout the crisis and at its climax. Tragedy does befall the Molesworth household, but not because Henry has set events in motion with his ill-timed vision. Throughout his intercourse with Mary, while she is certain of impending doom, Henry remains the clearheaded one. For example, while he is, at first, saddened by her conviction that revealing her secret now to her husband will blast his happiness forever, he thoughtfully considers Molesworth:

At first, my despondency was scarcely less than her own, but at length I began to question the certainty of that consequence which she dreaded. The first burst of this knowledge on your mind, might be expected to overwhelm all courage, and prostrate all hope, but surely this was a calamity not beyond the reach of a cure $[\ldots]$ He who so thoroughly knew the excellence of her heart, the purity of her present deportment, the untaintedness of her fidelity to him [ . . ] what sentiments but pity, forgiveness, and augmented tenderness, could find their way to his heart? (II: 188)

Unlike Mary or the unreasoning bachelor, Henry takes command of his sentiments, disciplines them, and takes up rational thought. His thoughts suggest not just a comprehensive understanding of their problem, but of his friend's qualities, conclusions arrived at through careful observation and consistent interaction. Thus he offers an extraordinary service. While she is too emotionally distraught to make her case to her husband, he labors under no such burden: "I am not born to shrink from any province, to falter and recoil from any task which justice and necessity prescribe. Assign to me the duty of contending with the grief and despair of your husband. Let me be the wall between his wrath and your offenses" (II: 189). Henry offers to be the bearer of bad news and to "urge your claims to the continuance of his love and his esteem in terms he cannot resist" (II: 189). He will take on the role of disinterested and rational negotiator-an eighteenth-century marriage counselor-in order to restore the domestic tranquility which he has inadvertently interrupted.

If Henry is of such good character, why, then, does tragedy still strike? Because, instead of grasping this reasonable offer of assistance, Mary clings to her former path of concealment and wrings from Henry a promise of "eternal silence" (II: 189). By choosing to retain her secret, she allows her conscience to prod her constantly until she takes sick and dies without revealing anything. It is her insistent choice to avoid discussing her past with her husband that ultimately destroys her, not any ruin brought about by 
Henry's negotiations. By tying the consequences and the story's tragic denouement to her decision, Brown allows Henry to break the stereotype of the disruptive bachelor who must be confined and controlled as much as social convention will allow.

Many of the themes Brown develops in "Thessalonica," "Trials of Arden," and "Lesson on Concealment" can also be found in his Memoirs of Stephen Calvert. Broken up into sections roughly ten to twenty pages in length, Calvert began its run in the June 1799 issue and continued through January 1800 , suffered a brief hiatus for two issues, and concluded in the April, May, and June 1800 issues. Since Brown placed all of the installments in the "Original Communications" section and allowed the novella to run through multiple issues of the Monthly Magazine, Calvert appeared alongside many of the short pieces already discussed. Brown also chose the Monthly Magazine's fiction carefully, for he never allowed two of his pieces to be printed in the same issue. No doubt this was good policy in light of his recurring search for printable matter, but since Calvert explores many of the same themes found in the other fictional pieces, its continual presence through eight issues also provided significant continuity for his editorial project, one sustained by the short fiction which appeared in the novella's absence. ${ }^{53}$

Like the three short stories already examined, Stephen Calvert seems on its surface to be a tale of youthful rebellion against authority and the eventual re-establishment of social order. ${ }^{54}$ The novella does not lend itself to easy summation. It begins at the end: Stephen Calvert has retreated to the wilderness because he has grown disenchanted with civilization and human companionship. ${ }^{55}$ Having begun in media res, Brown then relates the history of Calvert's English ancestors. The involvement of Calvert's grandfather in a planned Catholic uprising forces Calvert's father, a Protestant, to flee to Pennsylvania. Readers also learn that Calvert has a twin brother; the brothers were separated after his father migrated, and the twin is presumed dead. ${ }^{56}$ With the death of Calvert's father, the plot finally focuses on Stephen, who has inherited an estate from a distant relative and claims to have fallen in love with his cousin, Louisa, the daughter of his benefactor. Calvert is intent upon marrying Louisa until he meets Clelia Neville, for whom he develops an affection, even though her reputation is reportedly questionable. Calvert refuses to believe she is anything but virtuous, and his visits jeopardize his relationship with Louisa and directly contradict the advice and demands of family and friends, including Sydney Carleton, who acts as a guardian and mentor to Calvert and Louisa. Calvert's "rebellion" forms the central plot of the story and draws suspicion down upon his own 
character and reputation. Since he has refused to stop visiting the allegedly disreputable Clelia, it is easy for Louisa, Sydney, and others to believe additional reports of Calvert's dissipation, such as his apparently playing at cards. The end of the novella culminates with the realization that Calvert's long-lost twin accounts for some of these reports and that Clelia's reputation has been misrepresented. ${ }^{57}$

Calvert's rejection of authority and his "lawless and wild enthusiasm of character" $(112)^{58}$ can mislead readers, however, into misjudging his actions. Even as astute a reader as Steven Watts describes "the youthful protagonist" as growing "increasingly erratic and impulsive in his behavior," so that his "passions" eventually entangle him "in a knot of accusations and compromised principles." 59 While he finds the text a significant cultural artifact, Watts nevertheless characterizes the novella as centering "around Stephen's clumsy and frustrated attempts to find his way in the world." 60 The convoluted plot and Brown's often ambiguous writing style no doubt contribute to the difficulty of reading Stephen Calvert. And Calvert himself is frequently described (by himself and by others) as having a "character [that] contained no small portion of enthusiasm" (108), as one whose "fancy was perpetually figuring to itself a train of consequences to flow from any casual occurrences" (108).

As it does in Arthur Mervyn, the question of Calvert's character and his erratic behavior becomes an issue early in the text. Having initially determined to restore Calverton, the estate he inherits, to its rightful heir (Louisa), Calvert hesitates and rethinks his generosity, which leads Louisa to the following admission:

I cannot help suspecting you of some caprice or some faultiness [. . . ] To have formed this design, argued more generosity than I had ascribed to you; but to have relinquished it when once formed, evinces either a blameable fickleness or a laudable sagacity. (116)

Louisa ultimately fears that if she eventually uncovers his true motives, she will "find reason for esteeming you [Calvert] less" (116). Through Louisa's statements, which are reinforced by Sydney Carleton's alleged "voice of reason," readers might indeed see Calvert as erratic. But Calvert's realization that he does not want to enrich a stranger should Louisa marry gives him pause. As he puts it, "Power and property are intrinsically valuable, and I loved them for their own sake, as well as for the sake of the good which they would enable me to confer upon others" (117). The importance of "doing good" and of property to citizens of the early republic are historical commonplaces. Moreover, Calvert has demonstrated an interest of which Tyler's 
Van Rough would approve: he considers the main chance when musing over the fate of Calverton. Rather than acting erratically, Calvert displays circumspection, good citizenship, and a concern for property, but because she might not become the beneficiary of Calvert's munificence, Louisa charges him with suspicious motives.

This pattern of accusation repeats itself when Calvert stands by his assessment of Clelia Neville's character. Brown provides readers with considerable evidence that she is not the low woman that Sydney and Louisa charge her to be. Her accomplishments are frequently described and noted. Her neighbor, for example, states that Clelia "dresses and lives very genteel. A mighty reader [...] writes much, paints landscapes, plays very tastily upon-something-it is an hard, outlandish name. This is all she does" (156). Even Louisa admits that "During her abode here, the young lady's conduct has been free from reproach" (224). Why, then, does Louisa chastise Calvert for visiting this woman? In part, her assessment of Clelia is based upon false information, for Sydney accuses her of promiscuity, having observed at least one man stealing into her apartment (the visitor, it turns out, is Calvert). Her assessment is also founded upon her knowledge that Clelia has purposely concealed her marital status because she supposedly "abandoned" her husband.

In spite of the voices of authority and reason telling him he is wrong, however, Calvert steadfastly stands by Clelia. His loyalty to her demonstrates several qualities supposedly alien to the bachelor. First, there is the loyalty itself. By remaining her advocate, Calvert moves beyond the stereotype of the self-involved bachelor, for he takes the part of someone who can do very little to advance his own interests and is, in fact, harming them. Similarly, though he develops an emotional attraction to Clelia, he does not attempt to seduce her (nor does he make sexual advances toward Louisa or any other woman in the text), undercutting the notion that bachelors are slaves to their lusts.

Second, it turns out that Calvert has allied himself with someone who could be considered a "patriot" in the sense that she fled to Philadelphia to escape the clutches of a tyrant, her husband. When Clelia describes Belgrave, she uses words like "vices," "voluptuousness," “pollutions," and "punishment" (204). Her marriage deteriorated into a contest of wills, with her husband frequently taking revenge for alleged wrongs: "This vengeance he proceeded to inflict, by treating me with rudeness and contempt; by thwarting all my most trifling wishes; by forbidding his servants to bear my messages, or execute my orders; by affronting my friends and visitants; by interrupting me in my favourite employments of music and 
reading, or depriving me of the means of pursuing them" (204). Clelia states that she endured all of his mistreatment, including her husband's "neglect" of her (that is, his lack of sexual interest), which she charges to "his attachment to some other woman" (205). Her discoveries soon disabuse her of this notion. Having noted that "his associates were wholly of his own sex," Clelia then reveals the full extent of Belgrave's depredation:

This illusion came, at length, to an end. Belgrave's contempt and hatred of me exceeded even his regard for his own reputation, and to his own safety, from the animadversions of the law. So open, so shamcless was his conduct, that at length, my own eyes were allowed to witness-.

I cannot utter it-I was frozen with horror. I doubted whether hideous phantoms, produced by my own imagination, had not deceived me; till my memory, putting past incidents together, convinced me thcy were real.

My husband's presence-his house, became loathsome and intolerable. I flew to my only comforter, my aunt. (205)

Though couched in allusion and elided through the use of dashes, the source of Clelia's revulsion seems clear: Belgrave's lack of interest in her sexually stems from his homosexuality. Coupling his sexuality with his treatment of Clelia, eighteenth-century Americans would have viewed Belgrave only as depraved and immoral. ${ }^{61} \mathrm{He}$ would have appeared to them as a vice-ridden aristocrat submerged in luxury and as a tyrant. In this context, Clelia's alleged "abandonment" of Belgrave is not that different from the colonials' break with a tyrannical mother country. Clelia, then, was right to "abandon" her husband, and by allying himself with her, Calvert demonstrates an adherence to the American values of liberty and morality. Her history casts Clelia as more akin to the heroes of the last generation than to the fallen woman.

Calvert disrupts bachelor stereotypes in another way besides his loyalty to Clelia. An early scene demonstrates his sense of civic virtue. Hearing the call, "Fire! Fire!" (121), Louisa urges Calvert to follow the crowd and provide what relief he can. Though hesitant initially in his actions, once he sees the flames Calvert "ran forward with speed" and "pressed forward with eagerness" (121). Curious at first, he soon realizes his duty and rushes impulsively forward headlong into the fire to save the person rumored asleep inside. As historian Benjamin L. Carp has recently argued, "fire companies could contribute to a member's civic identity and foster collective pride in the community." ${ }^{62}$ This sense of civic identity stemmed in part from the willingness to risk one's life to protect property. Since eighteenth-century political ideology interconnected property and independence, protecting property, argues Carp, was akin to protecting independence and liberty. 
Carp also notes that "brotherhood and manhood were essential components of firefighting." ${ }^{63}$ While Calvert is no firefighter officially, and though the fire is also a plot contrivance to bring him into contact with Clelia Neville (who is the one asleep amid the flames), his willingness to risk his life to save the person, if not the property, would have displayed both his civic identity and his manliness. Calvert's manly courage in dashing into the building exemplifies how little he actually fits the bachelor stereotype.

Like Calvert, Sydney Carleton also undercuts the bachelor stereotype. Though Sydney acts as a meddler and a foil to Calvert's aims, his actions do not originate from malice or self-interest. Rather, he believes he has the best interests of Louisa and Calvert in view, even though readers come to find that his efforts have been misplaced and misguided. To an extent, the novella casts Sydney as a "villain" because he frequently opposes Calvert, initially appears as a rival for Louisa's hand, and, most importantly, is Clelia Neville's chief accuser. Like Calvert, though, Sydney's character works to undercut the bachelor stereotype. The narrative establishes Sydney as "a young man" who is "equal in age" to Calvert, single, and "newly initiated into the legal profession" (109). His profession is significant for multiple reasons. As noted before, the legal profession was one of the best ways to rise to prominence, respectability, and authority in the early republic. His profession bespeaks stability, rationality, and good citizenship. Moreover, as a member of a recognized and respectable profession, he contributes and has important ties to the community. Unlike the bachelor, who does not look far beyond his own pleasure, as a citizen of his community Sydney has a stake in upholding social order and maintaining social standards. Seen in this light, his opposition to Calvert becomes laudable, if misplaced.

With his profession and social standing in mind, his motivations are understandable. Based upon the information he has, Clelia Neville appears to him a disruptive force in the community; in his apparently irrational support of her, Calvert seems the same. Readers of the Monthly Magazine probably sympathized with Sydney and his motives, even though those same readers eventually came to understand that Sydney is wrong in his assessments. Like Calvert, Sydney offers a challenge to the stereotype of the bachelor by acting responsibly. Single men reading Brown's periodical would have found in Sydney a possible model to set against the stigma attached to their social status. They could emulate Sydney Carleton and perhaps achieve a higher degree of social acceptance. If Sydney's stability, profession, and social outlook could reflect the stereotyped interests of the married man, so, too, could single readers' actions. Married readers of Brown's periodical would also likely have found themselves sympathizing with and respecting 
Sydney, ultimately undercutting any prejudices they might hold against young single men.

In addition to the social respectability his profession provides, Sydney also appears thoughtful and considerate. He misjudges Clelia Neville's character, but his information is faulty. He believes Calvert acts immorally, especially when he lies about playing cards, but it is Calvert's long-lost twin brother who is the gambler. In short, Sydney is the dupe of circumstances beyond his control. How could he account for the appearance of a twin brother presumed dead? Moreover, Sydney frequently tries to reason with Calvert, attempting to be a mentor and a friend. A strong example of this occurs when Calvert confronts Sydney about his role in changing Louisa's mind about marriage. Calvert is understandably upset-furious, in fact; throughout the scene, Sydney appears objective, calm, thoughtful, telling Calvert that "It was agreeable, however, to my conceptions of duty, to act and to speak thus [for postponing the marriage]. I think I foresee all the consequences of my actions, and as this foresight has not shaken my purpose, these consequences, whatever they may be, will not molest my tranquility" (138). Sydney's arguments carry such conviction that they even make Calvert pause and re-evaluate whether he may be in the wrong, for "A secret conscience whispered me that Sydney was right" (138). Rather than a man consumed in his own irrational and childlike behavior, Sydney Carleton displays throughout the novella a voice of reason that, were the stereotypes accurate, he ought not to possess. These two characters ${ }^{64}$ and the entire plot of Memoirs of Stephen Calvert are consistent with and complement Brown's editorial project. They perform the same cultural work as the characters and plots found in "Thessalonica," "Trials of Arden," and "Lesson on Concealment," and, as such, complete Brown's efforts to validate the bachelor in his own eyes and in those of his readers-single and married.

One notes that throughout the fiction found in the Monthly Magazine, republicanism-whether of the classical or liberal variety-consistently reappears in different forms. This is not very surprising given the historical context in which Brown's work appeared. Not only was republicanism the dominant political philosophy in the $1790 \mathrm{~s}$, but it was also undergoing an important shift, accommodating and absorbing elements of the developing marketplace ethos. Yet it is pertinent to ask why this theme was so important to Brown and to his editorial duties. Of what particular interest was republicanism to Brown, or did it serve as a source of anxiety?

The answer to these questions, I suggest, lies in his choice of vocation and in concerns over gender identity. According to Joyce Appleby, republicanism was "primarily a male discourse." ${ }^{65}$ As such, it demanded that men 
perform multiple roles-to exercise self-interest and civic disinterest, to pursue the main chance and avoid unnecessary wealth or luxury, to work for the security of the household and for the public good, to be individuals and faceless public servants. This in itself was a difficult balance to effect, but for Brown the professional author, it might have been nearly impossible. Republicanism, then, demanded action, civic engagement, work, and effort. Eventually, it bodied forth the masculinity delineated by Michael Kimmel: the self-made man.

But as an author, Brown did not fit this paradigm. For one thing, as Emory Elliott argues, merchants and others worked to ensure that intellectuals remained a discredited band that retained as little cultural authority as possible. Whereas merchants were up and doing, intellectuals were idle and without practical use. Moreover, idleness and luxury were qualities defining the British, and its aristocracy in particular. As an author, one would seemingly be far from the republican ideal. Instead of engaging in civic action or in the marketplace activities, authors and intellectuals spent their time studying and writing. An author of fiction was even worse, for a man idled his time away creating "falsehoods" instead of tending community business-turnpikes and waterworks, for example. ${ }^{66}$ Brown indicates as much when he draws a distinction between types of authorship in the letter to Thomas Jefferson accompanying his complementary copy of Wieland. Brown acknowledges to Jefferson "that social and intellectual theories, that the history of facts in the processes of nature and the operations of government may appear to you the only laudable pursuits" (988). In contrast to these practical pursuits, he states "that fictious narratives in their own nature or in the manner in which they have been hitherto conducted may be thought not to deserve notice, and that, consequently, whatever may be the merit of my book as a fiction, yet it is to be condemned because it is a fiction" $(988) .{ }^{67}$ It is a critical commonplace to note that the early republicin spite of its bestsellers-disapproved and often condemned novels, even if they claimed to be "useful" tools of education. How, then, could Brown reconcile his vocational choice with his culture's reigning sense of masculine activity, with the very republican ideals upon which the nation was founded?

Further complicating this were the gender politics of the novel. As noted earlier, novel reading was gendered feminine; so was novel writing, and not just because it involved engagement in a marketplace dominated by women readers. If the early republic defined novel writing as a form of idleness, and republicanism described idleness in terms of effeminacy, then novel writing and effeminacy were closely linked. As an author of novels, Brown's own sense of masculinity was under a dual threat. Not only did he 
eschew the common form of masculinity interconnected with marketplace values and favor an alternate form of manliness, but he also bore the charge of feminization.

Editing the Monthly Magazine, though, allowed him to make these definitions more fluid and more flexible than they had been. If, as I argued earlier, his editorship provided Brown with a degree of authority because he had to command a knowledge of the subjects appearing in his publication, it also allowed him to contribute to American society, to exercise his civic duty. The appearance of Brown's fiction in the magazine achieves a synthesis of novel writing and republicanism, classical and liberal. Surrounding his fiction with nonfiction provides for a degree of disinterestedness. Brown is circulating knowledge and engaging in public discussion without seeming to be engaged in marketplace values. The context also lends credence to his understanding of fiction as exploring ideas and advocating lessons in morality. Moreover, by directing his magazine toward a male audience, he avoids dealing directly with the "feminized" marketplace of novel writing while still dealing in marketplace values. Dealing in nonfictional and fictional commodities offers him the opportunity to shore up his own masculinity while still sustaining his identity as author.

It is no wonder, then, that so many of his fictional characters, particularly those in the Monthly Magazine but also those in his novels Arthur Mervyn and Edgar Huntly, are so concerned with acting in the interests of civic virtue and for the good of others. They are, in a sense, acting as Brown is defining himself through his editorial duties. Similarly, offering alternative models of masculinity validates the social position of his single readers. The overall cultural work to be accomplished involves extending the understanding of republicanism and manhood to include other forms which, though not overtly engaged in the marketplace or in civic responsibility, under closer scrutiny reveal an equal engagement in cultural values. And perhaps this is the ultimate moral lesson that Brown aimed to teach his readers through his fiction. 
This page intentionally left blank 


\section{Chapter Five \\ Prospects}

Charles Brockden Brown was a man of letters who was unsure of himself, his marital status, and his social position in the early republic. He used the Monthly Magazine and American Review as a vehicle for establishing a male readership, for challenging the negative stereotype of the single man and the positive stereotype of the married man, and for validating bachelorhood as a viable alternative form of early republican masculinity. Through his editorial and authorial duties, he demonstrated that bachelors were men of reason and self-control with a definite interest in the social stability and ultimate prosperity of the new nation. What, then, is the larger significance of this line of argument? How do the findings in the previous chapters shed light on gender studies? The more familiar aspects of Brown's career? Other early national periodicals? Works of belles lettres from late eighteenth-century America? On other authors of American literature?

In many instances, investigations into the social position of women in the early republic have been well-developed. Mary Sumner Benson's Women in Eighteenth-century America (1935) pioneered the path ultimately followed by Nancy F. Cott, in The Bonds of Womanhood (1977); Mary Beth Norton, in Liberty's Daughters (1980); Linda K. Kerber, in Women of the Republic (1980); and many other historians of gender and the early national period. Despite the proliferation of such gender studies, one recent historian can still lament, "There has been very little historical literature on masculinity during the Revolutionary era." 1 This situation is changing, as Mark Kann's Republic of Men (1998) testifies. ${ }^{2}$ This work has sought to add to this small but growing body of literature and to provide balance to the insightful work that has already been done on American womanhood. It has attempted to show how gender stereotypes can prove limiting for men as well as women and how one man challenged patriarchal authority through the use of letters. 
Such a "balanced" approach to gender has significant implications for scholars of Brown's career as a whole and for interpretations of his novels in particular. Each of his novels focuses on a bachelor, involves marriage, or explores definitions of manhood. Wieland, for example, showcases competing visions of early national manhood. ${ }^{3}$ Wieland represents the emotional manhood of religious fervor frequently found among revivalists and distrusted by "men of reason," such as the Wieland family friend, Pleyel. While Wieland and Pleyel each offer a version of manhood, Wieland also makes clear that neither is sufficient, for the former leads to the family's destruction and the latter is unable to prevent the tragedy. Ormond, Arthur Mervyn, and Edgar Huntly all have bachelors at the center of their narratives. Ormond at first appears to be the classic bachelor, the murderer who attempts to rape the woman he seeks. But Ormond might also be examined with masculinity and gender power structures in mind. One might ask, for example, whether the gender stereotypes have ultimately shackled Ormond and driven him to monomania. ${ }^{4}$ Arthur Mervyn and Edgar Huntly are particularly important, for both of these novels were concurrent with Brown's editing of the Monthly Magazine. Both novels also appear in the periodical, Huntly in a fragment, Mervyn in summary form in "Walstein's School of History." The critical history of these two novels frequently draws attention to how each narrator may be unreliable; the motives of each protagonist always fall under scrutiny. In the light of Brown's interest in promoting bachelorhood, the actions of each character take on a new hue. Brown might indeed have hoped that readers understood his protagonists as virtuous rather than unreliable and their actions, though arguably suspicious, worthy of emulation (not unlike Franklin in The Autobiography). Moreover, each novel has an obvious connection to the issues of marriage, for Arthur Mervyn ultimately marries Achsa Fielding and Edgar Huntly is engaged to Waldegrave's sister.

This study's investigation also has implications for novels other than those by Charles Brockden Brown. While the readership of novels heavily consisted of white, middle-class women in the early national period, it also included men. Moreover, the early novel frequently deals with marriage, and while the images of women in these novels have been well-researched, ${ }^{5}$ the male characters have largely been left out of the critical portrait. One might look more closely, for example, at how gender might appear as a limiting factor to men as well as women. Looking at Webster's Coquette, Cathy Davidson notes that the novel exposes the restricted marital opportunities Eliza Wharton possesses and the limitations she faces in trying to make a life for herself. One might turn the lens slightly, ${ }^{6}$ however, and ask how gender limits the choices of the Reverend Boyer and Major Sanford. What forms of 
masculinity are not open to them? The novel seems to offer men the same choice it offers its heroine. Either men can aspire to be the Reverend Boyer (an insensitive prig) or they can become Major Sanford (a profligate and a rake). Perhaps part of the novel's argument is that new definitions of gender are needed equally for men and women. Such investigations have currency for a number of novels, from Rowson's Charlotte Temple to the largely unread novels by Sally Wood. The former in particular, with its hundred years of mega-popularity, offers a revealing story not just of the early republic, but of nineteenth-century America. ${ }^{7}$ What story does its popularity tell about changes in the culture? Studying masculinity in the early novel also offers a gauge by which to measure changing definitions of manhood. Rebecca Rush's Kelroy (1812) presents readers with a hero (in the titular character) very different from Webster's Boyer and Sanford, suggesting patterns of gender had already shifted in just fifteen years.

Another look at Brown's influence on succeeding generations might also be in order. Poe mentions Brown in his reviews, and Brown's influence on Poe's gothic imagination has been noted. ${ }^{8}$ Hawthorne, too, mentions Brown in "The Hall of Fantasy" (1843), where "In an obscure and shadowy niche was reposited the bust of our countryman, the author of Arthur Mervyn," 9 and Hawthorne's interest in gender relations appears throughout his work. Bachelorhood itself gained more respectability as the next century progressed. In the literary world, Washington Irving was himself a bachelor, and the antebellum generation of writers imagined some of the most famous single men in literary history, including Cooper's Natty Bumpo, Hawthorne's Reverend Dimmesdale, and Melville's Ishmael. While Brown's fingerprints might not be convincingly discernable on the creation of these characters, bachelorhood and manhood are central to their design. ${ }^{10}$

Closer inspection of periodical literature also seems in order in light of recent interest in popular literature. Work has already begun on periodicals printed "across the pond." In her introduction to Women and Print Culture, Kathryn Shevelow explains her purpose is "to delineate the process of simultaneous enfranchisement and restriction that marked women's visible entrance into print culture by tracing the early stages of the development of the popular periodical, as it emerged in the late seventeenth century." 11 She argues that "popular periodicals validated certain types of feminine experience, insisted upon the significance of certain feminine concerns as literary material and social agenda, and asserted women's intellectual capabilities and potential equality." 12 Responding to Shevelow's book, Shawn L. Mauer contends in Proposing Men that Women and Print Culture tells only part of the story. Mauer argues "that men's interest in and concern with women and 
with the norms of proper femininity served simultaneously to construct a masculine role or identity for the sentimental husband and father of the emerging middle class." ${ }^{13}$ For her, "the genre of the social periodical inculcated new and particularly powerful identities for men, as much as it did for women." 14 These two works and this study see the periodical as central to the construction of gender in the eighteenth century. On this side of the ocean, periodicals accomplished some of the same cultural work of presenting gender roles, the most famous of which was Godey's Lady's Book. Many periodicals surely played a role in constructing male gender types as well, an avenue of investigation little explored as of yet.

Finally, underlying the argument of this book is the belief that authoring a text and editing a text (be it periodical or book) are interconnected activities. When scholars speak of the profession of authorship, they need to consider all the activities of a man or woman of letters. Edward Larkin has already shown how Thomas Paine's editorship of the Pennsylvania Magazine played an important role in the development of his rhetoric and his understanding of his American audience. ${ }^{15}$ Brown's contemplation of manhood, as I point out above, flows through most of his writings. Intuitively, it would make sense that what is true for Paine and Brown might also be true for the likes of Benjamin Franklin, Philip Freneau, Washington Irving, Caroline Kirkland, William Cullen Bryant, Lydia Sigourney, Nathaniel Hawthorne, and William Dean Howells, to name but a few. My research implicitly suggests that editing and authoring are not separate careers for Brown. Is this true only for Brown? Only for writers in the colonial and early national periods? For all American writers? For all writers? And, if it is not, when do the two activities become separate spheres of activity, and why? What does such a bifurcation reveal about the state of letters and culture?

While this book begins to answer these questions, it also raises questions relevant to all periods of American literature and provides a rich vein of material for further investigation for all scholars. 


\section{Notes}

\section{NOTES TO CHAPTER ONE}

1. Mark Breitenberg, Anxious Masculinity in Early Modern England (New York: Cambridge University Press, 1996), 1.

2. Breitenberg, 1.

3. Breitenberg, 2.

4. Breitenberg, 2.

5. Breitenberg, 2.

6. Breitenberg, 17.

7. Breitenberg, 17.

8. This observation comes from Brown biographer Harry R. Warfel, Charles Brockden Brown: American Gothic Novelist (Baltimore: Johns Hopkins University Press), 28-29.

9. Quoted in Robcrt A. Ferguson, Law and Letters in American Literature (Cambridge: Harvard University Press, 1984), 130.

10. The law "led more effectually and more directly to advancement than any other profession," and "many young men with fathers well established in business or politics studied Blackstone as the surest means of building up a name or a fortune" (Warfel 28). For accounts of the importance of the legal profession in the second half of the eighteenth century, see Christopher Grasso, A Speaking Aristocracy: Transforming Public Discourse in Eighteenth-Century Connecticut (Chapel Hill: University of North Carolina Press, 1999) and especially Ferguson's l aw and letters.

11. Ferguson, 129.

12. Ferguson, 130 .

13. Steven Watts, The Romance of Real Life: Charles Brockden Brown and the Origins of American Culture (Baltimore: Johns Hopkins University Press), 39.

14. Watts, 33 .

15. Watts, 33 .

16. Quoted in Watts, 149.

17. Charles Brockden Brown, Alcuin: A Dialogue and Memoirs of Stephen Calvert, ed. Sydney J. Krause ct al. (Kent, OH: Kent State University Press, 1987), 272. 
18. Quoted in Warfel, 166.

19. Brown's projections were built on fantasy, for magazines failed quickly and frequently in the early republic. Furthermore, as John Tebbel and Mary Ellen Zuckerman observe, editing a periodical was "a part-time job in most cases" because "Often there were no salarics at all, not even an honorarium, and on other periodicals, editors were paid in proportion to the magazine's financial condition, which was usually uncertain." John Tebbel and Mary Ellen Zuckerman, The Magazine in America, 1741-1990 (New York: Oxford University Press, 1991), 10.

20. Norman S. Grabo, The Coincidental Art of Charles Brockden Brown (Chapel Hill: University of North Carolina Press, 1981), 158.

21. Quoted in Watts, 144. For a detailed examination of Brown's Literary Magazine, see Michael Cody's book, Charles Brockden Brown and the Literary Magazine: Cultural Journalism in the Early American Republic (Jefferson, NC: McFarland, 2004).."

22. For classical republicanism, see Bernard Bailyn, The Ideological Origins of the American Revolution Enlarged Edition (Cambridge: Harvard University Press, 1992), Gordon Wood's The Creation of the American Republic, 1776-1787 (New York: Norton, 1993), and J. G. A. Pocock's The Machiavellian Moment (Princeton: Princeton University Press, 1975). For an analysis of how economic changes wrought shifts in republicanism, see Joyce Applcby, Capitalism and a New Social Order: The Republican Vision of the 1790s (New York: New York University Press, 1984). For a dissenting view of Appleby's 1790s, see Lance Banning, The Jeffersonian Persuasion: Evolution of a Party Ideology, (Ithaca, NY: Cornell University Press, 1978).

23. Michael Kimmel, Manhood in America: A Cultural History (New York: Free Press, 1996), 17.

24. Kimmel, 18.

25. Kimmel, 16.

26. Quoted in Ferguson, 128.

27. Emory Elliott, Revolutionary Writers: Literature and Authority in the New Republic, 1725-1810 (New York: Oxford University Press, 1982), 4. For a concurring view of the disestablishment of the clergy as authority figures, though with different critical purposes in mind, see Ann Douglas The Feminization of American Culture (New York: Knopf, 1977) and Grasso's Speaking Aristocracy.

28. Elliott, 12.

29. Grantland S. Rice, The Transformation of American Authorship) (Chicago: University of Chicago Press, 1997), 5.

30. Rice, 4.

31. While cach work stakes out a position of authority, such as the seduction novel's frequent claim to be "founded on fact," the format of each, according to Rice, is an aesthetic response to the market forces driving book sales.

32. Brown makes this claim for himself in the prefaces to Wieland, or, the Transformation, ed. Sydney J. Krausc et al. (Kent, OH: Kent State 
University Press, 1977) and Edgar Huntly, or, Memoirs of a Sleepwalker, ed. Sydney J. Krause et al. (Kent, OH: Kent State University Press, 1984).

33. Jay Fliegelman, Prodigals and Pilgrims: The American Revolution Against Patriarchal Authority, 1750-1800 (New York: Cambridge University Press, 1982), 94.

34. Flicgclman, 50.

35. Fliegelman, 104.

36. It should be noted that while both Mary Beth Norton and Linda K. Kerber touch on the role of women of color and of the lower classes, they deal primarily with middle and upper-class white women. The changes in these women's lives in all likelihood had the greatest impact on Brown's life because he was of the same social status. When I speak of women in this book, therefore, I mean the middle and upper-class white women among whom Brown circulated.

37. Mary Beth Norton, Liberty's Daughters: The Revolutionary Experience of American Women, 1750-1800 (Ithaca, NY: Cornell University Press, 1996), xix.

38. Norton, xix.

39. Linda K. Kerber, Women of the Republic: Intellect and Ideology in Revolutionary America (New York: Norton, 1986).

40. Nancy F. Cott, The Bonds of Womanhood: "Women's Sphere" in New England, 1780-1835 (New Haven: Yale University Press, 1977). For a dissenting view of Cott's ideas, see Separate Spheres No More: Gender Convergence in American literature, 1830-1930, edited by Monika M. Elbert (Tuscaloosa, AL: University of Alabama Press, 2000).

41. Lee Virginia Chambers-Schiller, Liberty, A Better Husband: Single Women in America: The Generation of 1780-1840 (New Haven: Yale University Press, 1984), 3.

42. Chambers-Schiller, 1.

43. R. W. Conncll, Gender and Power (Cambridgc: Polity Prcss, 1987), 186.

44. That Connell should choose apprentices as his example is an interesting coincidence becausc Thomas and James Swords, the publishers of the Monthly Magazine may not have treated their young apprentices very well. According to June $\mathrm{N}$. Adamson, while little is known of their personal lives, the historical record does suggest that the brothers "must have been hard taskmasters to their apprentices, perhaps treating them as they had been treated." She gocs on to describe the poor room and board supplicd to one James Bogert, whose articles were ultimately cancelled, apparently by authorities outside the printing house who aimed to penalize the Swords brothers. Unfortunately, it is not known whether the treatment Bogert received was an isolated incident or a regular occurrence with the brothers. Sec June N. Adamson, "Thomas Swords and James Swords," in American Magazine Journalists, 1741-1850, edited by Sam G. Riley, Dictionary of Iiterary Biography Vol. 73 (Detroit: Gale, 1988), 309.

45. Danicl H. J. Morgan, Discovering Men (New York: Routledgc, 1992), 196-97. 
46. Chudacoff is primarily interested in the years $1880-1930$, but his introduction discusses American attitudes from the colonial period through the twentieth century. See Howard P. Chudacoff, The Age of the Bachelor: Creating an American Subculture (Princeton: Princeton University Press, 1999).

47. Chudacoff, 16.

48. Chudacoff, 25.

49. Quoted in Chudacoff, 26.

50. Chudacoff, 21.

51. Chudacoff, 21.

52. Katherine V. Snyder, Bachelors, Manbood, and the Novel, 1850-1925 (Cambridge: Cambridge University Press, 1999), 20-21.

53. Snyder, 21.

54. Also of note is "Walstein's School of History," which has been frequently cited as a summary of the plot of the first part of Arthur Mervyn (1799). See "Walstein's School of History. From the German of Krants of Gotha," Monthly Magazine and American Review, August 1799: 335-38.

55. The magazine's price also did not help. At $\$ 4.50$ a year, the Monthly Magazine was hardly a bargain for the economically struggling citizens of 1790 s America.

56. There are also two essay collections about Brown, but neither discusses the Monthly Magazine at length. See Revising Charles Brockden Brown: Culture, Politics, and Sexuality in the Early Republic, edited by Philip Barnard, Mark L. Kamrath, and Stephen Shapiro (Knoxville: University of Tennessee Press, 2004) and Critical Essays on Charles Brockden Brown, edited by Bernard Rosenthal (Boston: G. K. Hall, 1981). A single article has appeared involving the Monthly Magazine, but it does not examine the periodical as extensively as it does indigeneity and postcolonialism. See Steven Frye, "Constructing Indigeneity: Postcolonial Dynamics in Charles Brockden Brown's Monthly Magazine and American Review, American Studies, 39.3 (1998): 69-88.

57. Martin Samuel Vilas, Charles Brockden Brown: A Study of Early American Fiction (Burlington, VT: Free Press Association, 1904).

58. Lulu Rumsey Wiley, The Sources and Influence of the Novels of Charles Brockden Brown (New York: Vantage, 1950), 21.

59. Warfel, 170. Sce also David Lee Clark, Charles Brockden Brown: Pioneer Voice of America (New York: AMS Press, 1966).

60. See Donald A. Ringe, Charles Brockden Brown (New York: Twayne, 1966) and Arthur Kimball, The Rational Fictions of Charles Brockden Brown (McMinnville, OR: Linfield Research Institute, 1968).

61. Ringe later revised this book for Twayne in 1991, but without any additional analysis of the Monthly Magazine.

62. Grabo, xi.

63. Grabo, $x$.

64. Grabo, $x$.

65. Grabo, $x$. 
66. Alan Axelrod, Charles Brockden Brown: An American Tale (Austin: University of Texas Press, 1983), 28.

67. Watts, xviii.

68. Watts, xviii.

69. Watts, xviii.

70. Watts, xviii.

71. Watts, xviii.

72. Bill Christopherson, The Apparition in the Glass: Charles Brockden Brown's American Gothic (Athens, GA: University of Georgia Press, 1993), ix.

73. Christopherson, $x$.

74. Christopherson, ix.

75. Christopherson, 7.

76. Elizabeth Jane Wall Hinds, Private Property: Charles Brockden Brown's Gendered Economics of Virtue (Newark: University of Delaware Press, 1997), 12. "Most recent" is always a relative term; published too late for inclusion here is Peter Kafer, Charles Brockden Brown's Revolution and the Birth of American Gothic (Philadelphia: University of Pennsylvania Press, 2004). Kafer's index reveals, however, that he only references the Monthly Magazine on two occassions.

\section{NOTES TO CHAPTER TWO}

1. The New York Magazine, incidentally, was published by T. and J. Swords, the publishers of Charles Brockden Brown's Monthly Magazine and American Review.

2. David Paul Nord, "A Republican Literature: Magazine Reading and Readers in Latc-Eighteenth-Ccntury Ncw York," in Reading in America: Literature and Social History, ed. Cathy N. Davidson (Baltimore: The Johns Hopkins University Press, 1989), 11.5.

3. Nord, 128.

4. Nord, 128. Similarly, Arthur Scherr argues that Mathew Carey's American Museum contains numerous pieces which are aimed at women readers. Scherr contends that contrary to previous historical findings-and he has historians Linda K. Kerber and Mary Beth Norton in mind particularlyCarcy's periodical portrayed women positively and that magazines of the period were not hostile to their intellectual achicvements. See Arthur Scherr, "I Married Me a Wife": Male Attitudes Toward Women in the American Museum, 1787-1792 (Lanham, MD: Lexington Books, 1999).

5. Brown did write a letter advertising the Monthly Magazine to a friend whom he thought might be interested in the project and who, presumably, would circulate news of Brown's intentions to like-minded individuals. Reader response to the Monthly Magazine is equally scarcc, though clcarly some readers did write to it and enough supported it financially for eighteen issues.

6. Tebbel and Zuckerman, 6 .

7. Alfred Weber, "Introduction," in Somnabulism and Other Stories, ed. Alfred Weber (Frankfort, Germany: Peter Lang, 1987), ix-xxiii. See page xi.

8. Warfel, 171, emphasis his. 
9. For more on literary criticism in eighteenth-century magazines, see Frank Luther Mott, A History of American Magazines, 1741-1850 (New York: D. Appleton and Company, 1930) and William Charvat, The Origins of American Critical Thought, 1810-1835 (New York: Russell and Russell, 1968).

10. Warfel, 170-171.

11. It is obvious Brown grew quite bored with these Washington-inspired outpourings. His reviews of them become steadily more sour, and occasionally he remarks how tiresomely unoriginal these effusions had become.

12. I have relied heavily here upon F. L. Mott. For other sources which confirm Mott's observations, see Edward E. Chiclens, American Literary Magazines: The Eighteenth and Nineteenth Centuries (Ncw York: Grecnwood Press, 1986) and The Literary Journal in America to 1900: A Guide to Information Sources (Detroit: Gale, 1975), Neal L. Edgar, A History and Bibliography of American Magazines, 1810-1820 (Metuchen, NJ: Scarecrow Press, 1975), Lyon Richardson, A History of Early American Magazines, 1741-1789 (New York: Octagon Books, 1966), Riley's American Magazine Journalists, John Tebbel, The American Magazine: A Compact History (NY: Hawthorn Books, 1969), and James Playsted Wood, Magazines in the United States (New York: Ronald Press Company, 1956).

13. Mott, 39.

14. Mott, 40-41.

15. To a degree, what constitutes fiction in Brown's magazine (and in the eighteenth century) is somewhat difficult to define. Many of the short columns discussed later in this chapter could be considered very short stories, for many employ fictional devices such as plot and dialogue. But such pieces really come closer to being short sketches or brief anecdotes rather than recognizably full-fledged short stories. Thus, as I see it, while there is some overlap, the Monthly Magazine printed only five separate pieces of fiction.

16. Tebbel and Zuckerman, 10 .

17. Perhaps Brown believed he had exhausted the issue when he published his Alcuin: A Dialogue (1798), part of which was given over to women's education. Critics frequently cite Alcuin as Brown's pro-feminist polemic. But some critics, Hinds among them, note that the dialogue is far more conservative than commonly acknowledged, leaving Brown's commitment to the cause of women's rights very much in question.

18. Mott, 188.

19. For a discussion of "The Paper War" in the Columbian Magazine, see William J. Free, The Columbian Magazine and American Literary Nationalism (The Hague: Mouten, 1968).

20. Tebbel and Zuckerman, 5 .

21. The Medical Repository was also published by the Swords brothers and edited by Samuel Latham Mitchell.

22. These included Joseph Hopkinson, who composed "Hail, Columbia"; Richard Rush, eventual minister to France and England; John Quincy Adams; Charles Brockden Brown; Alexander Wilson, the ornithologist; and Gouverneur Morris. See Tebbel and Zuckerman, 9. 
23. William Charvat, The Profession of Authorship in America, 1800-1870 (New York: Columbia University Press, 1992), 6.

24. The first American magazine appeared in 1741, Andrew Bradford's American Magazine, or a Monthly View. It preceded Benjamin Franklin's General Magazine by three days. See Mott, 71.

25. Or, one might humorously add, at least a single woman reader. It is unclear whether the magazine's backers intended "Gentlemen" to be "Gentleman" or "Iady's" to be "Ladies." In either case, I would speculate that the mistake was probably the result of printer error or the absence of the proper typeface.

26. Almost all articles in the Monthly Magazine and American Review appeared pscudonymously or anonymously, making attribution of individual pieces largely speculative. Nevertheless, the periodical was the brainchild of the Friendly Club, whose membership consisted mostly of unmarried men in their twenties. Though Friendly Club members did not supply the volume of material they had originally promised Brown, they undoubtedly wrote some of the articles. It also seems likely that this homo-social interaction produced similar attitudes toward bachclorhood and marriage, especially since members would often exclude a member who married or who manifested more interest in his domestic life than in their companionship.

27. Candidus, "On Periodical Publications," Monthly Magazine and American Review, April 1799, 1-3.

28. The Monthly Magazine was published in three volumes. The first volume contains all the issues from 1799, beginning with April and ending with September-December, which was a single, eighty-page issue comprising the last four months of the ycar. (A ycllow fever epidemic forced production to cease briefly.) The other two volumes contain January-June and JulyDecember of 1800 . The pages for each volume are numbered consecutively, each issuc picking up where the previous onc had left off. To differentiate the volumes, throughout this study I will parenthetically cite volume and page number by Roman and Arabic numcrals respectively.

29. Victor J. Seidler, Rediscovering Masculinity: Reason, Language, and Sexuality (New York: Routledge, 1989), 16.

30. This was onc of the notions that galled Mary Wollstonecraft, who sarcastically addressed her female readers thus: "My own sex, I hope, will excuse me, if I treat them like rational creatures, instead of flattering their fascinating graces, and viewing them as if they were in a state of perpetual childhood, unable to stand alone." See Mary Wollstonecraft, A Vindication of the Rights of Woman (New York: Norton, 1988), 9, emphasis hers.

31. Nina Baym, American Women of Letters and the Nineteenth-Century Sciences (New Brunswick: Rutgers University Press, 2001), 8.

32. Baym, 4. One contributor to Brown's periodical ("E") did not even grant this much influcnce, arguing that women should aspire to be completely apolitical. Sec "Remarks on Female Politicians," Montbly Magazine and American Review, Deccmber 1800, 416-18.

33. Quoted in Norton, 192. 
34. Norton, 190. Among those cited by Baym is Margaret Fuller, whose feminism did not prevent her from telling students in 1837 that "it was 'not to be expected that women would be good Astronomers or Geologists or Metaphysicians' but 'they could and are expected to be good historians." Quoted in Baym, 4.

35. The embarrassment over appearing in print that Anne Bradstreet expresses in "The Author to Her Book" is a case in point, albeit one preceding Brown by over one hundred years. Still, Bradstreet's sentiments maintained a strong currency in the $1790 \mathrm{~s}$. See, for example, work by David S. Shields, espccially Civil Tongues and Polite Letters in British America (Chapel Hill: University of North Carolina Press, 1997).

36. "On Almanacs," Monthly Magazine and American Review, May 1799, 85-88.

37. One might argue that having a Protestant background in a largely Protestant country could account for her ignorance regarding the saints. Yet the narrator has not asked for details of the saints' decds, only their names, at least one of which she probably ought to recognize but does not.

38. "Dialogues of the Living: Dialogue II," Monthly Magazine and American Review, February 1800, 96-99.

39. As noted earlier, Charles Brockden Brown's editorial practice was not radically different from that employed by his contemporaries, and they frequently imitated their British counterparts. In this light, William's complaint, though commonplace, is also suspect. Moreover, the allegedly serious tone was also in keeping with contemporary periodicals and Enlightenment zeitgeist-print picces should be uscful and educational as well as entertaining.

40. Warfel, 6.

41. Warfel, 6-7.

42. This would have been especially easy in the case of Wieland, which was published by $\mathrm{T}$. and J. Swords and could, in all probability, have appeared alongside the Monthly Magazine in their bookshop on Pearl Street. Regular customers might also have spotted Brown's writings before 1798 in the Swords's New York Magazine.

43. Benson, May, Norton, and Kerber all discuss the poor reception that Wollstonecraft's book received in the United States. Benson, for example, states that the book's appearance could not have come at a worse time; that the zeitgeist of the nation was such that it was ready to reject Wollstonecraft's ideas immediately. Some reviews of the book were positive, but negative appraisals multiplied once Godwin published Wollstonecraft's memoirs in the late 1790s. See Mary Sumner Benson, Women in EighteenthCentury America: A Study of Opinion and Social Usage (New York: Columbia University Press, 1935).

44. Mary Beth Norton cites how specific words carried gendered meanings. Her example is the word "helpless," which was frequently applied to women, sometimes to children or a family; a man, on the other hand, might be "unfortunate" but was never helpless. Sce Norton, 117. 
45. “Gossiping: A Dialogue," Monthly Magazine and American Review, June $1799,169-71$.

46. Mary Beth Norton notes how "Apologies additionally littered women's comments on their supposed loquacity and love of gossip." See Norton, 114.

47. For the value of sympathy in the early republic, see the recent studies by Julia A. Stern, The Plight of Feeling: Sympathy and Dissent in the Early American Novel (Chicago: University of Chicago Press, 1997) and Elizabeth Barnes, States of Sympathy: Seduction and Democracy in the American Novel (New York: Columbia University Press, 1997). For more on sentiment and sympathy generally, among others, see Janet Todd, Sensibility: An Introduction (Ncw York: Methuen, 1986) and G. J. Barker-Benfield, The Culture of Sensibility: Sex and Society in Fighteenth-Century Britain (Chicago: University of Chicago Press, 1992).

48. "Anccdotes of Madame Du Barri," Monthly Magazine and American Review, June 1800, 401-02.

49. Mark E. Kann, On the Man Question (Philadelphia: Temple University Press, 1991), 68.

50. Kann, Man Question, 68.

51. Thomas Jefferson, Notes on the State of Virginia (1784), in Writings, ed. Merrill D. Peterson (New York: Library of America, 1983), 123-325. See especially pages $266-70$.

52. "List of Female Authors of the Eighteenth Century," Monthly Magazine and American Review, May 1800, 381.

53. "Memoirs of Hannah Morc," Monthly Magazine and America Review, Deccmber 1800, 46.5-69.

54. Whilc there were plenty of women writing, denunciations of female authorship still appeared in print, and women frequently cloaked themselves in anonymity to protect their (gentecl) reputations. Far more acceptable was the practice of circulating manuscripts among a circle of friends, which kept women safely out of the public sphere of print.

55. "Reflections on the Character of Mary Wollstonecraft Godwin," Monthly Magazine and American Review, August 1799, 330-35.

56. Pamela Clemit claborates on the transatlantic import of Godwin's ideas. Her book cstablishes the characteristics of the Godwinian Novel, traces their influence on Brown, and then discusses Brown's eventual influence on Shelley. Sec Pamela Clemit, The Godwinian Novel: The Rational Fictions of Godwin, Brockden Brown, Mary Shelley (Oxford: Oxford University Press, 1993).

57. See, for example, Norton's citation of Esther Edwards Burr's anger with a Princeton tutor, which she recorded in her diary. Burr claims the tutor said that "he did not think women knew what Friendship was, they were hardly capable of anything so cool and rational as friendship." Quoted in Norton, 106 , italics in original. The full text appears on page 257 of Burr's diary. See Esther Edwards Burr, The Journal of Esther Edwards Burr, 1754-1757, ed. Carol F. Karlson and Lauric Crumpacker (New Haven: Yale University Press, 1984). Norton acknowledges further that women of the time were 
“widely said to be irrational creatures" (118); see especially pages 115-16 and 118-19.

\section{NOTES TO CHAPTER THREE}

1. "Summary of the Late Improvements in Astronomy. From the Journal de Physique for 1798." Monthly Magazine and American Review, April 1799, 53-55.

2. Marina Benjamin, "Introduction," in Science and Sensibility: Gender and Scientific Enquiry, 1780-1945, ed. Marina Benjamin (Cambridgc: Basil Blackwell, 1991), 1-23. See page 9.

3. "On the Inequalitics of Solar Light," Monthly Magazine and American Review, May 1799, 81-83.

4. B might have changed his mind had he the opportunity to read Byron's poem "Darkness" (1816) or Robert Silverberg and Isaac Asimov's novel Nightfall (1990), both of which posit anarchy and barbarism if the sun's light ccased.

5. "On the Temperature of the Planetary System," Monthly Magazine and American Review, December 1800, 419-420.

6. Nina Baym notes that the "increasing mathematizing of all the sciences furthered their development but estranged them irrevocably from the general public." See Baym, 2. The picces found in the Monthly Magazine, though, already suggest a degree of alienation, albeit not of the magnitude Baym has in mind. Readers still needed a college degree to comprehend Brown's selections, though not the specialized degrees required today.

7. "The Family of Lincs," Monthly Magazine and American Review, August $1800,88-92$.

8. It is also worth noting that the writer of "The Family of Lines" is "refreshing" the reader's memory, suggesting again that Brown's audience possessed the sort of education usually denicd women.

9. "Description of a Universal Standard of Measure, Invented by Dudley Saltonstall, Esq. Attorney and Counsellor at Law at Canandaqua, County of Ontario-Described by S. M. H.," Monthly Magazine and American Review, June 1799, 174-81.

10. See Michael Warner, The Letters of the Republic: Publication and the Public Sphere in Eighteenth-Century America (Cambridge: Harvard University Press, 1990) and Jürgen Habermas, The Structural Transformation of the Public Sphere, trans. Thomas Burger (Cambridge: MIT Press, 1989).

11. Adam Workman, "To the Editor of the Monthly Magazine," Monthly Magazine and American Review, July 1799, 263.

12. Adam Workman, "To the Editor of the Monthly Magazine," Monthly Magazine and American Review, May 1800, 345.

13. George Baron, "To the Editor of the Monthly Magazine," Monthly Magazine and American Review, February 1800, 84.

14. Even if the problem were contrived merely to interest readers, the intellectual challenge to solve the puzzle remains intact.

15. As an interesting sidenote, in a fit of impatience "Humbug" humorously denounces the whole debate in a poem found in the May 1800 issue. 
16. "Philadelphia Water-Works," Monthly Magazine and American Review, Junc 1799-181-82.

17. "Remarks on the Erection of a Turnpike Road from the Genesce Country to Fort Schuyler, on the Mohawk River," Monthly Magazine and American Review, Junc 1799, 182-88.

18. William J. Gilmorc, Reading Becomes a Necessity of Life: Material and Cultural Life in Rural New England, 1780-1835 (Knoxville: University of Tennessec Press, 1989).

19. Similar arguments would be posed ten to fiftecn years later as New York State contemplated building the Eric Canal.

20. "On the State of American Literature," Monthly Magazine and American Review, April 1799, 15-19.

21. There is a consistent strain of lamentation over America's seeming indifference to intcllectual pursuit. Perhaps the most prominent example close to Brown's era is Irving's "The Iegend of Slcepy Hollow" (1820). The villagers, readers learn, "are apt to consider the costs of schooling a grievous burthen, and schoolmasters as mere drones." Moving weekly from house to house, Ichabod Crane completes chores, lest his room and board become "too onerous on the purses of his rustic patrons." See Washington Irving, "The Legend of Slecpy Hollow," in History, Tales and Sketeches, ed. James W. Tuttleton (New York: Library of America, 1983), 1062.

22. This quote is not very far from Elliott's argument concerning the discrediting of clergymen and intellectuals so that merchants could retain power.

23. Sec, for example, Thomas Jefferson's often anthologized letter to John Adams concerning the "natural aristocracy," in which he states respect for the law is central to a stable citizenry. Thomas Jefferson, "The Natural Aristocracy: To John Adams," in Writings, ed. Merrill D. Peterson (New York: Library of America, 1984.), 1304-1310. For an explication of the importance of the law to American letters, see Robert Fcrguson's Law and Letters in American Culture.

24. Warfel, 96.

25. Warfel, 96-97.

26. Quoted in Ferguson, 135.

27. Ferguson, 135 .

28. Jay Flicgclman, Declaring Independence: Jefferson, Natural Language, and the Culture of Performance (Stanford: Stanford University Press, 1993), 171. Consider, for example, Popc's famous lines: “True Wit is Nature to Advantage drest, / What oft was Thought but ne'er so well Exprest." See Alexander Pope, "An Essay on Criticism," Poetry and Prose of Alexander Pope, ed. Aubrey Williams (Boston: Houghton Mifflin, 1969), lines 297-98.

29. Fliegclman, 172.

30. Elliott, 18.

31. Mark R. Patterson, Authority, Autonomy, and Representation in American Literature, 1776-1865 (Princeton: Princeton University Press, 1988), 62.

32. Patterson, 62.

33. Patterson, 68.

34. Patterson, 77. 
35. Patterson, 77.

\section{NOTES TO CHAPTER FOUR}

1. The term, of course, is Jane Tompkins's; see Sensational Designs: The Cultural Work of American Fiction, 1790-1860 (New York: Oxford University Press, 1985).

2. Warfel, 166.

3. Warfel, 166-67. This was frequently Brown's experience with the Literary Magazine as well.

4. Cathy N. Davidson, Revolution and the Word: The Rise of the Novel in America (New York: Oxford University Press, 1986), 45.

5. Davidson, 112.

6. Davidson, 77.

7. Davidson, 98.

8. Davidson, 39.

9. Davidson, 47.

10. Davidson, $42-43$.

11. Christopher Looby, Voicing America: Language, Literary Form, and the Origins of the United States (Chicago: Univcrsity of Chicago Press, 1996), 181.

12. Looby, 181.

13. Mark E. Kann, A Republic of Men: The American Founders, Gendered Language, and Patriarchal Politics (New York: New York University Press, 1998), 62.

14. Consider, for example, Kann's use of Franklin's Polly Baker, who blames the bachelors and their powers of seduction for her fifth appearance before the court to answer charges of producing illegitimate children.

15. Charles Brockden Brown, "Thessalonica: A Roman Story," Monthly Magazine and American Review, May 1799, 99-117. "Thessalonica," "Trials of Arden," and "Lesson on Concealment" were all published anonymously, but scholars have attributed all three to Brown's pen. See in particular Ringe's Charles Brockden Brown and Charles E. Bennett, "The Charles Brockden Brown Canon," Unpublished dissertation, University of North Carolina at Chapel Hill, 1974.

16. The article about Morocco appeared in the "Original Communications" section, the Genesec Country in the "American Review," and the others in "Selections."

17. Hannah Webster Foster's Major Sanford also comes to mind, since he seduces Eliza Wharton after he has marricd.

18. Perhaps, too, Brown had in mind the fact that Shay's Rebellion and the Whiskey Rebcllion were not composed solely of unmarried young men.

19. Kann, Republic of Men, 81.

20. Kann, Republic of Men, 81.

21. Banning, 262.

22. Kann, On the Man Question, 17

23. Kann, On the Man Question, 17. 
24. Kann, On the Man Question, 4.

25. In addition to biographers Warfel, Clark, and Watts, see Warner Berthoff's "Brockden Brown: The Politics of the Man of Letters," Serif 3 (1966): 3-11.

26. Charles Brockden Brown, "The Trials of Arden," Monthly Magazine and American Review, July 1800, 19-36.

27. The review of Notes also includes an extract from one of Jefferson's letters.

28. Quoted in Barnes, 4.

29. Barncs, $x$.

30. Kann, Republic of Men, 57.

31. Quoted in Kann, Republic of Men, 58.

32. Kann, Republic of Men, 59.

33. Kann, Republic of Men, 58.

34. Kann, Republic of Men, 81.

35. Kann, Republic of Men, 62.

36. Quoted in Kann, Republic of Men, 62.

37. What this "violence" is the story does not reveal explicitly. Though rape might be implied, I posit that the phrase refers possibly to his attempt to marry her and probably to his "sordid pranks."

38. Kann, Republic of Men, 81.

39. Kann, Republic of Men, 82.

40. "A Lesson on Concealment; or, Memoirs of Mary Selwyn," Monthly Magazine and American Review, March 1800, 174-207.

41. It is surprising, then, to discover that "Lesson" has received very little treatment from Brown's critics. Of those who discuss the story, see Warner Berthoff, "'A Lesson on Concealment: Brockden Brown's Method in Fiction, Philological Quarterly 37 (January 1958): 45-57, Fritz Flcischmann, "Concealed Lessons: Foster's Coquette and Brockden Brown's 'I.csson on Concealment," in Early America Re-Kxplored: New Readings in Colonial Early National, and Antebellum Culture, ed. Klaus H. Schmidt and Fritz. Fleischmann (Ncw York: Peter Lang, 2000), 309-47, and Watts, Romance of Real Life.

42. For one (unsympathetic) version of the proliferation of sentimental heroines in the early republic, sec Leslic Fiedler Love and Death in the American Novel (New York: Anchor Books, 1992).

43. Both Clara Howard and Jane Talbot draw on and resemble the sentimental novels of the period, but Brown produced these in 1801, arguably too late to preserve his choice of authorship as a vocation. Moreover, even writing in this vein, Brown did not produce books dripping with the overwrought emotion of his contemporaries' work.

44. Quoted in Kann, Republic of Men, 84.

45. Quoted in Kann, Republic of Men, 84.

46. Robcrt A. Gross, The Minutemen and Their World (New York: Hill and Wang, 1976), 181-82.

47. Kann, Republic of Men, 53. Recall Kann's example of Polly Baker's defense.

48. See Grasso, A Speaking Aristocracy, especially pages 437-38.

49. Grasso, 437.

50. Grasso, 437. 
51. Kann, Republic of Men, 62.

52. Henry has fallen ill, and in a weak moment he sees a vision of Mary's brother and cries out; confused by the moment and pressed to explain his alarm, he cannot find a way to silence her inquiries, so he reveals what he thought he saw.

53. Both the fragment from the soon-to-be released Edgar Huntly and "Thessalonica" preceded the Calvert serialization, while "Lesson on Concealment" appeared during Calvert's hiatus and, with its publication in the issue immediately following Calvert's conclusion, "Trials of Arden" bookended the novella.

54. Unlike the other fiction published in the Monthly Magazine (excluding the fragment of Edgar Huntly), Memoirs of Stephen Calvert has garnered more attention from literary critics. No doubt its length has brought about some of this attention. Its two hundred pages make it more novel-like, and, given the critical bias favoring novels, more "worthy" to be read. Morcover, Calvert has been included in Brown collections, such as William Dunlap's Life of Charles Brockden Brown (1815), which published significant extracts of its subject's work, and Henry Colburn's Carwin, the Biloquist, and Other American Tales and Pieces (1822). While Calvert did not make the cut for S. G. Goodrich's first collected American edition of Brown's works (1827), the novella's stature had risen high enough to be included in the authorized Kent State Bicentennial Edition in 1987. For extended readings of Calvert, see Ferguson, Grabo, Watts, and Maurice J. Bennett, "A Portrait of the Artist in Eighteenth-Century Amcrica: Charles Brockden Brown's Memoirs of Stephen Calvert, William and Mary Quarterly 39.3 (July 1982): 492-507.

55. Calvert was supposedly to comprise five parts, and since Brown never wrote the remainder of the book, readers never discover what events have driven the novella's protagonist to isolate himself in the wilderness on the banks of Lake Michigan.

56. According to William Dunlap's diary, the full title was to have been Calvert; or The Lost Brothers. See Warfel, 115.

57. It becomes clear, for example, that Clelia is not entertaining several male visitors while Calvert is playing cards; Calvert is the only visitor, and it is his twin brother who is spotted at the card table.

58. Heretofore, the Monthly Magazine has been the source for all primary materials. Since Stephen Calvert is a volume in the Bicentennial Edition, however, for the convenience of myself and my readers I have chosen it instead of the periodical as my source text. As the editors note in the "Textual Essay," their reprint "is essentially that of the Monthly Magazine" with only minor emendations (363).

59. Watts, 186.

60. Watts, 186.

61. It is also worth noting that marriage has not tempered Belgrave any more than it has the other married men in Brown's fiction. 
62. Benjamin L. Carp, "Fire of Liberty: Firefighters, Urban Voluntary Culture, and the Revolutionary Movement," William and Mary Quarterly 58 (October 2001): 781-818. Sce page 787, emphasis his.

63. Carp, 787.

64. Though Calvert's long-lost twin is obviously a gambler, readers never learn enough about his character to judge effectively whether he fits into or breaks the bachelor stereotype. As noted carlier, critics have debated whether to heed or ignore Brown's claim that the selection of Calvert printed was only the first of five parts. Whether Brown intended to develop Calvert's twin and what shape that development might have taken can be left only to speculation.

65. Joyce Appleby, "Republicanism in Old and New Contexts," William and Mary Quarterly 43 (January 1986): 20-34; sce page 20.

66. One thinks, too, of Hawthorne's "Custom-House" introduction and what he imagines his ancestors' opinion might be of his vocation: "'What is he?' murmurs one gray shadow of my forefathers to the other. "A writer of story books! What kind of a business in life,-what mode of glorifying God, or being serviceable to mankind in his day and generation,-may that be? Why the degenerate fellow might as well have been a fiddler!' See Nathaniel Hawthorne, The Scarlet Letter, in Collected Novels, ed. Millicent Bell (New York: Library of America, 198.3), 127

67. Charles Brockden Brown, "[Charles Brockden Brown: Letter to Thomas Jefferson]," in The English Literatures of America, 1500-1800, ed. Myra Jehlen and Michael Warner (New York: Routledge, 1997), 987-88.

\section{NOTES TO CHAPTER FIVE}

1. Carp, 787n16.

2. Unfortunatcly, many studies touch only briefly on the carly national period, taking instead as their focus nineteenth- and twentieth-century masculinity. Sce, for example, Anthony Rotundo, American Manhood: Transformations in Masculinity from the Revolution to the Modern Era (New York: Basic Books, 1993) and Michael Kimmel Manbood in America: A Cultural History (Ncw York: Free Press, 1996).

3. Janet Moore Lindman also argues that differing versions of manhood were in contentious competition in the eighteenth century. She focuses specifically on Virginia and spotlights Christian manhood, born of the Great Awakening, and its challenge to the older, leisure class manhood prevalent in the colony. Sec Janet Moore Lindman, "Acting the Manly Christian: White Evangelical Masculinity in Revolutionary Virginia," William and Mary Quarterly 57 (April 2000): 393-416.

4. If this is so for Ormond, then he becomes a victim akin to Charlotte Perkins Gilman's narrator in "The Yellow Wall-paper."

5. See, for example, Cathy N. Davidson's Revolution and the Word, Flizabeth Barnes's States of Sympathy, Julia Stcrn's Plight of Feeling, and Shirley Samuels's Romances of the Republic: Women, the Family, and Violence in the Literature of the Early American Nation (New York: Oxford University Press, 1996). Samuels also takes family life as her focus. 
6. I borrow the phrase from Annette Kolodny.

7. For a history of Charlotte Temple's popularity, see Cathy N. Davidson, "The Life and Times of Charlotte Temple: The Biography of a Book," Reading in America: Literature and Social History, cd. Cathy N. Davidson (Baltimore: Johns Hopkins University Press, 1989), 157-79.

8. One frequently cited example is the similarity between the dark cave with the deep pit in Edgar Huntly and Poe's pit and darkened room in "The Pit and the Pendulum" (1842). For an impressionistic look at Brown's influence, see Wiley, 207-300.

9. Nathaniel Hawthorne, "The Hall of Fantasy," in Tales and Sketches, edited by Roy Harvey Pearce (New York: Library of America, 1982), 735.

10. It is worth noting in passing that several citizens of Boston in the novel are of the opinion that the Reverend Dimmesdale ought to marry.

11. Kathryn Shevelow, Women and Print Culture: The Construction of Femininity in the Early Periodical (New York: Routlcdge, 1989), 2.

12. Shevelow, 4-5.

13. Shawn L. Mauer, Proposing Men: Dialectics of Gender and Class in the Eighteenth-Century Periodical (Stanford: Stanford University Press, 1998), 2.

14. Mauer, 3.

15. Edward Larkin, "Inventing the American Public: Thomas Paine, the Pennsylvania Magazine, and American Revolutionary Discourse," Early American Literature 33 (1998): 250-76. 


\section{Bibliography}

Adamson, June N. "Thomas Swords and James Swords." In American Magazine Journalists, 1741-1850, edited by Sam G. Rilcy. Dictionary of Litcrary Biography. Vol. 73. Detroit: Gale, 1988.

"Anecdotes of Madame Du Barri." Monthly Magazine and American Review (June 1800): 401-02.

Appleby, Joyce. Capitalism and a New Social Order: The Republican Vision of the 1790s. New York: New York University Press, 1984.

--. "Republicanism in Old and New Contexts." William and Mary Quarterly 43 (January 1986): 20-34.

Axclrod, Alan. Charles Brockden Brown: An American Tale. Austin: University of Texas Press, 1983.

Bailyn, Bernard. The Ideological Origins of the American Revolution. 1967. Cambridge: Harvard University Press, 1992.

Banning, Lance. The Jeffersonian Persuasion: Evolution of a Party Ideology. Ithaca, NY: Cornell University Press, 1978.

Barker-Benficld, G. J. The Culture of Sensibility: Sex and Society in EighteenthCentury Britain. Chicago: University of Chicago Press, 1992.

Barnard, Philip, Mark L. Kamrath, and Stephen Shapiro, ed., Revising Charles Brockden Brown: Culture, Politics, and Sexuality in the Early Republic. Knoxville: University of Tennessec Press, 2004.

Barnes, Elizabeth. States of Sympathy: Seduction and Democracy in the American Novel. New York: Columbia University Press, 1997.

Baron, Gcorge. "To the Editor of the Monthly Magazine." Monthly Magazine and American Review (February 1800): 84.

Baym, Nina. American Women of Letters and the Nineteenth-Century Sciences. New Brunswick: Rutgers University Press, 2001.

Benjamin, Marina. "Introduction." In Science and Sensibility: Gender and Scientific Enquiry, 1780-1945, edited by Marina Benjamin. Cambridge: Basil Blackwell, 1991.

Bennett, Charles E. “The Charles Brockden Brown Canon." Diss. University of North Carolina at Chapel Hill, 1974.

Bennett, Maurice J. "A Portrait of the Artist in Eighteenth-Century America: Charles Brockden Brown's Memoirs of Stephen Calvert." William and Mary Quarterly 39 , no. 3 (July 1982): 492-507. 
Benson, Mary Sumner. Women in Eighteenth-Century America: A Study of Opinion and Social Usage. New York: Columbia University Press, 1935.

Berthoff, Warner B. "Brockden Brown: The Politics of the Man of Letters." Serif 3 (1966): 3-11.

-. "A Lesson on Concealment': Brockden Brown's Method in Fiction." Philological Quarterly 37 (January 1958): 45-57.

Breitenberg, Mark. Anxious Masculinity in Early Modern England. New York: Cambridge University Press, 1996.

Brown, Charles Brockden. Alcuin: A Dialogue and Memoirs of Stephen Calvert. 1798. Edited by Sydney J. Krause et al. Kent, OH: Kent State University Press, 1987.

-. "[Charles Brockden Brown: Letter to Thomas Jefferson]." In The English Literatures of America, 1500-1800, edited by Myra Jehlen and Michael Warner. New York: Routledge, 1997.

- Edgar Huntly, or, Memoirs of a Sleepwalker. 1799. Edited by Sydney J. Krause et al. Kent, OH: Kent University Press, 1984.

—. "A Lesson on Concealment; or, Memoirs of Mary Selwyn." Monthly Magazine and American Review (March 1800): 174-207.

—. "Thessalonica: A Roman Story." Monthly Magazine and American Review (May 1799): 99-117.

—. "The Trials of Arden." Monthly Magazine and American Review (July 1800): 19-36.

- Wieland, or, the Transformation. 1798. Edited by Sydncy J. Krausc et al. Kent, $\mathrm{OH}$ : Kent State University Press, 1977.

Burr, Esther Edwards. The Journal of Esther Edwards Burr, 1754-1757. Edited by Carol F. Karlson and Laurie Crumpacker. New Haven: Yalc University Press, 1984.

Candidus. "On Periodical Publications." Monthly Magazine and American Review (April 1799): 1-3.

Carp, Benjamin L. "Fire of Liberty: Fircfighters, Urban Voluntary Culture, and the Revolutionary Movement." William and Mary Quarterly 58 (October 2001): 781-818.

Chambers-Schiller, Lec Virginia. Liberty, A Better Husband: Single Women in America: The Generation of 1780-1840. New Haven: Yale University Press, 1984.

Charvat, William. The Origins of American Critical Thought, 1810-1835. 1936. New York: Russell and Russell, 1968.

- The Profession of Authorship in America, 1800-1870. 1968. New York: Columbia University Press, 1992.

Chielens, Edward E. American Literary Magazines: The Eighteenth and Nineteenth Centuries. New York: Greenwood Press, 1986.

- The Literary Journal in America to 1900: A Guide to Information Sources. Detroit: Gale, 1975.

Christopherson, Bill. The Apparition in the Glass: Charles Brockden Brown's American Gothic. Athens, GA: University of Georgia Press, 1993.

Chudacoff, Howard P. The Age of the Bachelor: Creating an American Subculture. Princeton: Princeton University Press, 1999. 
Clark, David Lee. Charles Brockden Brown: Pioneer Voice of America. 1952. New York: AMS Press, Inc., 1966.

Clemit, Pamcla. The Godwinian Novel: The Rational Fictions of Godwin, Brockden Brown, Mary Shelley. Oxford: Oxford University Press, 1993.

Cody, Michael Amos. Charles Brockden Brown and the Literary Magazine: Cultural Journalism in the Early American Republic (Jefferson, NC: McFarland, 2004).

Connell, R. W. Gender and Power. Cambridge: Polity Press, 1987.

Cott, Nancy F. The Bonds of Womanhood: "Woman's Sphere" in New England, 1780-1835. New Haven: Yale University Press, 1977.

Davidson, Cathy N. "The Life and Times of Charlotte Temple: The Biography of a Book." In Reading in America: Literature and Social History. edited by Cathy N. Davidson. Baltimore: Johns Hopkins University Press, 1989.

- Revolution and the Word: The Rise of the Novel in America. New York: Oxford University Press, 1986.

“Description of a Universal Standard Measure, Invented by Dudley Saltonstall, Esq. Attorney and Counsellor at Law at Canandaqua, County of OntarioDescribed by S. M. H." Monthly Magazine and American Review (June 1799): 174-81.

"Dialogues of the Iiving: Dialogue II." Monthly Magazine and American Review (Fcbruary 1800): 96-99.

Douglas, Ann. The Feminization of American Culture. New York: Knopf, 1977.

Edgar, Neal L. A History and Bibliography of American Magazines, 1810-1820. Metuchen, NJ: Scarecrow Press, 1975.

Elliott, Emory. Revolutionary Writers: Literature and Authority in the New Republic, 1725-1810. New York: Oxford University Press, 1982.

"The Family of Lines." Monthly Magazine and American Review (August 1800): 88-92.

Ferguson, Robert A. Law and Letters in American Culture. Cambridge: Harvard University Press, 1984.

Fiedler, Icslic. Love and Death in the American Novel. 1966. New York: Anchor Books, 1992.

Fleischmann, Frit7. “Concealed Lessons: Foster's Coquette and Brockden Brown's 'Lesson on Conccalment." In Early America Re-Explored: New Readings in Colonial, Early National, and Antebellum Culture, edited by Klaus $\mathrm{H}$. Schmidt and Fritz Flcischmann. New York: Pcter Lang, 2000.

Flicgelman, Jay. Declaring Independence: Jefferson, Natural Language, and the Culture of Performance. Stanford: Stanford University Press, 1993.

- Prodigals and Pilgrims: The American Revolution Against Patriarchal Authority, 1750-1800. Ncw York: Cambridge University Press, 1982.

Frec, William J. The Columbian Magazinc and American Iiterary Nationalism. The Hague: Mouten, 1968.

Frye, Steven. "Constructing Indigencity: Postcolonial Dynamics in Charles Brockden Brown's Monthly Magazine and American Review." American Studies 39, no. 3 (1998): 69-88.

Gilmorc, William J. Reading Becomes a Necessity of Jife: Material and Cultural Life in Rural New England, 1780-1835. Knoxville: University of Tennessec Press, 1989. 
Grabo, Norman S. The Coincidental Art of Charles Brockden Brown. Chapel Hill: University of North Carolina Press, 1981.

"Gossiping: A Dialogue." Monthly Magazine and American Review (June 1799): 169-71.

Grasso, Christopher. A Speaking Aristocracy: Transforming Public Discourse in Eighteenth-Century Connecticut. Chapcl Hill: University of North Carolina Press, 1999.

Gross, Robert A. The Minutemen and Their World. New York: Hill and Wang, 1976.

Hawthorne, Nathaniel. "The Hall of Fantasy." In Tales and Sketches, edited by Roy Harvey Pearce. New York: Library of America, 1982.

- The Scarlet Letter. In Collected Novels, editcd by Millicent Bell. New York: Library of America, 1983).

Hinds, Elizabeth Jane Wall. Private Property: Charles Brockden Brown's Gendered Economics of Virtue. Newark: University of Delaware Press, 1997.

Irving, Washington. "The Legend of Sleepy Hollow." In History, Tales and Sketches, edited by James W. Tuttleton. New York: Library of America, 1983.

Jefferson, Thomas. "The Natural Aristocracy: To John Adams." In Writings, edited by Merrill D. Peterson. New York: Library of America, 1984.

- Notes on the State of Virginia. In Writings, cdited by Merrill D. Peterson. New York: Library of America, 1984.

Kafer, Peter. Charles Brockden Brown's Revolution and the Birth of American Gothic (Philadelphia: University of Pennsylvania Press, 2004).

Kann, Mark E. On the Man Question: Gender and Civic Virtue in America. Philadelphia: Temple University Press, 1991.

- A Republic of Men: The American Founders, Gendered Language, and Patriarchal Politics. New York: New York University Press, 1998.

Kerber, Linda K. Women of the Republic: Intellect and Ideology in Revolutionary America. 1980. New York: W. W. Norton, 1986.

Kimball, Arthur. The Rational Fictions of Charles Brockden Brown. McMinnville, OR: Linfield Research Institute, 1968.

Kimmel, Michael. Manhood in America: A Cultural History. New York: Free Press, 1996.

Larkin, Edward. "Inventing the American Public: Thomas Paine, the Pennsylvania Magazine, and American Revolutionary Discourse." Early American Literature 33 (1998): 250-76.

Lindman, Janet Moore. "Acting the Manly Christian: White Evangelical Masculinity in Revolutionary Virginia." William and Mary Quarterly 57 (April 2000): 393-416.

"List of Female Authors of the Eighteenth Century." Monthly Magazine and American Review (May 1800): 381.

Looby, Christopher. Voicing America: Language, literary Form, and the Origins of the United States. Chicago: University of Chicago Press, 1996.

Mauer, Shawn L. Proposing Men: Dialectics of Gender and Class in the FighteenthCentury Periodical. Stanford: Stanford Univcrsity Press, 1998.

May, Henry F. The Enlightenment in America. New York: Norton, 1975. 
"Memoirs of Miss Hannah More." Monthly Magazine and American Review (December 1800): 46.5-69.

Morgan, Daniel H. J. Discovering Men. New York: Routledge, 1992.

Mott, Frank Luther. A History of American Magazines, 1741-1850. New York: D. Appleton and Company, 1930.

Nord, David Paul. "A Republican Literature: Magazine Reading and Readers in Late-Eighteenth-Century New York." In Reading in America: Literature and Social History, edited by Cathy N. Davidson. Baltimore: Johns Hopkins University Press, 1989.

Norton, Mary Bcth. Liberty's Daughters: The Revolutionary Fxperience of American Women, 1750-1800. 1980. Ithaca: Cornell University Press, 1996.

"On Almanacks." Monthly Magazine and American Review (May 1799): 85-88.

"On the Inequalities of Solar Light." Monthly Magazine and American Review (May 1799): 81-83.

"On the State of American Literature." Monthly Magazine and American Review (April 1799): 15-19.

"On the Tempcrature of the Planetary System." Monthly Magazine and American Review (December 1800): 419-20.

Patterson, Mark R. Authority, Autonomy, and Representation in American Literature, 1776-1865. Princeton: Princeton University Press, 1988.

"Philadelphia Water-Works." Monthly Magazine and American Review (June 1799): 181-82.

Pocock, J. G. A. The Machiavellian Moment: Florentine Political Thought and the Atlantic Republican Tradition. Princeton: Princeton University Press, 1975.

Pope, Alexander. "An Essay on Criticism." In Poetry and Prose of Alexander Pope, edited by Aubrey Williams. Boston: Houghton Mifflin, 1969.

"Reflections on the Character of Mary Wollstonecraft Godwin." Monthly Magazine and American Review (August 1799): 330-35.

"Remarks on Female Politicians." Monthly Magazine and American Review (December 1800): 416-18.

"Remarks on the Frection of a Turnpike Road from the Genesec Country to Fort Schuyler, on the Mohawk River." Monthly Magazine and American Review (June 1799): 182-88.

Rice, Grantland S. The Transformation of Authorship in America. Chicago: University of Chicago Press, 1997.

Richardson, Lyon. A History of Early American Magazines, 1741-1789. 1931. New York: Octagon Books, 1966.

Riley, Sam G., ed. American Magazine Journalists, 1741-1850. Dictionary of Literary Biography. Vol. 73. Detroit: Gale, 1988.

Ringe, Donald A. Charles Brockden Brown. 1966. New York: Twayne, 1991.

Rosenthal, Bernard, ed., Critical Fssays on Charles Brockden Brown. Boston: G. K. Hall, 1981.

Rotundo, E. Anthony. American Manhood: Transformations in Masculinity from the Revolution to the Modern Era. New York: Basic Books, 1993.

Samuels, Shirley. Romances of the Republic: Women, the Family, and Violence in the Literature of the Farly American Nation. Ncw York: Oxford University Press, 1996. 
Scherr, Arthur. "I Married Me a Wife": Male Attitudes Toward Women in the American Museum, 1787-1792. Lanham, MD: Lexington Books, 1999.

Seidler, Victor J. Rediscovering Masculinity: Reason, Language, and Sexuality. New York: Routledge, 1989.

Shevelow, Kathryn. Women and Print Culture: The Construction of Femininity in the Early Periodical. New York: Routledge, 1989.

Shields, David. Civil Tongues and Polite Letters in British America. Chapel Hill: University of North Carolina Press, 1997.

- Oracles of Empire: Poetry, Politics, and Commerce in British America, 1690-1750. Chicago: University of Chicago Press, 1990.

Shuffleton, Frank. "In Different Voices: Gender in the American Republic of Letters." Early American Literature 25 (1990): 289-304.

Snyder, Katherine V. Bachelors, Manhood, and the Novel, 1850-1925. Cambridge: Cambridge University Press, 1999.

Stern, Julia A. The Plight of Feeling: Sympathy and Dissent in the Early American Novel. Chicago: University of Chicago Press, 1997.

"Summary of the Late Improvements in Astronomy. From the Journal de Physique for 1798." Monthly Magazine and American Review (April 1799): 53-55.

Tebbel, John and Mary Ellen Zuckerman. The Magazine in America, 1741-1990. New York: Oxford University Press, 1991.

Todd, Janet. Sensibility: An Introduction. New York: Methuen, 1986.

Tompkins, Jane. Sensational Designs: The Cultural Work of American Fiction, 1790-1860. New York: Oxford University Press, 1985.

Vilas, Martin S. Charles Brockden Brown: A Study of Early American Fiction. Burlington, VT: Free Press, 1904.

"Walstein's School of History. From the German of Krants of Gotha." Monthly Magazine and American Review (August 1799): 335-38.

Warfel, Harry R. Charles Brockden Brown: American Gothic Novelist. Gainesville: University of Florida Press, 1949.

Warner, Michael. The Letters of the Republic: Publication and the Public Sphere in Eighteenth-Century America. Cambridge: Harvard University Press, 1990.

Watts, Steven. The Romance of Real Life: Charles Brockden Brown and the Origins of American Culture. Baltimore: Johns Hopkins University Press, 1994.

Weber, Alfred. "Introduction." In Somnabulism and Other Stories. By Charles Brockden Brown. Frankfurt, Ger.: Peter Lang, 1987.

Wiley, Lulu Rumsey. The Sources and Influence of the Novels of Charles Brockden Brown. New York: Vantage, 1950.

Wollstonecraft, Mary. A Vindication of the Rights of Woman. 1792. New York: Norton, 1988.

Wood, Gordon S. The Creation of the American Republic, 1776-1787. New York: Norton, 1993.

Wood, James Playsted. Magazines in the United States. New York: Ronald Press Company, 1956.

Workman, Adam. "To the Editor of the Monthly Magazine." Monthly Magazine and American Review (July 1799): 263.

- "To the Editor of the Monthly Magazine." Monthly Magazine and American Review (May 1800): 345. 


\section{Index}

A

Adams, Abigail, 24-25

Adams, John, 5, 113n2.3

Age of the Bachelor, 9

Albany, 50

Alcuin, 38, 56, 78, 108n17

American Magazine, 39, 52, 107n4, 108n24

American Museum, 19, 22, 23, 52

"American Review," 19, 36, 62, 70, 79, $114 \mathrm{n} 16$

Amcrican Revolution, 4, 5, 6, 8, 34, 49, 52, 55,57

"Anecdotes of Madame Du Barri," 32-35

Apparition in the Glass, 13

Appleby, Joycc, 4, 47, 49, 53, 62, 72, 76, 95

Arthur Mervyn, 11, 43, 59, 91, 97, 100, $106 \mathrm{n} 54$

Autobiography (of Bcnjamin Franklin), 52, 100

Axclrod, Alan, 12-13, 14

\section{B}

Banning, Lance, 65

Barlow, Joel, 3

Barnes, Elizabeth, 70

Baron, George, 48

Baym, Nina, 24

Benson, Mary Sumner, 99

Bonds of Womanhood, 99

Brackenridgc, Hugh Henry, 4, 5

Bradford, William, 39, 52

Breitcnbcrg, Mark, 1, 4

Brown, Elizabcth I.inn, 2, 3

Bryant, William Cullen, 102

Byrd, William, 82
C

Candidus, 23-24, 25, 46, 60

Carey, Mathew, 22, 39, 107n4

Carp, Benjamin I.., 93-94

Chambers-Schiller, Virginia I.ec, 7-8, 58

Charles Brockden Brown, 12

Charles Brockden Brown: A Study of Early American Fiction, 11

Charles Brockden Brown: An American Tale, 12

Charlotte Temple, 25, 60, 81, 101

Charvat, William, 22-23

Christopherson, Bill, 13-14

Chudacoff, Howard P., 9, 10, 58, 71

Civil War (Amcrican), 7

Clara Howard, 11, 43, 11.5n43

Clarissa, 81

Clark, David L.cc, 12

Coincidental Art of Charles Brockden Brown, 12

Columbian Magazine, 19, 23, 39, 108n19

Common Sense, 52

Connecticut, 25, 83, 8.5

Connecticut Wits, 25

Conncll, R. W., 9, 14

Conquest of Canaan, 3

Constitution (American), 4, 34, 55

Continental Army, 65

Continental Congress, 56

Contrast, The, 4

Van Rough, 4, 8, 49, 71, 91

Cooper, James Fenimorc, 101

Coquette, The , 5, 8, 25, 37, 46, 81, 100

Cott, Nancy F., 7, 99

Cowper, William, 19

Crevecoeur, J. Hector St. John de 5 


\section{D}

Davidson, Cathy N., 60, 81, 100

Davis, John, 20

Declaration of Independence, 4, 56, 69

Dennie, Joseph, 20, 22

"Description of the City of Morocco," 62

Description of the Settlement of the Genesee Country, 62

"Dialogues of the Living," 26-29, 32

Discovering Men, 9

Dunlap, William, 20, 116n56

Dwight, Timothy, 3, 20

\section{E}

Edgar Huntly, 10, 11, 19, 20, 25, 43, 51, 59, $78,97,100,116 n 53,116 n 54$, $118 \mathrm{n} 8$

Elliott, Emory, 4, 5, 8, 51, 57, 96, 11.3n22

Enlightenment, 24, 40, 110n39

F

"Family of Lines," 44-45

Federalists, 4, 5, 32, 34, 57, 65, 69

Ferguson, Robert A., 56

Ferris, Debby, 2

Fliegelman, Jay, 6, 8, 56-57, 83

Fonda, Henry, 73

Foster, Hannah Webster, 5, 37, 46, 81, 100, $101,114 \mathrm{n} 17$

Franklin, Benjamin, 52, 100, 102, 108n24, $114 \mathrm{n} 14$

French and Indian War, 9

French Revolution, 4, 32, 79

Freneau, Philip, 25, 102

Friendly Club, 10, 11, 18, 32, 59, 68, 109n26

"Friendship: An Original Letter," 69

G

Genesee tegion, 49, 50, 62, 114n16

Gentlemen and Lady's Town and Country Magazine, 23

Gilmore, William J., 49

Godey's Lady's Book, 102

Godwin, William, 36, 37, 69, 78, 110n43, $111 \mathrm{n} 56$

“Gossiping: A Dialogue," 29-32, 33

Gothic literature, 11, 13, 25

Grabo, Norman, 3, 12, 13

Grasso, Christopher, 85

Griffin, William, 24
Gross, Robcrt, 83

H

Habermas, Jurgen, 51

"Hall of Fantasy," 101

Hall, Thomas, 10

Hamilton, Alcxander, 5, 50

Hawthorne, Nathanicl, 101, 102, 117n66

Heloise, 3

"Henrietta Letters," 3

Henshaw, Thomas, 10

Herschel, William, 41, 42, 63

Hinds, Elizabeth Jane Wall, 14

Homosexuality, 9, 93

Howells, William Dean, 102

\section{I}

Inchbald, Elizabeth, 62

Irving, Washington, 101, 102, 113n21

\section{$\mathrm{J}$}

Jane Talbot, $115 \mathrm{n} 43$

Jefferson, Thomas, 4, 56, 60, 69, 70, 96, $113 \mathrm{n} 23,11,5 \mathrm{n} 27$

Jeffersonians, 4, 5, 32, 34, 65, 66

Jeffersonian Persuasion, 65

Journal de Physique, 40-41

"Journey into Africa," 62

K

Kann, Mark F., 9, 14, 32, 33, 52, 61-62, $63,64-65,72,74,75,82,99$

Kelroy, 101

Kerber, Linda K., 6-7, 34, 99

Kimball, Arthur, 12, 13

Kimmel, Michael, 4, 96

Kirkland, Caroline, 102

Kotzcbue, August von, 62

L

I.arkin, Edward, 102

Lennox, Charlotte, 35

"A Lesson on Concealment; or, Memoirs of Mary Selwyn," 15, 19, 20, 44, $45,51,52,79-90,95,114 \mathrm{n} 15$, $115 \mathrm{n} 41,116 \mathrm{n} 53$

Letters from an American Farmer, 5

Liberty's Daughters, 6, 99

Literary Magazine and American Register, 3, 13 
Locke, John, 6, 12

Looby, Christopher, 61

\section{M}

Madison, James, 69

Marketplace, 5, 7, 8, 14, 33, 81, 96

literary marketplace, $5,8,56,60,96,97$ marketplace ethos, 95

marketplace values, $4,5,7,8,97$

Marriage, 6, 8, 9, 15, 32, 52, 54, 58, 63, 64, $65,68,69,70,74,78,82$

and Charles Brockden Brown, 2, 6, 8, 55

Maryland, 9-10

Masculinity, 4, 8, 14, 28, 40, 43, 45, 52, 56, $58,59,61,63,68,69,70,76$, $81,96,97,100,101,102$

hegemonic masculinity, 9, 14, 15, 77

middle-class masculinity, 10

republican masculinity, 39, 99

Massachusetts, 10

Massachusetts Magazine, 22

Maucr, Shawn I.., 101-102

Medical Repository, 22, 108n21

Melville, Herman, 101

"Memoirs of Hannah More," 35-36

Memoirs of Stephen Calvert, 3, 10-11, 12 ,

$13,15,19,20,21,25,45, .51$,

$52,60,78,79,90-95,116 \mathrm{n} 53$,

$116 \mathrm{n} 54,116 \mathrm{n} .55,116 \mathrm{n} 58$,

$116 n 64$

M'Fingal, 52

Modern Chivalry, 5

Montagu, Lady Mary Wortley, 35

More, Hannah, 19, 35-36

Morgan, David H. J., 9

Mott, Frank Luther, 21-22

$\mathbf{N}$

New England, 10, 82

New Fingland Magazine of Knowledge and Pleasure, 2.3

New England Primer, 6

New Jersey, 24

Ncw York, 49, 50, 62, 113n19

New York City, 2, 23, 48, 49, 50, 62, 70, 74

New York Magazine, or Literary Repository, $17,107 \mathrm{n} 1,110 \mathrm{n} 42$

Nord, David Paul, 17-18, 23

Norton, Mary Bcth, 6, 7, 24, 34, 99

Notes on the State of Virginia, 70
$\mathrm{O}$

“On Almanacks," 25-26, 62-63

“On Pcriodical Publications," 23-24, 25, $27,28,60$

"On the Inequalities of Solar Light," 41, 62

On the Man Question, 9

"On the State of American Literature," 53-55

"On the Temperature of the Planetary Systcm," 42

"Original Communications," 18, 19, 41, 42, $62,69,79,90$

Ormond, 11, 59, 100

\section{P}

Paine, Thomas, 52, 102

"The Paper War," 21-22, 43, 108n19

Park, Mungo, 62

Patterson, Mark R., 57-58

Payne, Dolly, 2

Pennsylvania, 90, 102

Pennsylvania Magazine, 102

Philadelphia, 4, 48-49, 50, 92

Pocock, J. G. A., 85

Poe, Edgar Allan, 101, 118n8

Port Folio, 20, 22

Postal Act, 23

Potts, Susan A., 55, 56

Private Property, 14

Profession of Authorship in America, 23

Proposing Men, 101

Puritans, 1, 5, 33

Q

Quakers, 2, 55

$\mathbf{R}$

Rational Fictions, 12

Reading Becomes a Necessity of Life, 49

Remarks on Lovers' Vows, 62

"Remarks on the Erection of a Turnpike

Road," 49-50

Republic of Men, 9, 99

Republican, 15, 22, 34, 39, 53, 61, 62, 65, $77,8.5$

republican citizenship, $4,66,77$

republican manhood, 77,99

republican motherhood, 7

republican principles, 24

republicans, 33,76 
republican virtuc, $8,29,30,33,53,62$, 67,84

Republicanism, 49, 72, 95, 96, 97 classical republicanism, $14,49,53,67,84$

Revolution and the Word, 60

Revolutionary Writers, 4

Rice, Grantland S., 5, 8, 27, 46, 51

Richardson, Samuel, 60, 81

Ringe, Donald A., 12, 13

Romance of Real Life, 13

Rousseau, Jean-Jacques, 3

Rowson, Susanna, 60, 81, 101

Royal Society, 42

Rush, Rebecca, 101

\section{S}

Saltonstall, Dudley, 45-47, 48, 51

Seduction literature, $25,73,74,81,86$, $104 \mathrm{n} 31$

Seidler, Victor J., 24, 28

"Selections," 19, 35, 39-40, 42, 63, 70, 79

Sentimental literature, $25,37,60,70,73$, $81,115 \mathrm{n} 42,115 \mathrm{n} 43$

"Series of Original Letters," 61

Shay's Rebellion, 34, 63, 114n18

Shevelow, Kathryn, 101

Sidney, Algernon, 34

Simpson, Lewis P., 57

Sigourney, Lydia, 102

Slavery, 35,78

Smith, Adam, 70

Smith, Elihu Hubbard, 49

Snyder, Katherine V., 10

Sources and Influences of the Novels of

Stern, Julia, 70

Charles Brockden Brown, 11

Swords, T. and J., 59, 105n44, 107n1, $108 \mathrm{n} 21,110 \mathrm{n} 42$

T

Tebbel, John, 19, 21

Theory of Moral Sentiments, 70

Thespian Oracle, 39

"Thessalonica," 15, 19, 20, 25, 51, 62, 63-69, 70, 81, 90, 95, 114n15, $116 \mathrm{n} 53$

Thomas, Isaiah, 22

Time Piece; and Literary Companion, 22

"Trials of Arden," 15, 19, 20, 44, 45, $51-52,69,70-78,79,90,95$, $114 \mathrm{n} 15,116 \mathrm{n} 53$

Trumbull, John, 52
Twelve Angry Men, 73

Tyler, Royall, 4, 71, 91

V

Vilas, Martin Samuel, 11

Vindication of the Rights of Woman, 28, 37, $109 \mathrm{n} 30,110 \mathrm{n} 43$

Virginia, 9, 70, 117n 3

Vision of Columbus, 3

Virtuc, $13,14,34,65,67,82$

civic virtue, $4,47,62,65,67,72,78,85$, $87,93,97$

country virtue, 85

manly virtuc, 66

republican virtue, $8,29,30,34,53,67$, 84

\section{W}

"Walstcin's School of History," 100, 106n54

Warfel, Harry R., 12, 19, 20, 59

Warner, Michacl, 46, 51

Washington, George, 20, 69, 70, 72, 79, $108 \mathrm{n} 11$

Watts, Stcven, 2, 13, 91

Weber, Alfred, 19

Weekly Magazine, 61

Wheatley, Phillis, 35

Whigs, 32, 34, 35

Whiskey Rebellion, 34, 63, 114n18

Wieland, 11, 56, 59, 60, 96, 100, 110n42

Wiley, L.ulu Rumsey, 11-12

Wilkins, William Wood, 56

Williams, Samuel, 82

Wollstonecraft, Mary, 19, 28, 35, 36-38, $109 \mathrm{n} 30,110 \mathrm{n} 43$

Women and Print Culture, 101

Women in Eighteenth-century America, 99

Women of the Republic, 99

Wood, Sally, 101

Workman, Adam, 47-48, 51, 79

Y

Yale University, 85

Yellow fever, 49

Z

Zuckcrman, Mary Ellen, 19, 21 